\title{
Studies on tumor necrosis factor : endogenous mediators of sepsis and cachexia
}

Citation for published version (APA):

Debets, J. M. H. (1989). Studies on tumor necrosis factor : endogenous mediators of sepsis and cachexia. [Doctoral Thesis, Maastricht University]. Rijksuniversiteit Limburg. https://doi.org/10.26481/dis.19890622jd

Document status and date:

Published: 01/01/1989

DOI:

10.26481/dis.19890622jd

Document Version:

Publisher's PDF, also known as Version of record

\section{Please check the document version of this publication:}

- A submitted manuscript is the version of the article upon submission and before peer-review. There can be important differences between the submitted version and the official published version of record.

People interested in the research are advised to contact the author for the final version of the publication, or visit the DOI to the publisher's website.

- The final author version and the galley proof are versions of the publication after peer review.

- The final published version features the final layout of the paper including the volume, issue and page numbers.

Link to publication

\footnotetext{
General rights rights.

- You may freely distribute the URL identifying the publication in the public portal. please follow below link for the End User Agreement:

www.umlib.nl/taverne-license

Take down policy

If you believe that this document breaches copyright please contact us at:

repository@maastrichtuniversity.nl

providing details and we will investigate your claim.
}

Copyright and moral rights for the publications made accessible in the public portal are retained by the authors and/or other copyright owners and it is a condition of accessing publications that users recognise and abide by the legal requirements associated with these

- Users may download and print one copy of any publication from the public portal for the purpose of private study or research.

- You may not further distribute the material or use it for any profit-making activity or commercial gain

If the publication is distributed under the terms of Article $25 \mathrm{fa}$ of the Dutch Copyright Act, indicated by the "Taverne" license above, 


\section{Studies on}

\section{TUMOR NECROSIS FACTOR}




\title{
ENDOGENOUS MEDIATORS OF SEPSIS AND CACHEXIA
}

\section{STUDIES ON TUMOR NECROSIS FACTOR}

\author{
Proefschrift \\ ter verkrijging van de graad van doctor \\ aan de Rijksuniversiteit Limburg te Maastricht, \\ op gezag van de Rector Magnificus, Prof. Dr. F.I.M. Bonke, \\ volgens het besluit van het College van Dekanen, \\ in het openbaar te verdedigen \\ op donderdag, 22 juni 1989, om 16.00 uur \\ door \\ Jacobus Maria Hubert Debets \\ geboren te Kerkrade in 1958.
}


Promotor:

Prof. Dr. G. Kootstra

Co-promotores: $\quad$ Dr. W.A. Buurman

Dr. C.J, van der Linden

Beoordelingscommissie: Prof. Dr. F.T. Bosman (voorzitter)

Prof. Dr. J. Goris

Prof. Dr. L.G. Thijs

Prof. Dr. F. ten Hoor

Prof. Dr. C. van Boven.

CIP-DATA KONINKLIJKE BIBLIOTHEEK, DEN HAAG

Debets, Jacobus Maria Hibert

Studies on tumor necrosis factor : endogenous mediators

of sepsis and cachexia / Jacobus Mria Hubert Debets

Marstricht: Datawyse. - III.

Thesis Matsintht. - With ref. With summary in Dutch.

ISBN 90-9002890-0

5150605.9 UDC 616-006-097(043.3)

Stbject headings: cylokines / sepsis / cachexia.

Uitgawe: Datawyse - Maastricht

Druk: Krips Repro Meppel

Uitgave van dit proefschrift werd financieel gesteund door de Dr. Ir. van de Laar Stichting, Celltech en Sandoz BV. 
"Education is experience, and the essence of experience is self-reliance."

T.H. White, The once and future King. 


\section{CONTENTS}

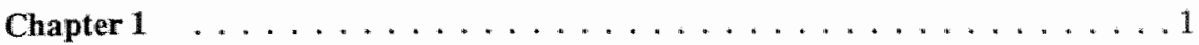

Introduction

General introduction $\ldots \ldots \ldots \ldots \ldots \ldots \ldots \ldots$

- The role of cytokines in inflammation and immunity

- Isolation of tumor necrosis factor

- Isolation of cachectin

- Structure and production of TNF/cachectin

- Biological effects of TNF

- cytotoxic and antitumor effects

- immunomodulatory effects

- hormonal and metabolic effects

The role of TNF/cachectin in human disease $\ldots \ldots \ldots \ldots \ldots$

Chapter $2 \ldots \ldots \ldots \ldots \ldots \ldots$

Introduction to and discussion of the experiments

References chapters 1 and $2 \ldots \ldots \ldots \ldots$

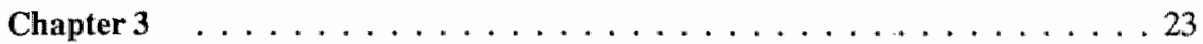

T cell-mediated secretion of tumor necrosis factor by monocytes

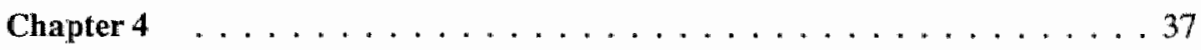

Fc-receptor cross-linking induces secretion of tumor necrosis factor by monocytes

Chapter 5

Cross-linking of both $\mathrm{F}_{\mathrm{c} \gamma \mathrm{RI}}$ and $\mathrm{F}_{\mathrm{C}} \mathrm{RII}$ induces secretion of tumor

necrosis factor by monocytes. Functional activation of FoyRII by treatment with proteases or neuraminidase

Chapter 6

The inhibitory effect of corticosteroids on the secretion of tumor necrosis factor by monocytes induced by different stimulatory agents

Chapter 7

Evidence of involvement of tumor necrosis factor in adverse reactions during treatment of kidney allograft rejection with antithymocyte globulin

Chapter 8

Plasma tumor necrosis factor and mortality in critically ill septic patients

Chapter 9

Summary

Chapter 10

Samenvatting

Dankwoord

Curriculum vitae 


\section{INTRODUCTION}

\section{GENERAL INTRODUCTION}

\section{The role of cytokines in inflammation and immunity}

Invasion of an organism by pathogenic organisms or substances evokes an immune response directed at eliminating the pathogen or preventing its detrimental effects on the organism. The inflammatory and immune processes involved in such a response require a complex interplay between different immunocompetent cells, which are often located at sites far away from the intruding pathogen. The recruitment of these cells and the orchestration of their complex activities is effected by hormone-like substances secreted by immune cells in response to the invading pathogen. These hormone-like molecules, which have been given the general name cytokines, not only serve regulatory purposes, but also function as effector molecules in the defence against the invading pathogen. Cytokines can exert their regulatory effects on the same cells which synthesize them (autocrine regulation), on cells in the immediate vicinity (paracrine regulation), or, after entering the circulation, on cells at sites different from the site of their production (endocrine regulation). The regulatory effects of cytokines are not restricted to immunocompetent cells, which are mainly of hemopoetic lineage. The function of cells of many other tissues and organs, like vascular endothelial cells, hepatocytes, connective tissue cells, muscle cells, and adipocytes is affected by cytokines as well.

Many different cytokines have already been characterized, and the list of known cytokines is still increasing steadily. The following groups of cytokines are currently discriminated: the largest group is formed by the interleukins, at this time comprising seven cytokines named interleukin 1 to 7 (IL-1 to IL-7). These cytokines are involved in immunoregulatory processes, generally enhancing cellular immune responses. Another group is formed by the interferons, consisting of interferon- $\alpha$ (IFN- $\alpha$ ), interferon- $\beta$ (IFN- $\beta$ ), and interferon- $\gamma$ (IFN- $\gamma$ ). These cytokines have virostatic properties and enhance various immune responses. Cytokines enhancing the maturation, differentiation, and clonal expansion of hemopoietic progenitor cells are named collonystimulating factors (CSF). This group consists of the following cytokines: the multicolony-stimulating factor CSF-1, the granulocyte colony-stimulating factor G-CSF, the macrophage colony-stimulating factor M-CSF, and the granulocyte-macrophage colony-stimulating factor GM-CSF. Finally, two cytokines have been identified primarily 
on the basis of their ability to induce necrosis of experimental tumors, and are therefore named tumor mecrosis factors. They consist of tumor necrosis factor- $\alpha$ (TNF), also known as cachectin, and tumor necrosis factor- $\beta$, also known as lymphotoxin (LT).

Most cytokines are polypeptides, which has made it possible to synthesize them on a large scale using recombinant DNA technology. The availability of recombinant cytokines has greatly facilitated their use for laboratory investigations, which has resulted in many new insights in their role in the regulation of inflammatory and uminune processes. In the wake of this basic research data have accumulated in recent years implicating several cytokines as host mediators involved in the pathogenesis of various human diseases like autoimmune diseases, immunodeficiency states, graft-vshost disease, cancer cachexia, and sepsis. TNF/cachectin has been one of the cytokines strongly believed to be involved in the pathogenesis of several human disease states, especially sepsis.

\section{Isolation of tumor necrosis factor}

A spontaneous regression of malignant tumors has occasionally been observed in cancer patients suffering from severe infections. At the end of the previous century the American physician Coley attempted to mimic these empirical findings by administering killed bacteria (Coley's toxin) to cancer patients, with variable results. Toxin therapy enjoyed some popularity in the nineteen thirties, but soon disappeared after the emergence of radiotherapy and chemotherapy. However, scientists remained interested in the mechanisms underlying this phenomenon. Carswell and Old isolated a serum factor present in BCG-infected mice after injection of endotoxin, which caused hemorrhagic necrosis of transplanted meth A sarcomas in these animals. They named this factor tumor necrosis factor (TNF) (1). It was a product of endotoxin-treated macrophages and was soon discovered to be present in other species too (2,3). Human TNF was isolated and characterized by Aggarwal and co-workers (4) and its gene was cloned and brought to expression by the same group (5). The availability of recombinant TNF (rTNF) intensified the scientific interest in its role in immune processes in the following years.

\section{Isolation of cachectin}

Other investigators, grouped around Cerami at the Rockefeller University, were interested in the mechanism underlying the severe cachectic state accompanying chronic parasitic infection in animals. They observed that parasitic infections in laboratory animals leading to cachexia were accompanied by a marked hypertriglyceridemia. This proved to be caused by a suppression of the enzyme lipoprotein lipase (LPL), which is responsible for the uptake of triglycerides in adipose tissue (6). Suppression of LPL was also found in mice injected with endotoxin and it was shown that a humoral mediator released by macrophages upon stimulation with endotoxin was responsible for the observed inhibition of LPL (7). Moreover, a cachectic state could be induced by administering conditioned medium from endotoxin-treated murine macrophages to healthy mice (8). The humoral mediator responsible for the observed inhibition of LPL was believed to be responsible for the cachexia as well, and 
was therefore named cachectin by these investigators. Cachectin was purified and proved to be a protein with a molecular weight of $17 \mathrm{kDa}$, which was produced by macrophages and macrophage-like cell lines after contact with endotoxin (9). After its $\mathrm{N}$-terminal amino acid sequence was determined it became clear that cachectin was identical to the tumor necrosis factor isolated by Carswell and Old (10).

\section{Structure and production of TNF/cachectin}

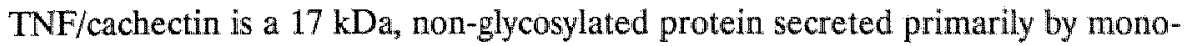
cytes and macrophages upon stimulation with endotoxin. Its gene is located on the short arm of chromosome 6 in man, and on chromosome 17 in the mouse, in close proximity to the major histocompatibility complex genes $(11,12)$. The TNF gene is closely linked to the gene coding for a structurally and functionally related cytokine, lymphotoxin (LT) or TNF- $\beta$, which shows $30 \%$ sequence homology to TNF, and binds to the same receptor as TNF.

A remarkable feature of the TNF gene and of several other genes coding for inflammatory mediators (e.g. LT, colony-stimulating factor, interleukin 1, fibronectid. and most interferons) is the presence of a repetitive oligonucleotide sequence (TTATTTAT) at the $3^{\prime}$-untranslated region of the gene, which seems to impart instability to the mRNA transcribed from these genes (13). This probably constitutes a built-in protective mechanism limiting production of these highly potent inflammatory mediators.

The regulation of endotoxin-induced TNF production has been studied both in murine and in human systems. In resting murine macrophages, a constant pool of TNF mRNA is present, which is not translated to TNF protein due to posttranscriptional inhibition. Endotoxin enhances TNF mRNA transcription and induces TNF mRNA translation (14). In resting human monocytes, no TNF mRNA can be detected. Upon stimulation of monocytes TNF mRNA is transcribed, and TNF protein is translated (15). TNF production by human monocytes as well as murine macrophages is enhanced by the T cell lymphokine interferon- $\gamma$ (IFN- $\gamma$ ) (16-18). In murine macrophages IFN- $\gamma$ stimulates TNF gene expression both at transcriptional and postranscriptional level $(19,20)$. Besides endotoxin other compounds have been shown to be capable of inducing monocyte TNF production. For example, protein kinase C activating agents strongly stimulate TNF production (15,21). Furthermore, prostaglandin E2 (22), vitamin D3 (23), the complement protein C5a (24), and the colony-stimulating factors GM-CSF and CSF-1 $(25,26)$ have all been shown to enhance TNF synthesis. Studies investigating the intracellular events regulating TNF expression have demonstrated that the second messenger cGMP initiates TNF production, whereas cAMP has an inhibitory effect on TNF production $(27,28)$.

Although it was initially believed that TNF was exclusively produced by cells of the monocyte/macrophage lineage, it has now become clear that several other mononuclear cells, like T lymphocytes, natural cytotoxic cells, and natural killer cells, have the capacity to synthesize this cytokine upon adequate stimulation (29-3L). TNF synthesis by these cells, however, is not induced by the agent classically used to trigger monocyte/macrophage TNF production, e.g. endotoxin. Effective stimuli are protein kinase $\mathrm{C}$ activating agents like phorbol diester, $\mathrm{Ca}^{2+}$-ionophores, and, in the case of $\mathrm{T}$ 
lymphocytes, also anti-CD3 mitogens in combination with interleukin 2 (32). Expression of the TNF gene has also been demonstrated in B cell lines and in several non-hemopoietic tumor cell lines (33-36). A remarkable finding of these studies is that tumor cell lines producing TNF are themselves resistant to the cytotoxic effects of TNF.

The kinetics of endotoxin-induced endogenous TNF production has been studied in several species. In rabbits, nanomolar concentrations of TNF were detected in the serum after injection of endotoxin. Peak levels were reached about $2 \mathrm{hr}$ after endotoxin administration. TNF was rapidly cleared from the circulation with an approximate half-life of 6-7 min (37). In baboons, peak serum levels of TNF, averaging about 20 $\mathrm{ng} / \mathrm{ml}$, were found between 1.5 and $2.5 \mathrm{hr}$ following infusion of live E. coli. Serum TNF became undetectable after $4-6 \mathrm{hr}$ (38). In man, TNF could be detected at low levels (ranging between 35 and $730 \mathrm{pg} / \mathrm{ml}$ ) in the plasma $90-180 \mathrm{~min}$ after endotoxin administration. It was rapidly cleared from the circulation, being undetectable $4 \mathrm{hr}$ after endotoxin infusion (39). These studies indicate that TNF is released in a burst-like manner, after which it is rapidly cleared from the circulation. In humans who were given recombinant TNF ( $\mathrm{rTNF}$ ) intravenously as an antitumor agent in phase I clinical trials, an approximate half-life of 15-30 min was calculated (40-42). The organ systems involved in the clearance of TNF in man are currently still unknown.

\section{Biological effects of TNF}

\section{Cytotoxic and antitumor effects}

TNF exerts its effects on cells through binding with a specific receptor, which is present on many different cell types. The cell membrane expression of this receptor is enhanced by interferon- $\gamma(43,44)$ and down-regulated by protein kinase $C$ activating agents (45-47). One of the best studied effects of TNF is its cytotoxic activity against various tumor cell. lines (48). Only cell lines possessing TNF receptors are sensitive to the cytotoxic activity of TNF. However, cytotoxicity is not solely dependent on the presence of TNF receptors, since many cell lines which are TNF-resistant express TNF

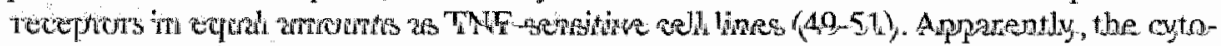
toxic effect of TNF on different cells is controlled both at receptor and post-receptor level.

On the basis of its cytotoxic activity TNF is considered to be an important mediator of monocyte/macrophage cytotoxicity against tumor cells $(52-56)$. It may thus constitute a key cytokine involved in the immune surveillance against tumors. Besides its in vitro cytotoxicity against tumor cells, TNF is known to induce hemorrhagic necrosis of several tumors in vivo $(1,57,58)$. It has also been demonstrated that TNF is the endogenous mediator responsible for the necrosis of experimental tumors induced by endotoxin (59). The in vivo antitumor activity of TNF however is not a result of its cytotoxic properties, but is caused by an effect of TNF on tumor vasculature, and requires the presence of a normally functioning $T$ lymphocyte system $(60,61)$. The cytotoxic and antitumor characteristics of TNF has prompted clinical research investi- 
gating its value as an anticancer agent. Several phase I studies of human rTNF have already been reported in the literature $(40-42,62)$. The clinical efficacy of rTNF and the types of cancer responsive to its antitumor effects are however currently still unknown.

A phenomenon morphologically cllosely resembling the hemorrhagic necrosis of implanted tumors after injection of endotoxin or TNF is the Schwartzman reaction. This reaction can be elicited in rabbits and mice after subcutaneous injection of endotoxin, followed $24 \mathrm{hr}$ later by a local or systemic injection of endotoxin, after which a hemorrhagic necrosis of the skin at the injection site occurs. In rabbits it is possible to replace endotoxin by a combination of TNF and $\mathrm{IL}-1$ to prepare skin for a hemorrhagic necrosis after injection of endotoxin $18 \mathrm{hr}$ later (63). In mice, local injection of human rTNF into a skin site which has been prepared by prior subcutaneous injection of endotoxin also induces hemorrhagic necrosis of the injected skin (64). These studies point to a role for TNF in the microvascular injury accompanying infectious disease and sepsis. In this connection it is relevant that TNF has strong thrombomodulatory influences on endothelial cells in vitro. TNF enhances procoagulant activity while suppressing production of the anticoagulant protein $\mathrm{C}$, thus favouring clot formation (65). Furthermore, TNF has been shown to induce fibrin formation in intratumoral blood vessels (66).

\section{Immunomodullatory effects}

Besides its cytotoxic and antitumor effects TNF has been shown to possess various immunomodulatory properties. Most of these have been discovered by in vitro investigations. TNF enhances inflammatory and immune processes in many different ways. It directly actiwates polymorphonuclear leukocytes $(67,68)$, it enhances $\mathrm{T}$ cell responses (69-71), and modulates B cell differentiation (72-75). It stimulates chemotaxis of immunocompetent cells, and increases their binding to endothelial cells (7679). TNF also modulates the expression of several cell membrane antigens involved in inflammatory and immune responses on different cell types. It differentially regulates expression of major histocompatibility antigens (80,81). TNF is capable of inducing expression of the IL-2 receptor (82), it induces expression of an activation antigen on endothelial cells $(83,84)$, and enhances expression of complement receptors on neutrophils (85). Besides these cellular effects TNF increases production of several inflammatory mediators like platelet activating factor $(86-87)$, prostaglandins, and collagenase (88). Furthermore, the production of several cytokines like interleukin 1 $(89,90)$, interleukin $6(91)$, interferon- $\beta 1(92,93)$, and the colony-stimulating factors GM-CSF and CSF-1 (94,95), is enhanced by TNF. Many of the immunomodulatory effects of TNF are mediated indirectly, via the induction of other cytokines. For example, it has been demonstrated that the induction of MHC class I antigens by TNF is mediated by interferon- $\beta 1$ (93). TNF is a protein characteristic of the acute phase response, having strong pyrogenic characteristics (96,97). Furthermore, TNF has been shown to induce production of several other acute phase proteins in vivo (98). Finally, TNF is probably an important effector cytokine in the immune response against viral and parasitic infections, since it has been shown to possess both antiviral (99-101) and antiparasitic (102) characteristics. 


\section{Hormonal and metabolic effects}

The hormonal and metabolic effects of acute TNF administration have been studied both in experimental animals, and in man. In rats, administration of human rTNF is accompanied by a hyperlipidemia due to inhibition of lipoprotein lipase, preventing uptake of lipids in peripheral adipose tissue, and a stimulation of hepatic lipogenesis (103). Furthermore, hepatic amino acid uptake greatly increases, serum trace metal concentrations decline, and levels of several stress hormones increase following TNF administration $(104,105)$. All of these changes are characteristic of the acute phase response, which has led the authors of the referred articles to speculate that TNF constitutes a key mediator of the acute phase response following trauma, sepsis, or burns. In man, acute administration of rTNF was found to be accompanied by a spectrum of hormonal and metabolic changes very much alike those found in rats (106). Furthermore, the same response was observed when endotoxin was administered to humans instead of TNF, indicating that TNF probably constitutes a key mediator of the acute phase response following acute infections and sepsis (107).

In summary, tumor necrosis factor is a cytokine characteristically produced during an acute phase response, with a broad range of immunoregulatory and inflammatory properties, which is likely to play an important role in the orchestration of host defence mechanisms against infectious and malignant diseases.

\section{THE ROLE OF TNF/CACHECTIN IN HUMAN DISEASE}

Besides its physiological role in inflammatory and immune processes depicted in the previous section a large body of literature has accumulated in recent years implicating TNF/cachectin as a host mediator involved in the pathogenesis of several human disease states. Investigations by Cerami and co-workers, exploring the mechanisms. underlying the metabolic derangements and cachexia accompanying chronic parasitic infections, have actually led to the discovery of cachectin, which later proved to be identical to tumor necrosis factor. Cachectin was believed to be the crucial mediator of cachexia on the basis of its observed effects on lipid metabolism, e.g. it strongly inhibits the expression of the enzyme lipoprotein lipase by adipocytes, thereby preventing uptake of lipids by these cellis. This phenomenon was held responsible for the hyperlipidemia and wasting diathesis characteristically accompanying (chronic) infectious diseases and cancer (108-110). Furthermore, mouse macrophages were shown to produce a mediator upon stimulation with endotoxin causing cachexia in mice, and cachectin was implicated as the causative macrophage product (8). The most convincing evidence implicating 'TNF/cachectin as a 'cachectic' protein came from a study demonstrating that a chinese hamster ovary tumor (CHO) transfected with the human TNF gene, thus continually secreting TNF, caused severe cachexia upon inoculation in mice, whereas non-transfected CHO cells did not (111). However, by lack of pair-fed controls in this study, it remained unclear whether the observed cachexia was caused by a true catabolic effect of TNF/cachectin or whether it was merely a consequence of reduced intake of food and water observed in mice with TNF-producing tumors. Several other studies have questioned the role of TNF/cachectin as mediator of 
cachexia. Administration of human rTNF to experimental animuals causes a short-lived repression of food and water intake, without causing true cachexia (112-114). In man, no cachexia is observed upon repeated administration of rTNF (41). Furthermore, two elegant studies have demonstrated that probably not TNF, but another, as yet undefined endotoxin-induced macrophage product is responsible for cachexia in a rat study (97,115). Therefore, although TNF/cachectin ranks first in a row of mediators held responsible for cachexia accompanying chronic infections or malignancy, final experimental proof is still lacking as to this day. Furthermore, it has as yet not been possible to detect circulating TNF in humans suffering from severe cachectic states. One study has demonstrated circulating TNF in cancer patients (116). However, it should be questioned seriously whether, in view of the unusually high levels of TNF reported in this study, truly TNF rather than a cross-reactive serum protein was detected in this study.

Besides its role in cachexia TNF is believed to be a key mediator involved in the pathophysiology of sepsis (117). During sepsis, circulating bacteria or bacterial compounds cause a complex pattern of derangements of host physiology, resulting in fever, shock, acidosis, cardiorespiratory insufficiency, renal failure, and widespread damage to other organ systems (118). In recent years data have accumulated indicating that the host derangements observed during sepsis are not caused directly by the infectious agents, but rather by endogenous mediators produced by cells of the immune system in response to overwhelming infection. TNF is strongly believed to be one of these mediators involved in the pathogenesis of sepsis. Its production is induced by bacterial compounds, most notably lipopolysaccharides from gram-negative microorganisms (endotoxin), in all species studied, both in vitro and in vivo (1,37,39,54). Administration of rTNF to experimental animals has been shown to result in pathophysiological changes almost identical to those observed during endotoxic shock states $(64,119-$ 121). Moreover, in several species it has been possible to prevent mortality during experimental sepsis by prior administration of neutralizing anti-TNF/cachectin antibodies $(38,122,123)$. In man, circulating TNF was detected shortly after administration of endotoxin to healthy volunteers (39), and the changes observed after administration of rTNF to humans are very much alike those seen during endotoxemia (107). Circulating TNF has also been demonstrated during sepsis in man $(124,125$, and chapter 8 of this thesis). In these studies a positive correlation was found between the presence of circulating TNF and mortality. These studies substantiate the involvement of TNF in the pathogenesis of sepsis. However, it remains to be determined whether its role is of a causative nature, in which case intervention studies with neutralizing anti-TNF antibodies in human sepsis would be justifiable. Finally, it remains to be mentioned that besides TNF other inflammatory mediators like interleukin 1, and platelet-activating factor are likely to be involved in the cascade of events resulting in sepsis as well (126-130).

Since TNF constitutes a potent inflammatory mediator with cytotoxic potential, numerous investigators have been interested in its possible involvement in the pathology of autoimmune diseases. In vitro studies demonstrated that TNF induces resorption of bone and cartilage and enhances production of prostaglandins by synovial cells (88,131-133). Moreover, we have demonstrated that TNF production by human mono- 
cytes is strongly induced by immune complexes (see chapter 4 of this thesis). TNF is therefore suspected to be in part responsible for the tissue destruction and pain accompanying rheumatoid arthritis. It has indeed been possible to demonstrate the presence of TNF in synovial fluid of patients with rheumatoid arthritis $(134,135)$. Besides TNF, other inflammatory mediators like interleukin 1 and interferon- $\gamma$ are likely to be involved in the pathology of rheumatoid arthritis as well $(136,137)$. TNF has also been implicated as a pathogenetic factor in such diverse autoimmune diseases as lupus nephritis (138), autoimmune vasculitis (139), autoimmune thyroiditis (140), and diabetes mellitus $(141,142)$. Besides in autoimmune diseases, TNF is also suspected to contribute to the pathologic changes accompanying several other diseases. For example, the pathologic changes observed during experimental malaria have in part been attributed to TNF, produced in the course of the anti-parasitic immune response (143). Another study showed that the skin and gut lesions accompanying experimental graft-vs-host disease in mice could be prevented by prior immunization with anti-TNF antibodies (144). During allograft rejection, raised serum levels of TNF have been detected in man, suggesting that TNF is involved in the inflammatory processes leading to rejection of the grafted organ (145).

In conclusion, besides its physiological role as inflammatory and immunoregulatory mediator, TNF/cachectin is strongly implicated as a pathogenetic factor involved in the derangements in host physiology and metabolism and tissue destruction accompanying several, both infectious and non-infectious, diseases. 


\section{INTRODUCTION TO AND DISCUSSION OF THE EXPERIMENTS}

The cytokine TNF/cachectin constitutes a pivotal mediator of the host response to infection. It has numerous immunoregulatory and inflammatory properties. TNF production is strongly induced by endotoxin. TNF is considered to be the prime endogenous mediator of the detrimental effects of endotoxin. TNF is therefore believed to contribute to the pathogenesis and pathophysiology of multiple organ failure and shock during sepsis (117-119). TNF is also implicated as a mediator in part responsible for the catabolic state accompanying infectious and malignant disease, referred to as cachexia $(8,111)$. Besides its role in the derangements of host physiology and metabolism in sepsis and cachexia, evidence has accumulated in recent years that TNF also contributes to the tissue destruction accompanying several non-septic inflammatory diseases like allograft rejection (145), graft-vs-host disease (144), and autoimmune diseases (138-142). Until recently, endotoxin constituted the only known stimulus of TNF production by monocytes and macrophages. In view of the possible involvement of TNF in various human disease states, the cellular processes regulating its production and secretion were studied in this thesis. Since monocytes constitute the primary cellular source of TNF in man, in vitro studies were conducted predominantly with purified monocyte cultures. In vitro studies investigating the regulation of TNF production and secretion by human monocytes are described in chapters 3 to 6 . Chapters 7 and 8 contain studies on the role of circulating TNF in two different patient populations.

Both in the in vitro and in vivo studies TNF concentrations were measured with a TNF-specific enzyme-linked immunosorbent assay (ELISA), developed in our laboratory. In this assay, the TNF concentration of test samples is measured according to the principles of a sandwich-ELISA. In short, TNF molecules present in the test samples are captured by monoclonal anti-TNF antibodies, coated to the bottom of wells of a microtiter plate. After washing away unbound TNF molecules, the number of bound TNF molecules are quantitated by sequential incubation with rabbit anti-TNF antibodies and peroxidase-conjugated goat anti-rabbit antibodies, after which a peroxidasesensitive substrate is added to the wells. The amount of substrate transformed during the enzyme reaction, giving an estimate of the number of TNF molecules present in the well, is measured by determining the optical density at a fixed wavelenght. A standard titration curve is obtained by measuring optical densities at known concentrations of recombinant TNF. An example of such a titration curve, obtained in $100 \%$ normal human plasma, is shown in the figure. The data of this figure were kindly given to us by Dr. A. Lawson and Dr. J. Hipkiss from Celltech (Slough, UK). The intra-assay coeffi- 


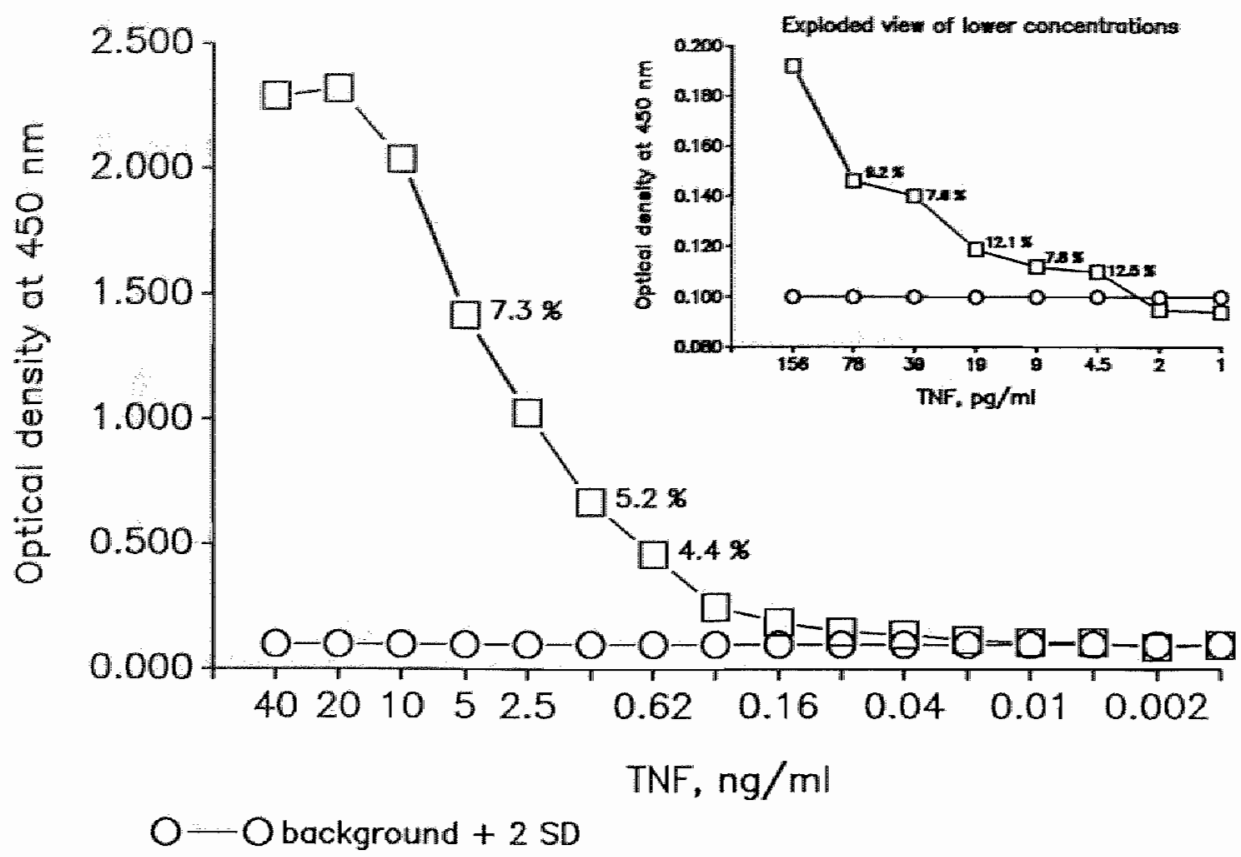

Figure. TNF ELISA: standard titration curve of rTNF, Insert: exploded view of the lower concentrations of $\mathrm{rTNF}$. Percentages indicate intra-assay coefficients of vartance (cv), defined as $\mathrm{cv}=\mathrm{sd} / \mathrm{m}$, where $\mathrm{m}$ and scl respectively represent the mean and the standard theviation of optical densities obtained at serial measurements of known TNF concentrations during one assay.

cients of variance at different TNF concentrations are shown in the figure. The inter-assay coefficient of variance of the TNF ELISA is less than 7\%. The lower detection limit is $5-10 \mathrm{pg} / \mathrm{ml}$. Comparable results are found at lower serum or plasma concentrations.

TNF is produced primarily by monocytes and macrophages upon activation with bacterial compounds like endotoxin $(14,15)$. Bacterial products therefore constitute the most likely stimulus of TNF synthesis during infectious diseases. In non-infectious inflammatory diseases in which TNF is believed to be involved, other mechanisms underly the induction of TNF synthesis. Many of these diseases, like for instance allograft rejection or graft-ws-host disease, are accompanied by activation of the $T$ lymphocyte system. It has been shown that $T$ cell mitogens like lectins (146), or anti-CD3 monoclonal antibodies (147), induce TNF synthesis by peripheral blood mononuclear cells (PBMC). The influence of two different $T$ cell mitogens, the lectin PHA and the anti-CD3 monoclonal antibody OKT3, on the secretion of TNF by PBMC was studied in chapter 3. Both mitogens dose-dependently induce TNF secretion by PBMC. TNF secretion is shown to correlate with and to be dependent on 
proliferation of $T$ lymphocytes. Although others have demonstrated the capacity of $T$ lymphocytes to produce TNF upon activation (29), in the experiments alescribed in chapter 3 TNF is produced predominantly by monocytes. The T cell lymphokine IFN-y is shown to be an important humoral mediator of T cell-dependent TNF secretion by monocytes. In contrast to murine experiments, in which IFN- $\gamma$ induces TNF secretion only in the presence of endotoxin (19). IFN-y-induced TNF secretion by human monocytes is shown to occur in the absence of endotoxin. This study implicates that in many non-infectious diseases accompanied by $T$ cellular activation, like allograft rejection or graft-vs-host disease, local TNF production in inflammatory areas may contribute to the tissue damage. In graft-vs-host disease the involvement of TNF in tissue destruction has indeed been demonstrated (144).

Receptors for the $\mathrm{Fc}_{\mathrm{c}}$ domain of antibodies (FCR) are present on many cells of hemopoietic lineage. On human monocytes, $\mathrm{FcR}$ for $\operatorname{IgG}\left(\mathrm{Fc}_{\mathrm{c}} \mathrm{R}\right)$ are abundantly present. These receptors link the cellular immune system to the humoral immune system by activating immunocompetent cells upon binding of Fc ligand of antibodies. $F_{c \gamma R}$ have been shown to induce secretion of various inflammatory mediators (148152). Humoral regulation of TNF secretion was studied by investigating the capacity of ForR to induce TNF secretion by monocytes. The results of this study are presented in chapter 4. Cross-linking of Foy $\mathbb{R}$, for instance with immune complexes, is shown to strongly induce TNF secretion. This finding has several implications with regard to the role of "TNF in humoral immune responses as well as in immune complex diseases. TNF has in vitro cytotoxic $(53,55)$, antiviral $(99)$, and antiparasitic (102) properties, suggesting its involvement in immune responses against malignant cells, viruses, or parasites in vivo. Generation of TNF during immune responses against malignant cells, viruses, or parasites may well be mediated by Foy $R$ on monocytes and macrophages involved in these responses. TNF has been suggested to contribute to the tissue damage observed in immune complex diseases like rheumatoid arthritis $(134,135)$. Immune complex-induced TNF secretion may thus constitute the mechanism underlying the release of TNF in affected joints, leading to local tissue damage.

Two different For are constitutively expressed on human monocytes, a $72 \mathrm{kDa}$

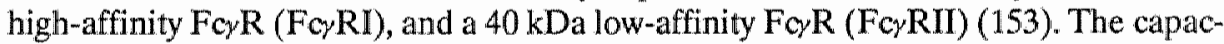
ity of both FcrR to induce TNF secretion by monocytes is studied in chapter 5 . Both receptors have been shown to induce other functions of monocytic cells, like superoxide production (154), and cytotoxicity (155). In chapter 5 it is demonstrated that on untreated monocytes, only cross-linking of F $\mathrm{C}_{\gamma} \mathrm{RI}$ leads to TNF secretion. However, after treatment of monocytes with proteolytic enzymes or with the desialylating enzyme neuraminidase, TNF secretion can also be induced by cross-linking of FcyRII, apparently due to an increased affinity of this receptor for the cross-linking antibody. A remarkable finding of this study is that TNF secretion can only be induced when For R are cross-linked through Fc-FcyR interactions. Since proteases and neuraminidase are enzymes likely to be present in areas of inflammation, these findings suggest that FcyRII functions as a stand-by receptor, activated during inflammatory processes.

Corticosteroids strongly suppress immune and inflammatory processes, for which purpose they are often used in clinical medicine. One important mechanism underlying the immunosuppressive and antiinflammatory effects of corticosteroids is the 
inhibition of release of inflammatory mediators by immunocompetent cells $(156,157)$. TNF is believed to be involved in the pathogenesis and pathophysiology of various disease states, many of whom are amenable to treatment with corticosteroids. However, in each of these disease states TNF synthesis is likely to be induced by different pathways. The influence of corticosteroids on the induction of TNF secretion by different stimulatory agents is therefore studied in chapter 6 . Corticosteroids are shown to inhibit TNF secretion by monocytes, the degree of inhibition however being dependent on the stimulus used to induce TNF secretion. Strong inhibition is found when TNF secretion is induced by endotoxin or through cross-linking of $\mathrm{Fc} \gamma$. This finding may, in view of the involvement of TNF in sepsis and immune complex diseases, in part explain the beneficial effect of corticosteroids in experimental animal sepsits studies (reviewed in 158), and in immune complex diseases like rheumatoid arthritis. Poor inhibition is found when TNF secretion is induced by silica. This may in part account for the absence of a beneficial effect of corticosteroids in pneumoconiosis, a disease state in which various inflammatory mediators, among which TNF (159), may be involved. Finally, only minimal inhibition is found when TNF secretion is induced by the protein kinase C-activating compound PMA. The clinical relevance of this finding remains as yet unclear.

Kidney allograft recipients experiencing acute allograft rejection are frequently treated with antibodies directed against cell membrane antigens of ' $T$ lymphocytes, as for example with antithymocyte globulin (ATG), or with the monoclonal antibody OKT3. The administration of these antibodies to humans often evokes a vigorous febrile response, accompanied by various other subjective and objective symptoms (160-164). These side effects have been attributed to the release of cytokines from lysed lymphocytes (165). In chapter 3 it has been demonstrated that the anti-T lymphocyte antibody OKT3 induces TNF secretion in cultures of PBMC. Since many of the side effects observed during administration of anti-T lymphocyte antibodies to humans are very similar to those observed after administration of recombinant TNF to humans (40-42), the involvement of TNF in the etiology of side effects of treatment of kidney allograft rejection with ATG was studied. The results of this study are described in chapter 7. It is demonstrated that the first ATG administration is accompanied by a rapid rise in plasma TNF levels. Side effects of ATG treatment are present during the period of raised plasma TNF levels, suggesting that the side effects are, at least in part, caused by TNF. No detectable plasma levels of another pyrogenic cytokine, interleukin 1, were present during ATG therapy. The second ATG dose was neither accompanied by side effects nor by significant plasma levels of TNF, confirming the contribution of TNF in the etiology of these side effects. In vitro studies suggest that ATG-induced TNF release is not a result of lysis or activation of $T$ lymphocytes. Fc receptor-induced TNF secretion by monocytes, as described in chapter 4 , may be one of the mechanisms responsible for the release of TNF in these experiments. This study strongly suggests the involvement of TNF in the etiology of adverse reactions during anti-T cell antibody therapy. However, other inflammatory mediators like IL-1, IL-6, IFN- $\alpha$, and IFN- $\gamma$ may also be involved.

Numerous experimental animal studies have implicated TNF as a key mediator involved in the pathogenesis of sepsis and septic shock. However, only scarce data are 
available on its role in human sepsis, primarily due to the scancity of assays sensitive enough to measure low levels of circulating TNF. Using a sensitive enzyme-linked immunosorbent assay for TNF, the presence of circulating TNF and its relation to patient outcome was studied in septic patients. The results of this study are shown in chapter 8. In one of four septic patients, circulating TNF can be detected during sepsis. Mortality in these patients is significantly higher than in patients in whom no circulating TNF can be detected. This difference in mortality is not caused by differences in severity of sepsis or multiple organ failure between both patient groups. These findings confirm clinical data from others, demonstrating a correlation between the presence of circulating TNF and mortality in patients suffering from meningococcal sepsis (124, 125). The question whether the presence of circulating TNF during sepsis is merely a prognostic sign indicating poor patient outcome, or whether TNF plays a pivotal role in the etiology of shock and multiple organ failure during sepsis, as has been suggested by results from animal experiments $(38,122,123)$, remains as yet unanswered.

In conclusion, the immunoregulatory and inflammatory cytokine TNF plays a pivotal role in the orchestration of host defence mechanisms against infectious and malignant disease. Besides its physiological role TNF is also implicated as an endogenous mediator contributing to the pathology of various disease states like sepsis, cachexia, autoimmune diseases, graft-vs-host disease, and allograft rejection. In this thesis it is demonstrated that besides the classical pathway of induction of TNF synthesis by bacterial compounds like endotoxin, TNF production and secretion is also likely to be induced during non-infectious inflammatory diseases accompanied by activation of the cellular and humoral immune systems. Furthermore, the presence of circulating TNF is demonstrated in two different patient populations, and the relation between the presence of circulating TNF and the symptomatology and outcome of these patients is discussed.

Undoubtedly, TNF does not act as an isolated mediator during immune responses. It is involved in cascade events, in which a complex interplay between many different inflammatory mediators takes place. For example, TNF initiates synthesis of various other cytokines involved in the acute phase response, like IL-1, IL-6, and platelet activating factor. In its turn, TNF synthesis is regulated by these cytokines, giving rise to complex feedback patiways. Also, physiological and metabolic derangements as observed during sepsis and cachexia are not likely to be caused by one single mediator. Future research has to demonstrate whether interference with the synthesis of single inflammatory cytokines like "TNF offers therapeutic opportunities in the treatment of disease states in which these cytokines are believed to be involved. 


\section{REFERENCES CHAPTERS 1 AND 2}

1. Carswell EA, Old LJ, Green $\$$, Fiore N, Williamson B. 1975. An endotoxin-induced serum factor that causes necrosis of tumors. Proc Natl Acad Sci USA 72:3666.

2. Matheys N. 1981. Tumor necrosis factor from the rabbit. V. Synthesis in witro by mononuclear phagocyles from various thssues of normal and $\mathrm{BCG}$-injected rabbits. $\mathrm{Br} J \mathrm{Cancer} 44.418$.

3. Malthers $\mathbb{N}_{\text {. }} 198 \mathrm{~L}$. Production of an anti-tumour cytotoxin by buman monocytes. Immunology 44:135.

4. Aggarwal BB, Kolir WJ, Hass PE, Moffat B, Spencer SA, Henzel WJ, Bringman TS, Nedwin GE, Goeddel DV, Harkins RN. 1985. Human tumor mecrosis factor. Production, purification, and characterization, J Biol Chem 2602345 .

5. Pennica D, Nedwin GE, Hayflick JS, Seeburg PH, Derynck R, Palladino MA, Kohr WJ, Aggarwal BB, Goeddel DV, 1984, Human tumour necrosis factor: precursor structure, expression and homom logy to lymphotoxin. Nature 312:724.

6. Rouzer CA, Cerani A. 1980. Hypertrighyceridemiat associated with Trypanosoma Brucei Bracei infection in rabbits: role of defective triglyceride removal. Mol Biochen Parasitol 2:31.

7. Kawakami M, Cerami A. 1981. Studies of endoloxin-induced decrease in lipoprotein lipase activity. $J$ Exp Med 1.54:63:1,

8. Cerami $A_{*}$ Vkeda $Y_{*}$ Le Trang $N_{n}$ Hotez PJ, Beutler B. 1985. Weight loss associated with an endotoxin-induced mediator from peritoneal macrophages: the role of cachectin (tumor necrosis factor). Immuniol Lett 11:173.

9. Beutler B; Mahoney J, Le Trang N, Pekala P, Cerami A. 1985. Purification of cachectin, a lipoprotein lipase-suppressing hormone secreted by endotoxin induced RAW 264.7 cells. I Exp Med 161.984.

10. Beutler B, Greenwald D, Hulmes JD, Chang M, Pan Y'-CE, Mathison J, Ulewitch R, Cerami A. 1985. Identity of tumour necrosis factor and the macrophage-secreted factor cachectin. Nature $316: 552$.

11. Müller U, Jongeneel CV, Nedospasov SA, Fischer Lindahl K, Steinmetz M. 1987. Tumour necrosis factor and lymphotoxin genes map close to H-2D in the mouse major histocompatibility complex. Nature $325: 265$.

12. Spies T, Morton CC, Nedospasov SA, Fiers W, Pious D, Strominger JL. 1986. Genes for the tumor necrosis factors $\alpha$ and $\beta$ are linked to the human major histocompatibility complex. Proc Natl Acad Sci USA 83:8699.

13. Caput D, Beutler B, Hartog $K$, Thayer $R$, Brown-Shiner S, Cerami A. 1986 . Identification of a common nucleotidle sequence in the $3^{3}$-untranslated region of mRNA molecules specifying inflammatory mediators. Proc Nall Acad Sci USA 83:1670.

14. Beutler B, Krochin N, Milsark IW, Luedke C, Cerami A. 1986. Control of cachectin (tumor necrosis factor) syathesis: mechanisms of endotoxin resistance. Science 232:977.

15. Sariban E, Imamura $K$, Luebbers $R$, Kufe D. 1988. Transcriptional and postranscriptional regulation of tumor necrosis factor gene expression in human monocytes. J Clin Invest 81:1506.

16. Philip R, Epstein LB. 1986. Tumour necrosis factor as immunomodulator and mediator of monocyte cylotoxicity induced by itself, $\gamma$-interferon and interleukin $=1$. Nature $323: 86$.

17. Debets JMH, van der Linden CI, Spronken IEM, Buurman WA. 1988. T cell-mediated production of tumotir necrosis factor- $\alpha$ by monocytes. Scand J Immunol 27:601.

18. Scuderi P, Sterling KE, Ratatio AB, Grogan TM, Rippe RA. 1987. Recombinant interferon- $\gamma$ stimulates the production of thuman tumor necrosis factor in vitro. J Interferon Res 7:155,

19. Beutler B, Tkacenko V, Milsark I, Krochin $N$, Cerami A. 1986. Effect of $y$ interferon on cachectin expression by mononuclear phagocytes. Reversal of the lpsd (endotoxin resistance) phenotype. If Exp Med 164:1791.

20. Collart MA, Belin D, Vassalli J-D, de Kossodo S, Vassalli P. 1986.y interferon enhances macrophage transcription of the tumor necrosis lactor/cachectin, interleukin 1 , and urokinase genes, which are controlled by short-lived repressors. I Exp Med 164:2113.

21. Nedwin GE, Svedtersky LP, Bringman TS, Palladino M.A, Jr, Goeddel DV. 1985. Effect of interleukin 2 , intertleron- $\gamma$, and mitogens on the production of tumor necrosis factors $\alpha$ and $\beta$.J Immunol 135:2492. 
22. Kunkel SL, Spengler M, May MA, Spengler R, Larrick I, Remick D. 1988. Prostaglandin E2 regulutes macrophage-derived tumor necrosis factor gene expression. J Biol Chem 263:5380.

23. Steffen M, Cayre Y, Manogue KR, Moore MAS. 1988. 1,25-Dihydroxywitamin D3 transeriptionally regulates tumour necrosis factor mRNA during HL-60 cell differentiation. Inmunology $63: 43$.

24. Okusawa S, Yancey KB, van der Meer JWM, Endres S, Lonnemann G, Hefter K, Frank MM, Burke JF, Dinarello CA, Gelfand JA. 1988. C5a stimulates secretion of turnor necrosis factor from human mononuclear cells in vitro. J Exp Med 168:443.

25. Warren MK, Ralph P. 1986. Macrophage growth factor CSF-1 stimulates human monocyte production of interferon, tumor necrosis factor, and colony-stimulating activity. J Immunol 1372281 .

26. Cannistra SA, Rambaldi A, Spriggs DR, Herrmann F, Kufe D, Griffin JD. 1987. Human granulocytcmacrophage colony-stimulating factor induces expression of the tumor necrosis factor gene by the U937 cell line and by normal human monocytes. J Clin Invest 79:1720.

27. Katakami $Y$, Nakao $Y$, Koizumi T, Katakami N, Ogawa R, Fujita T. 1988. Regulation of inmour necrosis factor production by mouse peritoneal macrophages: the role of cellular gyclic AMP. Immunology 64:719.

28. Renz H, Gong J-H, Schmidt A, Nain M, Gemsa D. 1988. Release of tumor necrosis factor- $\alpha$ from macrophages. Enhancement and suppression are dose-dependently regulated by prostaglandin E2 and cyclic nucleotides. J' Immunol 141:2388.

29. Cuturi MC, Murply M, Costa-Giomi MP, Weinman R, Perussia B, "Trinchieri G. 1987, lindependent regulation of tumor necrosis factor and lymphotoxin production by human peripheral blood lymphocytes. I Exp Med 165:1581.

30. Jadus MR, Schmunk G, Djeu JY, Parkman R. 1986. Morphology and lytic mechanisms of interleukin 3-dependent natural cytotoxic cells: tumor necrosis factor as a possible mediator. I Immunol $137: 2774$.

31. Wright SC, Bonavida B. 1987. Studies on the mechanism of natural killer cell-mediated cytotoxicity. VII. Functional comparison of human natural killer cytotoxic factors with recombinant lymphotoxin and tumor necrosis factor. J Imnunol 138:1791.

32. Steffen M, Ottmann OG, Moore MAS. 1988. Simultaneous production of tumor necrosis factor- $-x$ and lymphotoxin by normal T cells after induction with IL-2 and anti-T3. J Immunol 140:2621.

33. Sung S-SI, Jung LKL, Walters JA, Chen W, Wang CY, Fu SM. 1988. Production of tumor necrosis factor/cachectin by human B cell lines and tonsillar B cells. J Exp Med 168:1539.

34. Spriggs DR, Imamura K, Rodriguez C, Sariban E, Kufe DW. 1988. Tumor necrosis factor expression in human epithelial tumor cell lines. J Clin Invest 81:455.

35. Williamson BD, Carswell EA, Rubin BY, Prendergast JS, Old LI. 1983. Human tumor necrosis factor produced by human B-cell lines: synergistic cytotoxic interaction with human interferon. Proc Natl Acad Sci USA 80:5397.

36. Rubin BY, Anderson SL, Sullivan SA, Willianson BD, Carswell EA, Old L.J. 1986. Nonhema topoietic cells selected for resistance to lumor necrosis factor produce tumor necrosis hactor J Exp Med 164:1350.

37. Beutler BA, Milsark IW, Cerami A. 1985. Cachectin/tumor necrosis factor: production, distribution, and metabolic fate in vivo. J Immunol 135:3972.

38. Tracey KJ, Fong Y, Hesse DG, Manogue KR, Lee AT, Kuo GC, Lowry SF, Cerami A. 1988. Anti-cachectin/TNF monoclonal antibodies prevent septic shock during lethal bacteraemia. Nature 330:662.

39. Michie HR, Manogue KR, Spriggs DR, Revtaug A, O'Dwyer S, Dinarello CA, Cerami A, Wolff SM, Wilmore DW. 1988. Detection of circulating tumor necrosis factor after endotoxin administration. N Engl J Med 318:1481.

40. Chapman PB, Lester TJ, Casper ES, Gabrilove JL, Wong GY, Kempin SI, Gold PJ, Welt S, Warren $\mathrm{RS}_{\text {, Stanes }} \mathrm{HF}$, Sherwin SA, Old $\mathrm{W}$, Oetggen $\mathrm{HF}$. 1987. Clinical pharmacology of recombinant human tumor necrosis factor in patients with advanced cancer. J Clin Oncol 5:1942.

41. Blick M, Sherwin SA, Rosenblum M, Gutterman J. 1987. Phase I study of recombinant tumor necrosis factor in cancer patients. Cancer Res 47:2986.

42. Creaven PJ, Plager JE, Dupere $S$, Huben RP, Takita H, Mittelman A, Proefrock A. 1987. Phase I clinical trial of recombinant human tumor necrosis factor. Cancer Chemother Pharmacol 20:137. 
43. Agrgarwal SB, Eessalu TE, Hass PE. 1985. Characterization of receptors for human tumour necrosis factor and their regulation by y-inter feron. Nature 318:605.

44: Tsufimoto $M_{3}$ Feinman $R_{\text {s }}$ vilcek J. 1986. Differential effects of type I IFN and IFN- $y$ on the binding of tumor necrosis factor to receptors in two human cell lines. I Immunol 137:2272.

45. Unglatib $\mathrm{R}$, Maxdeiner $\mathrm{B}$, Thoma $\mathrm{B}$, Pfizenmaier K, Scheurich P. 1987. Downiregulation of umor necrosis factor (TNF) sensitiwity via modulation of TNF binding capacity by protein kinase C activators. I Exp Med 166:1788.

46. Holtmanin $\mathrm{H}$, Wallach $\mathrm{D}$. 1987 . Down regulation of the receptors for tumor necrosis factor by inter leukin 1 and $4 \beta$-phorbol-12-myristate-13-acetate. I Immunoll 139:1161.

47. Aggarwal BB, Eessalu TE. 1987. Effect of phorbol esters on down-regulation and redistriburion of cell surface receptors for tumor necrosis factor- $\alpha$. J Biol Chem $262: 16450$.

48. Sugarman BJ, AggarwalBB, Hass PE, Figari IS, Palladino MA, Jr, Shepard HM. 1985. Recombinant human tumor necrosils factor- ex effects on proliferation of normal and transformed cells in vitro. Seience $230 \% 43$.

49. Tsujimoto $M$, Yip YK, Vilcek J. 1985. Tumor necrosis factor: specific binding and internalization in sensitive and resistant cells. Proc Nat Acad Sci USA 82:7626.

50. Seheurich $\mathbb{P}$, Ucer $U_{3}$ Krönke $M_{9}$ Pfizenmaier $K$. 1986. Quantification and characterization of high-affinity membrane receptors for tumor necrosis factor on human leukemic cell lines. Int $J$ Cancer 38:127.

51. Pfrzemmaier K, Krönke M, Scheurich P, Nagel GA. 1987. Turnor necrosis factor (TNF) alpha: control of TWF-sensitivity and molecular mechanisms of TNF-mediated growth inthibition. Blut 551.

52. Ortaldo JR, Mason LH, Mathieson BJ, Liang S-M, Flick DA, Heberman RB. 1986. Mediation of mouse nateral cytotoxic activity by tumour necrosis factor. Nature 321;700.

53. Urban JL, shepard HM, Rothstein JL, Sugarman BJ, Schreber H. 1986. Tumor mecrosis factor: a potent effector molecule for tumor cell killing by activated macrophages. Proc Natl Acad Sci USA 83.5233.

54. Kornbluth RS, Edgington TS. 1986. Tumor necrosis factor production by human monocytes is a regulated event: induction of TMF- $a$-mediated cellular cytotoxicity by endotoxin. J Immunol 137: 2585.

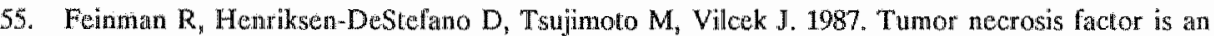
important mediator of tumor cell killing by human monocytes. J Immunol 138:635.

56. Decker T, Lohmann-Matthes M-L, Gifford GE. 1987. Cell-associated tumor necrosis factor (TNF) as a killing mechanism of activated cytotoxic macrophages. J Immunol 138:957.

57. Haranaka K, Satoni N, Sakurai A. 1984. Antitunor activity of murine tumor necrosis factor (TNF) agaimst transplanted murine tumors and theterotransplanted human tumors in nude mice. Int $J$ Cancer $34: 263$.

58. Brouckaert PGG, Leroux-Roels GG, Guisez Y, Tavernier J, Fiers W, 1986. In viwo antï-tumour activity of recombinant human and nurine TNF, alone and in combination with murine IFN- $\%$, on an syngencic nurine melanoma. Int J Cancer 38:763.

59. North R.I, Favell EA, 1988. The antitumor function of tumor necrosis factor (TNF). II. Analysis of the role of endogenous TNF in endotoxin-induced hemorhagic necrosis and regression of an established sarconad. J Exp Med 167:1086.

60. Palladino MA, Jr, Refat Shalaby M, Kramer SM, Ferraiolo BR, Baughman RA, Deleo AB, Crase D, Maralino B, Aggarwal BB, Figari IS, Liggitt D, Patton IS. 1987. Characterization of the antitumor activities of human tumor necrosis factor $-\alpha$ and the comparison with other cytokines: induction of turnor-specific imnumity. I Inmunol 138:4023.

61. Havell EA, Fiers W, North RJ. 1988. The antitumor function of tumor necrosis factor (TNF). I. Therapeutic action of TNF against an established murine sarcoma is indirect, immunologically dependent, and limited by severe toxicily. J Exp Med 167:1067.

62. Kinura $K$, Taguchi $T$, Urushizaki 1 , Ohno $R, A$ be $O$, Furue $H$, Hattori $T$, Ichithashi $H_{3}$ Inoguchi $K$, Majima $H$, Nittani $H_{\text {, }}$ Ota $K$, Saito T, Suga S, Suzuoki $Y$, Wakui A, Yamada K. 1987. Phase ll study of recombinant human tumor necrosis factor. Cancer Chemother Pharmacol 20:223.

63. Movat HZ, Burrowes CE, Cybulsky MI, Dinarello CA. 1987. Acute inflammation and a Schwartzman-like reaction ind uced by interleukin- $\mathbb{1}$ and tumor necrosis factor. Am J Pathol 129:463. 
64. Rothstein $\pi$, Schreiber H. 1988. Synergy between tumor mecrosis factor and bacterial products causes hemorrhagic necrosis and lethal shock in normal mice. Proc Nat Acad Sci USA 85:607.

65. Nawroth PP, Stern DM 1986. Modulation of endodhelial cell hemostatic properties by tumor necrosis factor. J Exp Med 163:740.

66. Nawroth $P_{0}$ Handley D, Matsueda G, De Waal $R$, Gerlach $H_{0}$ Blohm D, Stern D. 1988. Tumor necrosis factor/cachectin-induced intravascular fibrin formation in meth A fibrosarcomas. $J$ Exp Med 168:637.

67. Shalaby MR, Palladino MA, Jr, Hirabayashi SE, Eessalu TE, Lewis GD, Shepard HM, Aggarwal BB. 1987. Receptor binding and activation of polymorphonuclear neutrophils by tumor necrosis factor-alpha. J Leuk Biol 41:196.

68. Shalaby MR, Aggarwal BB, Rinderknecht E, Svedersky LP, FinkJe BS, Palladino MA, Jr. 1985. Activation of human polymorphonuclear meutrophil functions by interferon-gand tumor necrosis factors. J Immunol $135: 2069$.

69. Scheurich P, Thoma B, Ucer U, Pfizenmaier K. 1987. Immunoregulatory actiwity of recombinamt human tumor necrosis factor (TNF)- $a$ : induction of TNF receptors on liuman T cells and TNFamediated enhancement of $\mathrm{T}$ cell responses. IInmunol 138:

70. Yokota S, Geppert TD, Lipsky PE. 1988. Enhancement of antigen- and mitogen-induced human T lymphocyte proliferation by tumor necrosis factor- $\alpha$. J Inmunol 140:531.

71. Hackett RJ, Davis LS, Lipsky PE. 1988. Comparative effects of tumor necrosis factor-or and $1 \mathrm{~L}-1 \%$ on mitogen-induced T cell activation. J Immunol 140:2639.

72. Kehrl JH, Miller A, Fauci AS. 1987. Effect of tumor necrosis factor $\alpha$ on mitogen-activated human $B$ cells. J Exp Med 166:786.

73. Jelinek DF, Lipsky PE. 1987. Enhancement of human B cell proliferation and differentiation by tumor necrosis factor- $a$ and interleukin 1. J Immunol 139:2970.

74. Kashiwa $\mathrm{H}$, Wright SC, Bonavida B. 1987. Regulation of B cell maturation and differentiation. I. Suppression of pokeweed mitogen-induced B cell differentiation by turnor necrosis factor (TNF). J Immunol 138:1383.

75. Janssen $O_{1}$ Kabelitz D. 1988. Tumor necrosis factor selectively inhibits activation of human $B$ cells by Epstein-Barr virus. II Immunol 140:125.

76. Ming WJ, Bersani L, Mantovani A. 1987. Tumor necrosis factor is cliemotactic for monocytes and polymorphonuclear leukocytes. J Immunol 138;1469.

77. Gamble JR, Harlan JM, Klebanoff SJ, Vadas MA. 1985. Stimulation of the acherence of neutrophils to umbilical vein endothelium by hum fin recombinant tumor necrosis factor. Proc Natl Acad Sci USA 82:8667.

78. Pohlman TH, Stanness KA, Beatty PG, Ochs HD, Harlan JM. 1986. An endothelial cell surface factor(s) induced in vitro by lipopolysaccharide, interleukin $\mathbb{1}$, and tumor necrosis factor- $a$ increases neutrophil adherence by a CDw18-dependent mechanism. J Immunol 136:4548.

79. Cavender D, Saegusa $Y$, Zifr M. 1987. Stimulation of endothelial cell binding of lymphocytes bytumor necrosis factor. J Immunol 139:1855.

80. Pfizenmaier K, Scheurich $P$, Schlüter $C$, Krönke M. 1987. Tumor necrosis factor enthances HLA. $A, B, C$, and HLA-DR gene expression in human turnor cells. $J$ Inmunol 138:975.

81. Leeuwenberg JFM, van Damme I, Meager T, Jeunhomme TMAA, Buurman WA. 1988, Effects of tumor necrosis factor on the interferon- $\gamma$-induced major histocompatibility complex class II antigen expression by human endothelial cells. Eur J Immonol 18:1469.

82. Lee JC, Truneh A, Simith MF, Jr, Tsang KY. 1987. Induction of interleukin 2 receptor (TAC) by tumor necrosis factor in YT cells. J Immunol 139:1935.

83. Pober JS, Bewilacqua MP, Mendrick DL, LaPierre LA, Fiers W, Gimbrone MA, Jr. 1986. Two distinct monokines, interleukin 1 and tumor necrosis factor, each independently induce biosynthesis and transient expression of the same antigen on the surface of cultured human vascular endothelial cells. J Immunol 136:1680.

84. Pober IS, Gimbrone MA, Jr, LaPierre LA, Mendrick DL, Fiers W, Rothlein R, Springer TA. 1986. Overlapping patterns of actiwation of human endothelial cells by interleukin 1, tumor necrosis factor, and immune interferon. I Immunol 137:1893. 
85. Berger $M_{3}$ Wethler EM, Walls RS. 1988. Tumor necrosis factor is the major monocyte product that increases complement receptor expression on mature human neutrophils. Blood 71:151.

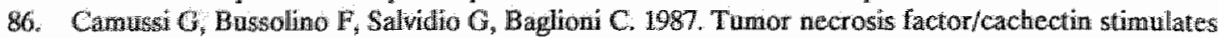
peritoneal mactophages, polymorphonuclear neutrophils, and vascular endothelial cells to synthesize and release platelet-activating factor. J Exp Med 166:1390.

87. Bussolino $F$, Camussi $G$, Baglioni $\mathrm{C}$. 1988. Synthesis and release of platelet-activating factor by human viscular endotheliall cells treated with tumor necrosis factor or interleukin 1 .. . I Biol Chem 263:11856.

88. Dayer IM, Beutler B, Cerami A. 1985. Cachectin/tumor necrosis factor stimulates collagenase and prostaglandin E2 production by human synowial cells and dermal fibroblasts. J Exp Med 162:2163.

89. Nawroth PP, Bank I, Handley $D_{n}$ Cassimeris J, Chess L, Stern D. 1986. Tumor necrosis factor/ca chectin interacts with endothelial cell receptors to induce release of interleukin 1 . J Exp Med $163: 1363$.

90. Bachwich PR, Chensue SW, Larrick JW, Kunkel SL. 1986. Tumor necrosis factor stimulates interleukin-1, and prostaglandin E2 production in resting macrophages. Biochem Biophys Res Com $136: 94$.

91. Zhang Y, Lin J.X, Yip YK, Villeek J. 1988. Enhancement of CAMP levels and of protein kinase activity by tumor necrosis factor and interleukin 1 in human fibroblasts: role in the induction of interleukin 6. Proc Natl Acad Sci USA 85:6802.

92. Leeuwenberg JFM, van Damme J, Jeunhomme GMAA, Buurman WA. 1987. Interferon $\beta 1$, an intermediate in the tumor necrosis factor $a$-induced increased MHC class II expression and an autocrine regulator of the constitutive MHC class I expression. J Exp Med 166:1180.

93. DefFilippi P, Poupart P, Tavernier J, Fiers W, Content J. 1987. Induction and regulation of mRNA encoding $26-\mathrm{kD}$ a protein in human cell lines treated with recombinant human tumor necrosis factor. Proc Natl Acad Sci USA 84:4557.

94. Munker R, Gasson J, Ogawa M, Koeffler HP. 1986. Recombinant human TNF induces production of granulocyte-monocyte colony-stimullating factor. Nature 323:79.

95. Oster W, Lindemann A, Horn S, Mertelsmann R, Hermann F. 1987. Tumor necrosis factor (TNF)-alpha but not TNF-beta induces secretion of colony stimulating factor for macrophages (CSF-1) by human monocytes, Blood 70:1700.

96. Dinarello CA, Cannon JG, Wolff SM, Bernheim HA, Bentler B, Cerami A, Figari IS, Palladino MA, $\mathrm{Jr}, \mathrm{O}^{\prime} \mathrm{Connor} \mathrm{JV}$. 1986. Tumor mecrosis factor (cachectin) is an endogenous pyrogen and induces production of interleukin 1. J Exp Med 163:1433.

97. Kettelhut IC, Goldberg AL. 1988. Tumor necrosis factor can induce fever in rats without activating protein breakdown in muscle or lipolysis in adipose tissue. J Clin Invest 81:1384.

98. Perlmutter DH, Dinarello CA, Punsal PI, Colten HR. 1986. Cachectin/tumor necrosis factor regulates hepatic acute phase gene expression. J Clin Inwest 78:1349.

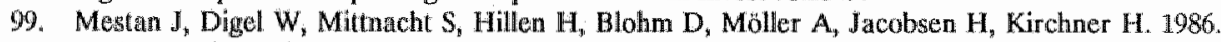
Antiviral effects of recombinant tumour necrosis factor in witro. Nature 323:816.

100. Wong GHW, Goeddel DV. 1986. Tumour necrosis factors $\alpha$ and $\beta$ inhibit virus replication and synergize with interferons. Nature 323:819.

101. Paya CV, Kenmotsu N, Schoon RA, Leibson PJ. 1988. Tumor necrosis factor and lymphotoxin secretion by human natural killer cells leads to antiviral cytotoxicity. J Immunol 141:1989.

102. Esparza I, Mämnel D, Ruppel A, Falk W, Krammer PH. 1987. Interferon $\gamma$ and lymphotoxin or tumor necrosis factor act synergistically to induce macrophage killing of tumor cells and schistosomula of Schistosoma Mansoni. J Exp Med 166:589.

103. Feingold KR, Grunfeld C. 1987. Tumor necrosis factor-alpha stimullates hepatic lipogenesis in the rat in vivo. J Clin Invest 80:184.

104. Warren RS, Donner DB, Fletcher Starnes H, Jr, Brennan MF. 1987. Modulation of endogenous hormone action by recombinant human tumor necrosis factor. Proc Nat Acad Sci 84:8619.

105. Wurren RS, Fletcher Starnes H, Jr, Alcock N, Calvano S, Brennan MF, 1988. Hormonal and metabolic response to recombinant human tumor necrosis factor in rat: in vitro and in wiwo. Am J Physiol 255:E206. 
106. Warren RS, Starnes HF, Jr, Gabrilove JL, Oetggen HF, Brenran MF. 1987. The acute metabolic effects of tumor necrosis factor administration in humatas. Areli Surg 122:1396.

107. Michie HR, Spriggs DR, Manogue KR, Sherman ML, Rewhatg A, ODwyer ST, Arthur K, Dinarello CA, Cerami A, Wolff SM, Kufe DW, Wilmore DW. 1988. Tumor necrosis factor and endoroxin induce similar responses in human beings. Surgery 104:280.

108. Beisel WR. 1984, metabolic effects of infection. Progress in Food and Nutrition Science 8:43.

109. Brenneman DE, Mathur SN, Spector AA. 1975. Characterization of the hyperlipidemia in mice bearing the Ehrlich ascites tumor. Eur J Cancer 11:225.

110. Spiegel RJ, Schaefer EJ, Magrath IT, Edwards BK. 1982. Plasma lipid alterations in leukemial and lymphoma. Am J Med 72:775.

111. Oliff A, Defeo-Jones D, Boyer M, Martinez D, Kiefer D, Vuocolo G, Wolfe A, Socher SH. 1987. Tumors secreting human TNF/cachectin induce cachexia in mice. Cell $50: 555$.

112. Tracey KJ, Wei H, Manogue KR, Fong X, Hesse DG, Nguyen HT, Kuo GC, Beutler B, Cotran RS, Cerami A, Lowry SF. 1988. Cachectin/tumor necrosis factor induces cachexia, anemia, and inflammation. J Exp Med 167:1211.

113. Sacher $\mathrm{SH}$, Friedman A, Martinez D. 1988. Recombinant human tumor mecrosis factor induces acute reductions in food intake and body weight in mice. J Exp Med 167:1957.

114. Mahony SM, Tisdale MJ. 1988. Induction of weight loss and metabolic alterations by human recombinant tumour necrosis factor, Br J Cancer 58:345.

115. Goldberg AL, Kettelhut IC, Furuno K, Fagan JM, Baracos V. 1988. Activation of protein breakdown and prostaglandin E2 production in rat skeletal muscle in fever is signalled by a macrophage product. distinct from interlleukin 1 or other known monokines. J Clin Invest 81:1378.

116. Balkwill F, Burke F, Talbot D, Tavernier J, Osborne R, Naylor S, Durbin $\mathrm{H}_{4}$ Fiers W. 1987. Evidence for tumour necrosis factor/cachectin production in cancer. Lancet ii:1229.

117. Beutler B, Cerami A. 1986. The endogenous mediator of endotoxic shock. Clin Res 34:192,

118. Harris RL, Musher DM, Blloom K, Gathe J, Rice L, Sugarman B, Williams TW, Jr, Young EJ. 1987. Manifestations of sepsis. Arch Int Med 147:1895.

119. Tracey KJ, Beutler B, Lowry SF, Merryweather J, Wolpe S, Milsark IW, Harini RJ, Fahey III, TJ, Zentella A, Albert JD, Shires GT, Cerami A. 1986. Shock and tissue injury induced by recombinan human cachectin. Science 234:470.

120. Tracey KJ, Lowry SF, Fahey III TJ, Albert JD, Fong Y, Hesse $\mathrm{D}$, Beutler B, Manogue KR, Calvano S, Wei H, Cerami A. 1987. Cachectin/tumor necrosis factor ünduces lethal shock and stress hormone responses in the dog. Surg Gynecol Obst 164:415.

121. Kettelhut IC, Fiers W, Goldberg. 1987. The toxic effects of tumor necrosis factor in wivo and their prevention by cyclooxygenase inhibitors. Proc Natl Acad Sci USA 84:4273.

122. Beutler B, Milsark IW, Cerami AC. 1985. Passive immunizationa against cachectin/tumor necrosis factor protects mice from lethal effect of endotoxin. Science $229: 869$.

123. Mathison JC, Wollson E, Ulewitch RJ. 1988. Participation of tumor necrosis factor in the mediation of gram megative bacterial lipopolysaccharide-induced injury in rabbits. J Clin Invest 81:1925.

124. Waage A, Halstensen A, Espevik T*. 1987. Association between tumour necrosis factor in ser um and fatal outcome in patients with meningococcal disease. Lancet i: 355.

125. Girardin E, Grau GE, Dayer J-M, Roux-Lombard P, Lambert P-H. 1988. Tumor necrosis factor and interleukin-1 in the serum of children with severe infectious purpura. N Engl I Med 319:397.

126. Okusawa S, Gelland JA, Ikejima T, Connolly RJ, Dinarello CA. 1988. Interleukin 1 induces a shock-like state in rabbits. Synergism with tumor necrosis factor and the effect of cyclooxygenase inhibition. J Clin Invest 81:1162.

127. Bertini $R$, Bianchi $M_{0}$ Ghezi $P$. 1988. Adrenalectomy sensitizes mice to the lethal effects of interleukin 1 and tumor necrosis factor. J Exp Med 167:1708.

128. Waage A, Espevik T. 1988. Interleukin 1 potentiates the lethal effect of tumor necrosis factor c/cachectin in mice. J Exp Med 167:1987.

129. Sun X, Hsueh W. 1988. Bowel necrosis induced by tumor necrosis factor in rats is mediated by platelet-activating factor. J Clin Inwest 81:1328.

130. Weinberg JR, Wright DIM, Guz A. 1988. Interleukin-1 and tumour necrosis factor cause hypotension in the conscious rabbit. Clin Sci 75:251. 
131. Saklatvala J. 1986. Tumour necrosis factor a stimulates resorption and inhibits synthesis of proteoglycain in cartllage. Nature $322-547$.

132. Thomson BM, Mundy $G R$, Chambers TJ. 1987. Tumor necrosis factors $\alpha$ and $\beta$ induce osteoblastic cells to istimulate osteoclastic bone resorption. II Immunol 138:775.

133. Bertolini DR, Nedwin GE, Bringman TS, Smith DD, Mundy GR. 1986. Stimulation of bone resorption and inlibition of bone formation in vitro by human tumour necrosis factors. Nature $319: 516$.

134. Hopkins $\$ \mathrm{~J}$, Meager A. 1988. Cytokines in synovial fluid: II. The presence of tumour necrosis factor and interferon. Clin exp Immunol 73:88.

135. Saxne T, Palladino MA, Jr, Heinegard $D$, Talal N, Wollheim FA. 1988. Detection of tumor necrosis factor $\alpha$ but not tumor necrosis factor $\beta$ in rheumatoid arthritis synovial fluid and serum. Arthr Rheum 31:1041.

136. Stashenko P, DeWhirst FE, Peros. WJ, Kent RL, Ago JM. 1987. Synergistic interactions between interlewkin 1 , tumor necrosis factor, and lymphotoxin in bone resorption. J Immunol 138:1464.

137. Buchan G, Barrett K, Turner M, Chantry D, Maini RN, Feldmann M. 1988. Interleukin-1 and tumour necrosis factor mRNA expression in rheumatoid arthritis: prolonged production of IL-1a. Clin exp Immunol $73: 449$.

138. Jacob $\mathrm{CO}$, McDevitt HO. 1988. Tumour necrosis factor $\alpha$ in murine autoimmune 'lupus' nephritis. Nature 331:356.

139. Magilavy DB, Rothstein JL. 1988. Spontameous production of tumor necrosis factor $a$ by Kupffer cells of MRL/fpr mice. J Exp Med 168:789.

140. Taverne $\mathrm{J}_{4}$ Rayner DC, Van der Meide PH, Lydyard PM, Bidey SP, Cooke A. 1987. Cytotoxicity of turnor necrosis factor for thyroid epithelial cells and its regulation by interferon- $\gamma$. Eur J Immunol 17:1855.

141. Pujol-Borrell R, Todd I, Doshi M, Franco Bottazzo G, Sulton R, Gray D, Adolf GR, Feldmann M. 1987. HLA class II induction in haman islet cells by interferon- $\gamma$ plus tumour necrosis factor or lymphotoxin. Nature 326:304.

142. Campbell IL, Iscaro A, Harrison LC. 1988. IFN- $\gamma$ and tumor necrosis factor- $\alpha$. Cytot oxicity to murine islets of Langerhans. J Immunol 141:2325.

143. Clark IA, Cowden WP, Butcher GA, Hunt NH. 1987. Possible roles of tumor necrosis factor in the pathology of malaria. Am J Pathol 129:192.

144. Piguet P.F, Grau GE, Allet B, Vassalli P. 1987. Tumor necrosis factor/cachectin is an effector of skin and gut lesions of the acute phase of graft-vs.-host disease. J Exp Med 166:1280.

145. Maury CPI, Teppo A-M. 1987. Raised serum levels of cachectin/tumor necrosis factor $\alpha$ in renal allograft rejection. J Exp Med 166:1132.

146. Nedwin GE, Svedersky LP, Bringman TS, Palladino MA, $J r_{r}$ Goeddel DV. 1985. Effect of interleukin 2 , interferon $\gamma_{0}$ and mitogens on the production of tumor nectosis factors $\alpha$ and $\beta$. J Immunol $135: 2492$.

147. Sung S-SJ, Bjorndithl JM, Wang CY, Kao HT, Fu SM. 1988. Production of tumor necrosis factor/cachectin by human T cell lines and peripheral blood T lymphocytes stimulated by phorbol myristate acetate and anti-CD3 antilyody. J Exp Med 167:937.

148. Ragsdale CG, Arend WP. 1979. Neutral protease secretion by human monocytes. J Exp Med 149:954.

149. Passwell JH, Dayer J-M, Merler E. 1979. Increased prostaglandin production by human monocytes after membrane receptor activation. J Immunol 123:115.

150. Passwell JH, Dayer J-M, Gass K, Edelson PJ. 1980. Regullation by Fc fragments of the secretion of collagenase, PgE2, and lysozyme by mouse peritoneal macrophages. J Immunol 125:910.

151. Rouzer CA, Scott WA, Kempe J, Cohn ZA. 1980. Prostaglandin synthesis by macrophages requires a specific receptor-ligand interaction. Proc Natl Acad Sci USA 77:4279.

152. Rouzer CA, scott WA, Hamill AL" Cohn ZA. 1980. Dynannics of leukotriene C production by macrophages. J Exp Med 152:1236.

153. Looney RI, Abraham $\mathrm{GN}$, Anderson CL. 1986. Human monocytes and U937 cells bear two distinct Fe receptors for $\operatorname{lgG}$. J Immunol 136:1641.

154. Anderson CL, Guyre PM, Whitin JC, Ryan DH, Looney RJ, Fanger MW. 1986. Monoclonal antibodies to $F_{C}$ receptors for IgG on human mononuclear phagocytes. J Biol Chem 261:12856. 
155. Graziano RF, Fanger MW. 1987. FoR RI and FoyRI on monocytes and granulocytes are cytotoxac trigger molecules for tumor cells. J Immunol 139:3536.

156. Ruers TJM, Buurman WA, van Boxtel $\mathrm{CJ}$, van der Linden $\mathrm{CJ}$, Kootstra $G$. 1987. Inmunohistological observations in rat kidney allografts after local steroid administration. J Exp Med 166:1205.

157. Cupps TR, Fauci AS. 1982. Glucocorticoid-mediated immunoregulation in man. Immunol Rev $65: 133$.

158. The veterans administration systemic sepsis cooperative study group. 1987. Effect of high-dose glucocorticoid therapy on mortality in patients with clinical signs of systemic sepsis. N Engl J Med 317:659.

159. Borm PJA, Palmen N, Engelen JJ, Bunrman WA. 1988. Spontaneous and stimulated release of iumor necrosis factor (TNF)-alpha from blood monocytes of miners with coal workers" pneumoconiosis. Amer Rev Resp Dis 138:1589.

160. Goldstein G. 1986. An overview of Orthoclone OKT3. Transplant Proc 18:927.

161. Hoitsma AJ, van Lier HJJ, Reekers P, Koene RAP. 1985. Improved patient and graft survival after treatment of acute rejections of cadaveric renal allografts with rabbit antithymocyte globulin. Transplantation 39:274.

162. Ortho Multicenter Transplant Study Group. 1985. A randomized clinical trial of OKT3 monocllonall antibody for acute rejection of cadaveric renal transplants. N Engl J Med 313:337.

163. Ponticelli $C$, Rivolta $E$, Tarantino $A_{s}$ et al, 1986. Clinical experience with Orthoclone OKT 3 in renal transplantation. Transplant Proc 18:942.

164. Waymack JP, Penn I, First MR, Alexander JW. 1987. Portal vein gas and sepsis alter administration of OKT3. Lancet $: 984$.

165. Goldstein G, Schindler J, Sheahan M, Barnes L, Tsai H. 1985. Orthoclone OKT3 treatment of acute renal allograft rejection. Transplant Proc 17:129. 


\title{
T CELL-MEDIATED SECRETION OF TUMOR NECROSIS FACTOR BY MONOCYTES
}

\author{
Debets, J.M.H., C.J. van der Linden, I.E.M. Spronken, and \\ W.A. Buurman. Scand. J. Immunol. 1988;27:601.
}

\section{SUMMARY}

The aim of this study was to examine the production of tumour necrosis factor (TNF) $-\alpha$ by peripheral blood mononuclear cells activated by mitogens. Considerable amounts of TNF, ranging from 1.0 to $5.0 \mathrm{ng} / \mathrm{ml}$, were present in the supernatants of cultures of human peripheral blood mononuclear cells (PBMC), stimulated with either the anti-CD3 monoclonal antibody OKT3 or the lectin phytohaemagglutinin (PHA). The amount of TNF secreted in the supernatant was closely correlated to the degree of $T$ cell proliferation in such cultures, as measured by $\left[{ }^{3} \mathrm{H}\right] \mathrm{TdR}$ incorporation. In the absence of proliferating $T$ cells the mitogens did not induce secretion of TNF by monocytes. Supernatants of proliferating T cells were shown to induce TNF secretion by monocytes. The macrophage-activating factor gamma interferon (IFN- $\gamma$ ) was also shown to induce, in the absence of endotoxin, TNF secretion by monocytes in a dose-dependent manner. The induction of TNF production by supernatants of proliferating $T$ cells could largely be abrogated by passaging the supernatants on an anti-IFN$\gamma$ column before adding them to the monocytes. It is therefore concluded from this study that the production of TNF by monocytes can be induced by proliferating T cells and that this induction can largely be attributed to the $\mathrm{T}$ cell lymphokine IF $\mathrm{N}-\gamma$.

\section{INTRODUCTION}

Tumour necrosis factor $-\alpha$ (TNF), also called cachectin, is a 17 kDa protein produced and secreted by monocytes and macrophages $(4,8,31)$. In addition to microbial products like lipopolysaccharide (LPS) lectins were also shown to induce TNF production (27), suggesting that TNF release is also under the control of T cell processes, as has been reported for the monokine interleukin 1 (IL-1) $(24,25,35)$. The T lymphocyte product interferon-gamma (IFN-y) may be involved in this process as a mediator although the capacity of IFN-y, to induce TNF secretion is disputed $(27,32,33)$. 
It has recently been shown that not only monocytes but also $\mathrm{T}$ lymphocytes and natural killer cells are able to produce TNF after stimulation (11).

In this study we examined whether, in analogy to $\mathrm{L}-1$, TNF production by monocytes can be regulated by $T$ cell processes. We found that TNF is produced and secreted by monocytes in mitogen-stimulated peripheral blood mononuclear cell (PBMC) cultures and that this production is dependent on the presence of proliferating $\mathrm{T}$ cells. It was concluded that TNF production by monocytes can be regulated by $\mathrm{T}$ cell processes and that this regulation is largely mediated by the T cell lymphokine IFN $-\gamma$.

\section{MATERIALS AND METHODS}

Reagents. Human cDNA derived rIFN- $\gamma$ was kindly provided by Hoffmann La Roche (Basle, Switzerland). It contained about $34 \mathrm{pg}$ LPS per $10^{3}$ IU of IFN $\gamma$, as determined by a chromogenic Limulus amoebocyte lysate assay. rIL-2 was kindly provided for this study by Biogen, Geneva (Dr Galazka). rTNF was kindly prowided by Knoll Ag/BASF (Ludwigsh affen, FRG), in collaboration with Biogen, Genewa. The specific actiwity is $8 \times 10^{6}$ lytic units/mg protein in a $48 \mathrm{~h} \mathrm{L929}$ assay without mitomycin. Recombinant human GM-CSF (specific activity more than $4 \times 10^{7} \mathrm{U} / \mathrm{mg}$ protein) was kindly provided by Dr M.A. Cantrell (Immunex, Seattle, Wash., USA). PHA15 (Wellcome, Beckentam, Kent, UK) was used for lectin stimulation of T cells. 4- $\beta$-phorbol-12-myristate-13-acetate (PMA), LPS from Salmonella typhimurium, and polymyxin B sulphate were purchased from Sigma (St Louis, Mo., USA).

Antibodites. The anti-CD3 monoclonal antibody OKT3 was obtained with the OKT3-secreting hybridoma (CRL8001), purchased from the ATCC (Rockwille, Md., USA). Filter-sterilized ascites was used in different dilutions in culture medium to stimulate $T$ cells. Anti-Leu-1, an anti-CD5 monoclonal antibodly, was purchased from Becton Dickinson (Mountain View, Calif., USA). The anti-monocyte monoclonal antibody PDV 11-2 was a kind gift from Dr F. Koning (Leiden, The Metherlands). The monoclonal antibody D9D10 against human IFN-y was kindly provided by Dr M. de Ley (Letwen, Belgium). Monoclonal antibodies against TNF were derived from anti-TNF-secreting hybridomas obtained by a standard cell fusion procedure. Rabbit polyclonal antibodies against TNF were raised by immunizing rabbits with highly purified human rTNF. IgG was semipurified by ammonim sulphate precipitation of the collected serum.

Cell cultures. PBMC were prepared by buoyant density centrifugation on Lymphoprep (Nycomed, Oslo, Norway) of buffy coats of donor blood obtained from the local blood bank. Cells were cultured in $25 \mathrm{~cm}^{2}$ culture flasks (Greiner, Nürtingen, FRG), or in 24-well culture plates (Greiner), in RPMI 1640 (Gibco, Paisley, UK) supplemented with $10 \%$ heat-inactivated fetal calf serum, $100 \mathrm{IU} / \mathrm{ml}$ penicillin, and $100 \mu \mathrm{g} / \mathrm{ni}$ streptomycin (Flow Irvine, $\mathrm{UK}$ ), at $37^{\circ} \mathrm{C}$ in humidified $5 \% \mathrm{CO}_{2}$ and $95 \%$ air. The culture medium used in the experiments contained endotoxin levels ranging between 50 and $400 \mathrm{pg} / \mathrm{ml}$. Monocyles were isolated from $\mathrm{PBMC}$ by adherence to plastic for 1 th and extensive washing of non-adherent cells and, in some cases, additional removal of remaining Tl lymphocytes by incubating the cells for $30 \mathrm{~min}$ with anti-Lea 1 at $4^{\circ} \mathrm{C}$, lollowed by incubation for $1 \mathrm{~h}$ with rabbit complement at $37^{\circ} \mathrm{C}$. Monocytes were cultured under the same conditions as the PBMC. Activated Thmphocytes were prepared by isolating the non-adherent cell fraction of $\mathrm{PBMC}$ after $24 \mathrm{~h}$ of mitogen stimulation and by removing remaining monocytes by treatment with the anti-monocyte monoclonal antibody PDV $11-2$ for 30 min at $4^{\circ} \mathrm{C}$ and rabbil complement for 1 hat $37^{\circ} \mathrm{C}$. Proliferation of cells was sustained by adding rlL-2, $10 \mathrm{U} / \mathrm{ml}$, to the cultures.

Proliferation of cells was assessed by incubating $100 \mu \rrbracket$ of resuspended cells with $0.5 \mu \mathrm{Ci}\left[{ }^{3} \mathrm{H}\right] \mathrm{TdR}$ (methyl- $\left.{ }^{3} \mathrm{H}\right]$ thymidine, Amersham International, Amershan, Bucks., UK; specific activity $5.0 \mathrm{CH}$ mmoll) in a round-bottomed microtitre plate for $4 \mathrm{~h}$ and, after the cells had been harvested with a cell harvester, measuring radioactivity in a liquid scintillation counter. Proliferation was assessed in triplicate. 
The purity of the isolated $T$ cells and monocytes was analysed by incubating the cells with the monoclonal antibodies OKT 3 and PDV $11-2$ for 30 min at $4^{\circ} \mathrm{C}$, after which the cells were washed wice and incubated with an FTC-labelled rabbit anti-mouse antibodly for 30 min at $4^{\circ} \mathrm{C}$. Cells were counted with a FACS IV (Becton Dickinson).

TNF enzyme-linked immunosorbent assay (ELISA). TNF concentrations of cell-free supernatants of the cell cultures were determined with a TNF-specific ELISA. Immunoassay plates (96-well plates; Nunc, Roskilde, Denmark) were coated overnight at $4^{\circ} \mathrm{C}$ with three monoclonal anti-TNF antibodies at a concentration of $5 \mu \mathrm{g} \mathrm{Ig} / \mathrm{ml}$. Plates were blocked with 1\% (w/ $/ \mathrm{w})$ BSA in PBS for $1 \mathrm{~h}$ at room temperature. After four washes with washing buffer (WB, consisting of PBS, 0.1\% BSA, 0.1\% Tween 20) test samples were added to the plate for $1 \mathrm{~h}$ at room temperature. A standard titration curve was obtained by making serial dilutions of a known sample of rTNF. Next, the plates were washed five times with WB and sequentially incubated with rabbit anti-TNF immune serum, biotinylated anti-rabloit antibody (Amersham) and horseradish peroxidase-labelled streptavidin (Amersham). After adding substrate (o-phenylenediamine, Sigma, $0.43 \mathrm{mg} / \mathrm{ml}$ ) to the plate for 5-10 min, the colour reaction was stopped with $1.0 \mathrm{M}$ $\mathrm{H}_{2} \mathrm{SO}_{4}$ and light absorption was measured with a micro-ELISA autoreader (Flow) with it $493 \mathrm{~nm}$ filtcr. The ELISA had a lower detection limit of $50 \mathrm{pg} / \mathrm{ml}$.

Affinity chromatography. In some experiment.s, supernatants of mitogen-stimulated PBMC were used to induce TNF secretion by monocytes. From these supernatants TNF and IFN $y$ were removed by passaging the supernatants on a protein A-Sepharose 4B column (Pharmacia Fine Chemicals, Uppsala, Sweden) loaded with a rabbit anti-TNF antibody and a CNBr-activated Sepharose $4 \mathrm{~B}$ column (Pharmacia) loaded with IgG from the anti-human IFN-y -producing clone D9D 10 , respectively. "The flow-tJrough fractions did not contain any detectable TNF or IFN- $\gamma$ after passaging on the respective columns, as determined with the TNF ELISA and with titration on Hep-2 cells. Next, these supernatants were clialysed overnight at $4^{\circ} \mathrm{C}$ against RPMI before adding them to the cell cultures.

Endotoxin measurements. Endotoxin concentrations were measured with a chromogenic Limulus lysate assay purchased from Kabivitrum (Stockholm, Sweden).

\section{RESULTS}

\section{TNF production in mitogen-stimulated PBMC}

PBMC were stimulated with the anti-CD3 monoclonal antibody OKT3 and with PHA. TNF could be detected in the supernatant of mitogen-stimulated PBMC, sampled after 24,48 , and $72 \mathrm{~h}$, whereas TNF was absent in the non-stimulated cultures (Table I). Since OKT3 and PHA are T cell mitogens, we examined whether T cell proliferation and TNF production are correlated. For this purpose PBMC were incubated with different concentrations of OKT3 and PHA. Fig. 1 gives the dose-response curves for $T$ cell proliferation and TNF production in such mitogen-stimulated PBMC cultures. The figure shows that $\mathrm{T}$ cell proliferation and TNF concentration correlate similarly to mitogen concentration.

\section{TNF production in mitogen-stimulated PBMC is T cell-dependent}

Since $\mathbf{T}$ cell proliferation and TNF production appeared to be correlated, we examined whether TNF production is $T$ cell-dependent or caused by a direct effect of the mitogens on monocytes. Incubation of highly purified monocytes with OKT3 and PHA for $24 \mathrm{~h}$ did not lead to a measurable TNF production. TNF production could, however, be induced by LPS and PMA indicating that the monocytes were viable and capable of producing TNF (Table II). 


$\frac{\text { Concentration of TNF- }-\alpha(\mathrm{ng} / \mathrm{ml})}{24 \mathrm{~h} \quad 48 \mathrm{~h} \quad 72 \mathrm{~h}} \quad \begin{array}{r}{\left[{ }^{3} \mathrm{H}\right] \mathrm{TdR}-} \\ \text { uptake(cpm) }\end{array}$

\section{Experiment 1}

$\begin{array}{lcrrr}\text { Unstimulated cells } & <0.05^{\mathrm{b}} & <0.05 & <0.05 & 4869 \\ \text { + OKT3 } & 3.18 & 2.97 & 1.36 & 51,983 \\ \text { + PHA } & 5.64 & 3.83 & 2.15 & 53,127\end{array}$

\section{Experiment 2}

$\begin{array}{lrrrr}\text { Unstimulated cells } & 0.08 & <0.05 & <0.05 & 751 \\ \text { + OKT3 } & 2.19 & 1.29 & 0.72 & 39,898 \\ \text { +PHA } & 4.51 & 2.58 & 1.46 & 70,423\end{array}$

\section{Experiment 3}

$\begin{array}{lrrrr}\text { Unstimulated cells } & <0.05 & <0.05 & <0.05 & 854 \\ \text { + OKT3 } & 0.60 & 1.00 & 0.44 & 28,136 \\ \text { + PHA } & 2.10 & 2.16 & 2.75 & 55,390\end{array}$

$\mathrm{a}_{2 \times 10^{6}}$ PBMC were incubated with a 1:500 dilution of OKT3 ascites or a 1:100 dilution of PHA15, and the "TNF concentration was measured at 24,48 , and $72 \mathrm{~h}$. Cell proliferation was measured on day 3 of culture. Data from 3 out of 8 different experiments are shown.

${ }^{b} 0.05 \mathrm{ng} / \mathrm{mll}$ constituted the lower detection limit of the TNF ELISA.

TABLE II. Lack of TNF production by isolated monocytes treated with OKT3 and PHA ${ }^{a}$

\begin{tabular}{lcrr}
\hline Treatment & Expt 1 & Expt 2 & Expt 3 \\
\hline None & $<0.05^{\mathrm{b}}$ & $<0.05$ & $<0.05$ \\
OKT3 & $<0.05$ & $<0.05$ & $<0.05$ \\
PHA & $<0.05$ & $<0.05$ & $<0.05$ \\
LPS & 0.81 & 1.03 & 0.34 \\
PMA & 2.37 & 1.93 & 0.64 \\
\hline
\end{tabular}

"Approximately $5 \times 10^{5}$ purified monocytes, obtained by adherence and additional removal of remaining $\mathrm{T}$ lymphocytes by complement lysis as described in Methods, were incubated with a 1:500 dilution of OKT3 ascites, a 1:10 dilution of PHA, $10 \mu \mathrm{g} / \mathrm{ml}$ LPS, and $10 \mathrm{ng} / \mathrm{ml}$ PMA, respectively, and the TNF concentration (mg/ml) was measured $24 \mathrm{~h}$ later. Data from 3 out of 6 different experiments are shown.

${ }^{6} 0.05 \mathrm{ng} / \mathrm{ml}$ constituted the lower detection limit of the TNF ELISA. 

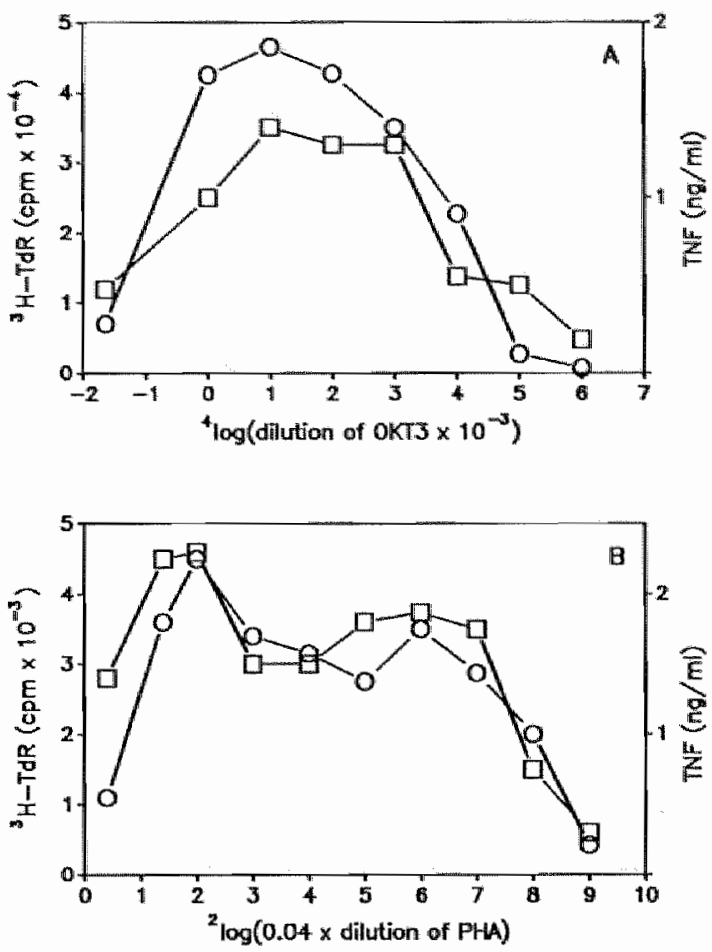

Figure 1. Dose-response curves of TNF production and Tcell proliferation in mitogen-stimulated PBMC cultures. PBMC at a concentration of $1 \times 10^{6}$ cells/ml were incubated with dilutions of OKT3 ascites (A) and PHA (B). Cell proliferation (open circles) was measured on day 3 of culture and TNF concentration in the supernatant (open squares) was measured after $24 \mathrm{~h}$. The results are means of duplicate cultures and are representative of 10 different experiments.

Next, the influence of $T$ cells on TNF production by monocytes was studied by adding proliferating $T$ cells to isolated monocytes. Table III shows that monocyte-depleted, $T$ cell-enriched cell populations produced only low amounts of TNF, despite persistent cell proliferation sustained by exogenous rIL-2. However, TNF production was greatly increased by the addition of such isolated proliferating $\mathrm{T}$ lymphocytes to purified monocytes. To exclude the influence of rIL-2 on monocytes, rIL-2 was added to purified monocytes. The monocytes did not produce TNF after incubation with IL-2 for $24 \mathrm{~h}$ (Table III). It was therefore concluded that the mitogens OKT3 and PHA do not have a direct effect on monocytes but exert their effect via activation of $\mathrm{T}$ cells.

\section{IFN- $y$ and GM-CSF both induce TNF production by monocytes}

To examine whether a humoral $\mathrm{T}$ cell product was responsible for the T cell-mediated TNF production observed, we examined whether the lymphokines IFN- $\gamma$ and GM-CSF, which are both known inducers of monocyte tumoricidal activity, can induce TNF production by monocytes. Fig. 2 shows that both IFN- $\gamma$ and GM-CSF induce TNF 


\begin{tabular}{lcc}
\hline & $\begin{array}{c}\text { TNF } \\
\text { (ng/ml) }\end{array}$ & $\begin{array}{r}{[3 \mathrm{H}] \mathrm{TdR}} \\
(\mathrm{cpm})\end{array}$ \\
\hline Experiment 1 & 11.5 & 71,210 \\
PBMC + OKT3 & $<0.05^{\mathrm{b}}$ & 29,160 \\
Activated T lymphocytes + rIL-2 & $<0.05$ & 440 \\
Monocytes + rIL-2 & 1.31 & 33,040 \\
Monocytes + activated & & \\
T lymphocytes + rlL-2 & & \\
& & \\
Experiment 2 & 2.16 & 14,970 \\
PBMC + OKT3 & 0.68 & 76,410 \\
Activated T lymphocytes + rIL-2 & $<0.05$ & 920 \\
Monocytes + rIL-2 & 4.64 & 42,380 \\
Monocytes + activated & & \\
T lymphocytes + rIL-2 & & \\
\hline
\end{tabular}

\footnotetext{
${ }^{a}$ Approximately $1 \times 10^{6}$ activated $\mathrm{T}$ lymphocytes (see Materials and Methods) and $5 \times 10^{5}$ monocytes, obtained by adherence and additional removal of remaining $T$ lymphocytes by complement lysis, were. incubated with rIL-2, $10 \mathrm{U} / \mathrm{ml}$, and the TNF concentration was measured $24 \mathrm{~h}$ later. In the same experiment, $1 \times 10^{6}$ proliferating T lymphocytes were added to $5 \times 10^{5}$ monocytes $+\mathrm{rIL}-2,10 \mathrm{U} / \mathrm{ml}$, and the TNF concentration was also measured after $24 \mathrm{~h}$. The TNF concentration in supernatant of unseparated PBMC of the same individual was measured $24 \mathrm{~h}$ after induction of mitogenesis with $O K 73$. Cell proliferation was assessed on day 3 of culture in all experiments. Data from 2 out of 6 different experiments are shown.

${ }^{\mathrm{b}} 0.05 \mathrm{ng} / \mathrm{ml}$ constituted the lower detection of the TNF ELISA.
}

production by purified monocytes in a dose-dependent manner. IFN- $\gamma$ appeared to be a far more potent stimulus for TNF production than GM-CSF, since the maximal amount of TNF produced by monocytes after incubation with both cytokines is about eight times higher for IFN- $\gamma$ than for GM-CSF. Both cytokines show an inhibitory effect at higher concentrations.

To exclude the possibility that IFN- $\gamma$ acts only as a 'primer' of monocytes and that the secretion of 'TNF is induced by low concentrations of endotoxin present in the culture medium, this medium, containing IFN- $\gamma$ at different concentrations, was incubated with the endotoxin-neutralizing compound polymyxin B sulphate before adding it to monocytes. The amount of polymyxin B sulphate used, i.e. $1 \mu \mathrm{g} / \mathrm{ml}$, was found to inhibit at least $1 \mathrm{ng} / \mathrm{ml}$ of LPS (Greve, Buurman et al., unpublished observations), whereas the medium including IFN-y always contained less than $500 \mathrm{pg} / \mathrm{ml}$ of LPS. Fig. 3 shows that there is only a partial reduction of TNF production at the higher concentrations of IFN- $\gamma$, while at lower concentrations, TNF production is not inhibited at all. It is therefore concluded that IFN- $y$ is able to induce TNF production and secretion by monocytes in the absence of endotoxin. 


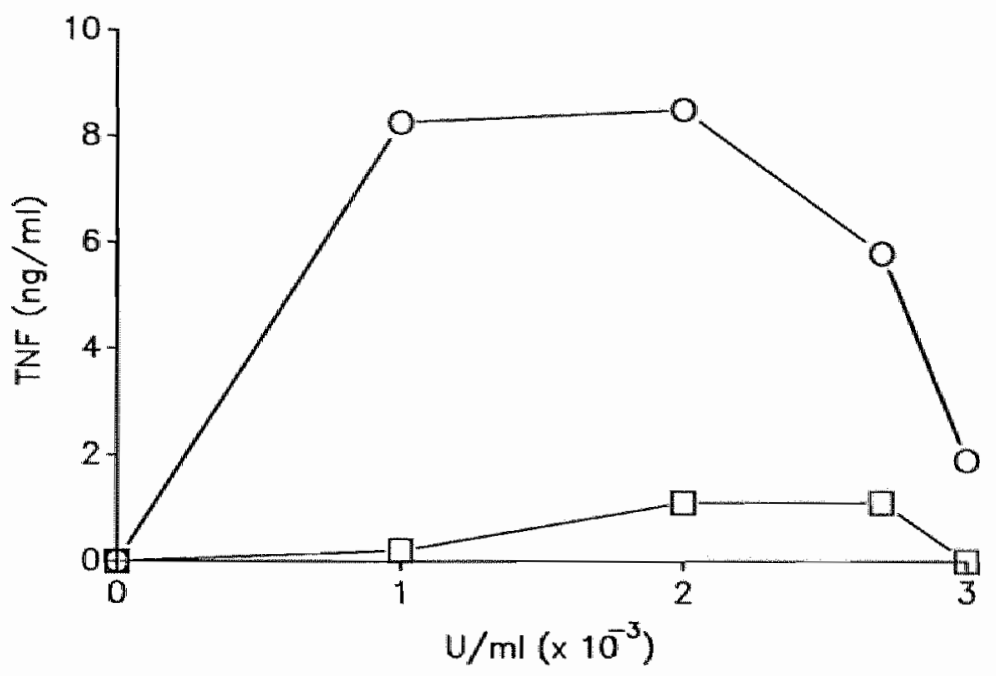

Figure 2. TNF production by monocytes, isolated by adherence and extensive washing, induced by IFN-y and GM-CSF. Approximately $5 \times 10^{5}$ monocytes were incubated with IFN- $\gamma$ (open circles) or GM-CSF (open squares), and after $24 \mathrm{~h}$ cell-free supernatants were harvested for measurement of TNF concentration. The results are representative of four different experiments.

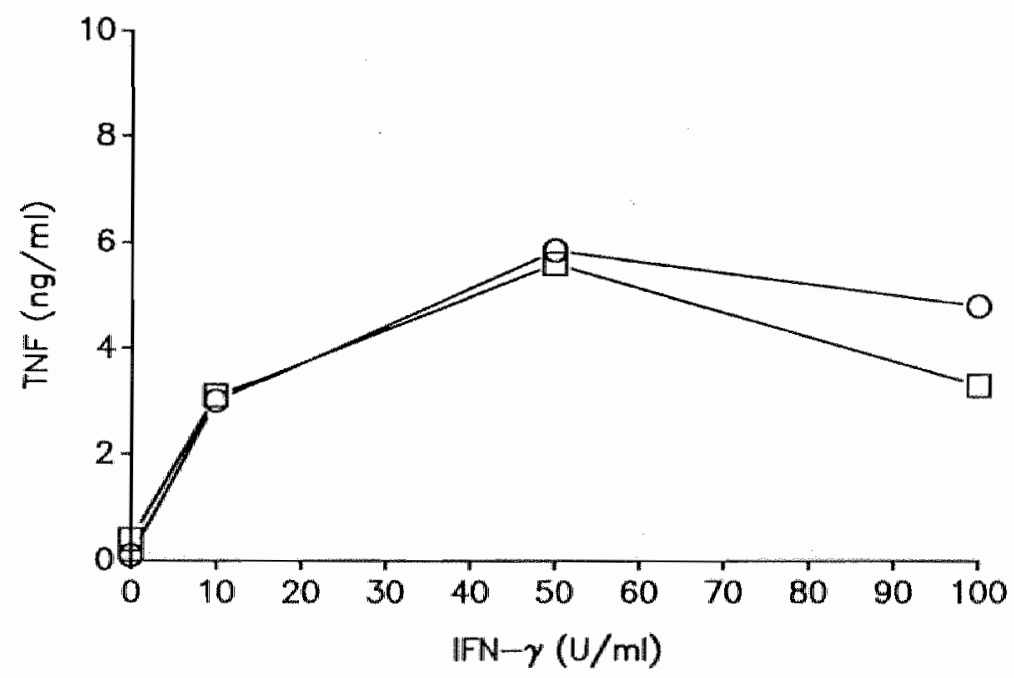

Figure 3. TNF production by monocytes, induced by IFN- $\gamma$ in the presence of polymyxin B sulphate. Approximately $5 \times 10^{5}$ monocytes, isolated by adherence and extensive washing, were inciubated with IFN- $y$ (open circles) or with $\mathbb{I F N}-y$, preincubated for $2 \mathrm{~h}$ at $37^{\circ} \mathrm{C}$ with $1 \mu \mathrm{g} / \mathrm{ml}$ polymyxin $\mathrm{B}$ sulphate (open squares). After $24 \mathrm{~h}$, cell-firee supernatant was harvested for measurement of the TNF concentration. TNF production by monocytes incubated with $1 \mu \mathrm{g} / \mathrm{ml}$ polymyxin B sulphate was in this experiment the same as for monocytes incubated with culture medium alone, and averaged $0.15 \mathrm{ng} / \mathrm{ml}$. Data are from one representative experiment out of four different experiments. 


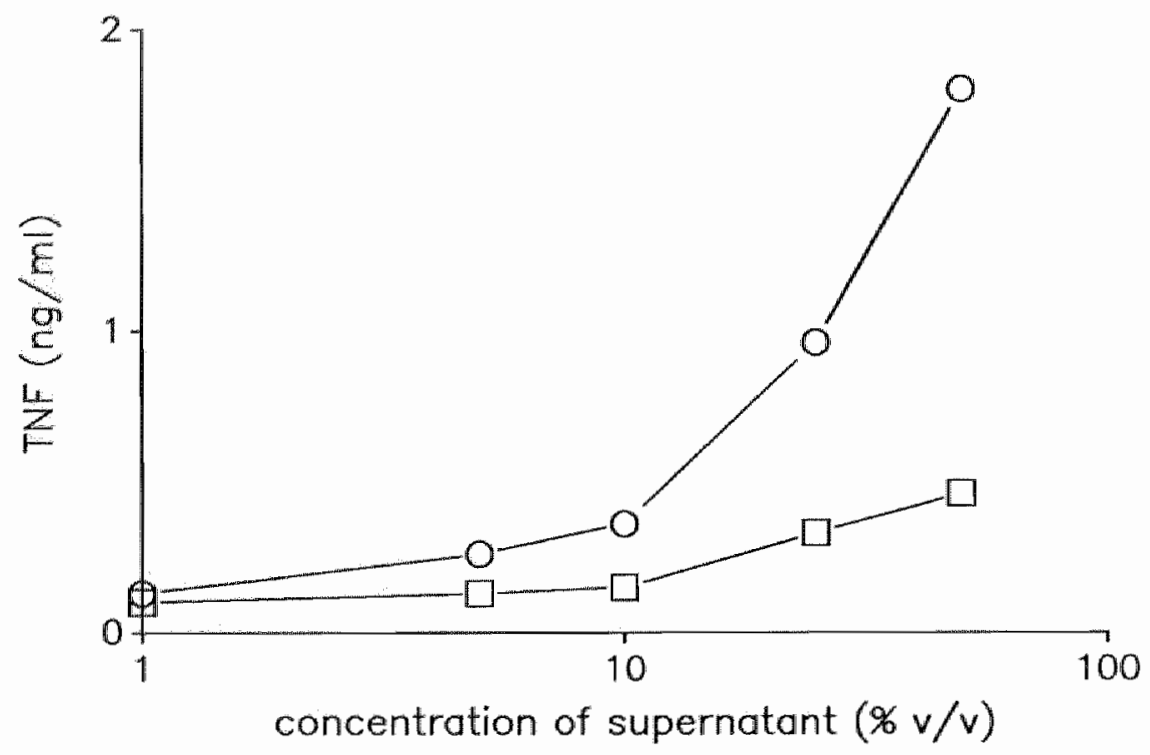

IFigure 4. TNF production by monocytes induced by supernatant of mitogen-stimulated PBMC. $5 \times 10^{6}$ PBMC were incubated in a $25 \mathrm{~cm}^{2}$ culture flask with OKT3 1:500 ascites and after 3 days the cell-free stupernatant of these cultures was harvested and passaged on an anti-TNF column. Part of this supernatant (containing approximately 70 IU of IFN- $\gamma$ ) was also passaged on an anti-IFN- $\gamma$ column. Next, this supernatant was added in several dilutions to approximately $5 \times 10^{5}$ monocytes isolated by adherence and extensive washing, and alter $24 \mathrm{~h}$ samples of supernatant were taken for measurement of the TNF concentration. Open circles represent supernatant that had only beem passaged on an anti-TNF column. Open squares represent supernatant that had been passaged on an anti-TNF collumn as well as on an anti-IFN- $\gamma$ collumn (containing substantially less than 2 IU/ml IFN- $\gamma$ and less than $50 \mathrm{pg} / \mathrm{ml}$ TNF). TNF production by monocytes incubated with 1:500 OKT3 ascites for $24 \mathrm{~h}$ as for monocytes incubated with culture medium alone averaged $0,1 \mathrm{ng} / \mathrm{m}$. Data are from one representative experiment out of lixe different experiments.

It was also studied whether the GM-CSF-induced TNF secretion was dependent on the presence of low amounts of endotoxin in the culture medium. Preincubation of medium containing GM-CSF at the same concentrations as used in the experiment of Fig. 2 with $1 \mathrm{\mu g} / \mathrm{ml}$ polymyxin B sulphate completely inhibited TNF secretion by monocytes (data not shown).

\section{T cell-induced TNF production by monocytes is predominantly mediated by IFN- $\gamma$}

Next, experiments were performed to determine whether IFN- $\gamma$, produced by proliferating $\mathrm{T}$ lymphocytes, is responsible for the $\mathrm{T}$ cell-mediated TNF production in mitogen-stimulated PBMC cultures. For this, cell-free supernatants of mitogen-stimulated PBMC were added after 3 days of culture to purified monocytes in several dilutions in culture medium. Before supernatants were added to the monocytes, they were first passaged on an anti-TNF column to remove all TNF in order to prevent possible regulatory influences of exogenous TNF. Part of each supernatant was further 


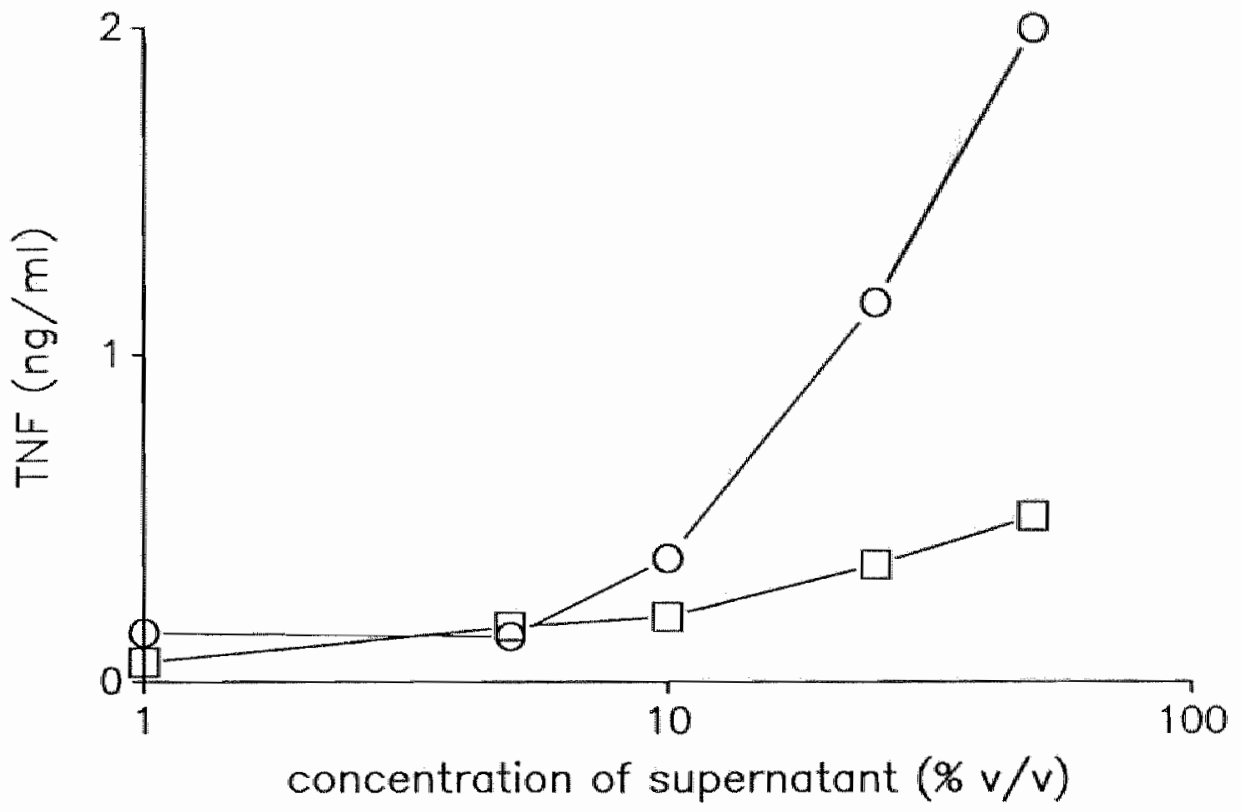

Figure 5. TNF production by monocytes induced by supernatant of proliferating $T$ lymphocytes in the absence of mitogen. 5x106 $\mathrm{PBMC}$ were stimulated with OKT3 1:500 ascites and after 24 h the non-adherent cells were separated from the adherent cells, washed, and treated with the anti-monocyte monoclonal antibody PDV 11-2 and complement to obtain a T cell-enriched cell population. Proliferation of the cells was sustained with $10 \mathrm{U} / \mathrm{ml}$ rIL-2. The cell-free supernatant of these cells was harvested after 2 datys. After being passaged on an anti-TNF column, and in part also on an anti-IFN- $\gamma$ column, the supernatant was added in several dilutions to approximately $5 \times 10^{5}$ monocytes isolated by adherence and extensive washing. Open circles represent supernatant that had only been passaged on an anti-TNF column. Open squares represent supernatant that had been passaged on an anti-TNF column as well as on an anti-IFN- $\gamma$ column. The supernatant of the monocytes was taken $24 \mathrm{~h}$ later for measurement of the TNF concentration. Data are from one representative experiment out of four different experiments.

passaged on an anti-IFN- $\gamma$ column. Fig, 4 shows that cell-free supernatants of mitogenstimulated PBMC induce TNF production by purified monocytes in a dose-related manner. The figure also shows that the TNF production-inducing activity of these supernatants was largelly abrogated by passage on an anti-IFN- $y$ column. To further exclude the role of mitogen in this process the capacity of mitogen-free supernatant of proliferating T cells to induce TNF production by monocytes was studied. Fig 5 shows that the supernatant of proliferating $T$ cells induces TNF production by monocytes in the absence of mitogen, and that the induction of TNF production was largely abrogated by passage on an anti-IFN- $\gamma$ column. 


\section{DISCUSSION}

TNF is a monokine produced by monocytes after stimulation with bacterial LPS $(5,9,17,20)$. The production and secretion of another monokine, IL-1, which resembles TNF in many ways, is induced in a similar way $(1,2,21)$. Furthermore, it is known that $\mathbb{L}-1$ can be produced by monocytes by a $T$ cell-dependent mechanism $(24,25,35)$. The fact that TNF can be detected in the supernatant of mitogen-stimulated PBMC cultures (27) suggests that there also exists a $T$ cell-dependent mechanism of production for TNF. Our data show that TNF is produced in mitogen-stimulated PBMC cultures, and that the amount of TNF produced correlates with the rate of $T$ cell proliferation in such cultures. This was found both with lectin- and OKT3-induced mitogenesis. A similar phenomenon was observed in two-way mixed lymphocyte cultures (MLC), in which $\mathrm{T}$ cell proliferation is induced by alloantigen stimulation (data not shown). It is further shown that TNF is predominantly produced by monocytes. In our system only marginal production by proliferating $T$ cells was observed, indicating that $T$ lymphocytes can produce TNF, as was shown by Cuturi et al. (11), who reported that activation of $T$ cells is accompanied by TNF production, especially after activation with phorbol diester and calcium ionophore. The T cell dependence of the mitogen-induced TNF secretion was demonstrated by experiments in which TNF secretion by purified monocytes could be induced by adding proliferating $T$ cells to the monocytes. The data strongly suggest that proliferating T cells induce TNF production by monocytes, although a minor contribution by $T$ cell-derived TNF is not excluded.

The monokines TNF and, to a lesser extent, IL-1 are known to play an important role as mediators of monocyte cytotoxicity $(9,13,15,20,28,34)$. Monocyte cytotoxicity can be regulated by $T$ cell processes. It is predominantly mediated by the production of monocyte-activating factors by T lymphocytes, of which IFN- $y$ is the most important $(12,18,19,22,23,26,29)$. This lymphokine is produced by mitogen-stimulated, proliferating $\mathrm{T}$ cells $(14,30)$. IFN- $y$ enluances monocyte cytotoxicity by increasing the production of hydrogen peroxide $(16,26)$, and by priming monocytes for the production and secretion of monokines with cytocidal activity, i.e. TNF and IL-1 $(2,3,6,10,32)$. It is generally supposed that for the secretion of these cytocidal monokines by murine macrophages besides IFN- $\gamma$, a second, triggering signal is necessary. This second signal can be provided by bacterial lipopolysaccharide $(6,29)$. Data on the potential of IFN-y to induce production and secretion of TNF by human monocytes in the absence of LPS are conflicting $(27,32,33)$. In this study we have shown that IFN- $y$ can induce TNF secretion by human monocytes in the absence of endotoxin. Our data, which differ from those obtained by Nedwin et al. (27), but are in agreement with the findings of others $(32,33)$, strongly suggest that human and murine monocytes/macrophages differ with respect to the need for a triggering signal to induce the secretion of TNF.

The experiments show that the TNF-inducing activity of supernatants of mitogenstimulated PBMC can largely be abrogated by passaging the supernatants on an anti-IFN- $\gamma$ column. From this it is concluded that the T cell-dependent TNF production that we found in our study is, at least to a great extent, induced by IFN- $\gamma$.

It was also found that recombinant human granulocyte-macrophage colony-stimulating factor (GM-CSF) could induce TNF secretion by monocytes, although it con- 
stituted a far less potent stimulus for TNF secretion than IFN- $\gamma$. Moreover, the GM-CSF-induced TNF secretion was shown to be dependent on the presence of endotoxin in the culture medium, since it could be totally abrogated by polymyxin $B$ sulphate. This finding is in accordance with those of other investigators (7).

So far it is generally believed that the secretion of TNF by monocytes depends on the presence or absence of bacterial LPS. This study makes it probable that TNF is produced under many conditions in which the immune system is activated.

In conclusion, the results of this study show that in man, TNF is produced by monocytes in mitogen-stimulated PBMC, and that TNF production is dependent on the presence of proliferating $T$ cells. This $T$ cell-dependent TNF production seems to be largely mediated by the T cell product IFN- - . This finding has potential significance for many disease processes in which the T cell system is involved, for example in the host defence mechanisms against malignancies and viral infections or in the pathophysiology of autoimmune processes like rheumatoid arthritis.

\section{Acknowledgments}

We thank Mrs A.J.J.M. Daemen for her help in developing the TNF ELISA, and Mrs C.M.P. Spronck for her secretarial assistance.

\section{REFERENCES}

1. Arend WP, Massoni RJ. 1986. Characteristics of bacterial lipopolysaccharide induction of interleukin 1 synthesis and secretion by human monocytes. Clin Exp Immunol 64:656.

2. Arenzana-Seisdedos F, Virelizier J-L. 1983. Interferons as macrophage-activating factors. II. Enhanced secretion of interleukin 1 by lipopolysaccharide-stimulated human monocytes. Eur J Immunol 13:437.

3. Arenzana-Seisdedos F, Virelizier J-L, Fiers W. 1985. Interferons as macrophage-activating factors. III. Preferential effects of interferon- $\gamma$ on the interleukin 1 secretory potential of fresh or aged hum man monocytes. I Immunol 134:2444.

4. Beutler B, Cerami A. 1987. Cachectin: more than a tumor necrosis factor. N Engl J Med 316:379.

5. Beutler B, Krochin N, Milsark IW, Luedke C, Cerami A. 1986. Control of cachectin (tumor necrosis factory synthesis: mechanisms of endotoxin resistance. Science 232:977.

6. Beutler B, Tkacenko V, Milsark I, Krochin N, Cerami A. 1986. Effect of $\gamma$ interferon on cachectin expression by mononuclear phagocytes. Reversal of the lpsd (endotoxin resistance) phenotype. I Exp Med 164:1791.

7. Cannistra SA, Rambaldi A, Spriggs DR, Hermann F, Kufe D, Griffin JD. 1987. Human granulocytemacrophage colony-st imulating factor induces expression of the tumor necrosis factor gene by the U937 cell line and by normal human monocytes. J Clin Invest 79: 1720.

8. Carswell EA, Old LJ, Green S, Fiore N, Williamson B. 1975. An endotoxin-induced serum fuctor that causes necrosis of tumors. Proc Natl Acad Sci USA 72:3666.

9. Chen AR, McKinnon KP, Koren HS. 1985. Lipopolysaccharide (LPS) stimulates fresh human monocytes to lyse actinomycin D-treated. WEHI-164 target cells via increased secretion of a monokine similar to tumor necrosis factor. J Immunol 135:3978.

10. Collart MA, Belin D, Vassalli J-D, de Kossodo S, Vassalli P. 1986. $\gamma$ interferon enhances macrophage transcription of the tumor mecrosis factor/cachectin, interleukin 1, and urokinase genes, which are controlled by short-lived repressors. J Exp Med 164:2113. 
11. Cuturi MC $C_{3}$ Murphy $M_{*}$ Costa-Giomi MP, Weinman $R$, Perussia $B_{,}$Trinchieri $G$. 1987. Independent regulation of tumor necros"s factor and iymphotoxin production by human peripheral blood lymphocytes. J Exp Med 165:1581.

12. Dean RT, Virelizer 1 L. 1983. Interferon as a macrophage activating factor. I. Enhancement of cytotoxicity by fresh and matured human monocytes in the absence of other soluble signals. Clin Exp Immunol $\$ 1: 501$.

13. Decker T, Lohmanin Mathes M-L, Gifford GE. 1987. Cell-associated tumor aecrosis factor (TNF) ats at killing mechanism of activated cytotoxic macrophages. J Inumunol 138:957.

14. Farrar WL, Birchenill-Sparks MC, Young HB. 1986. Interleukin 2 induction of interferon- $y$ mRNA syathesis. I Immunal 137:3836.

15. Feinman $R$, Henriksen-DeStefano $D$, Tsujimoto $M$, Vilcek J. 1987. Tumor necrosis factor is an inportant mediator of tumor cell killing by human monocytes. J Immunol 138:635.

16. Frentid M, Pick E. 1986. The mechanism of action of lymphokines. $\mathrm{XX}$. The enzymatic basis of hydrogen peroxide production by lymphokine-activated macrophages. J Immunol 137:1312.

17. Gifford GE, Lohmann-Matuhes. M-L. 1986. Requirement for the continual presence of lipopolysaccharide for production of tumor necrosis factor by thioglycollate-induced peritoneal murine macroplages. Int J Cancer 38:135.

18. Hamilton TA, Somers SD, Becton DL, Celada A, Schreiber RD, Adams DO. 1986. Analysis of defficiencies in IFN-y-mediated priming for tumor cytotoxicity in peritoneal macrophages from $\mathrm{A} / \mathrm{J}$ nive. I Immunol 137:3367.

19. Jones CM, Prince CA, Langford MP, Hester JP. 1986. Identification of a human monocyte cytotoxicity-inducing factor from T cell hybridomas produced from Sezary's cells. J Inmunol 137.571..

20. Kornbluth RS, Edgington TS. 1986. Tumor necrosis factor production by human monocytes is a regulated event: induction of TNF- $\alpha$-mediated cellular cytotoxicity by endotoxin. $J$ Immunol $137: 2585$

21. Lepe-Zuniga JL, Gery I. 1984. Production of intra- and extracellular interlewkin-I (IL-1) by thuman monocytes. Clin Irnmunol Immunopathol 31:222.

22. Mackiay RJ, Russell SW. 1986. Protein changes associated with stages of accivation of monse macrophages for tumor cell killing. J Immunol 137:1392.

23. Meltzer MS, Benjamin WR, Farrar JJ. 1982. Macrophage activation for tumor cytotoxicity. induction of nacrophage tumoricidal activity by lymphokines from EL-4, a continuous T cell line. JImmunol 129:2802.

24. Mizel SB, Oppenheim JJ, Rosenstreich DL. 1978. Characterization of lymphocyte-activating factor (LAF) produced by a macrophage cell line, P388D1. I. Enhancement of $L A F$ production by activated T' lymphocytes. II Immunol 120:1497.

25. Mizel SB, Oppenlyeim JJ, Rosenstreich DL. 1978. Characterization of lymphocyte-activating factor (LAF) produced by a macrophage cell line, P388D1.. II. Biochemical characterization of LAF induced by activated T cells and LPS. J Immunol 120:1504.

26. Nathan CF, Prendergast TJ, Wiebe ME, Stantey ER, Platzer E, Remold HG, Welte K, Rubin BY, Murray HW. 1984, Activation of human macrophages. Comparison of other cytokines with interfe. ron- $y_{4}$ J Exp Med 160:600.

27. Nedwin GE; Svedersky LP, Bringman TS, Palladino MA, Jr, Goeddel DV, 1985. Effect of interieukin 2 , interferon $\gamma$, and mitogens on the production of tumor necrosis factors $\alpha$ and $\beta$. J Immunol $135: 2492$.

28. Onozaki K, Matsushima K, Aggarwal BB, Oppentheim J. 1985. Human interleukin 1 is a cytocidal factor for several tumor cell lines. J lmmunol 135:3962.

20. Pace JL, Russell SW, Torres BA, Johnson HM, Gray PW. 1983. Recombinant mouse y interferon induces the prining step in macrophage activation for tumor cell killing. J Immunol 130:2011.

30. Pang RHL, Yip YK, Vilcek J. 1981. Immune interferon induction by a monoclonal antibody specific for human T cells. Cell Immunol 64:304.

31. Pennica D, Nedwin GE, Hayflick JS, Seeburg PH, Derynck R, Palladino MA, Kohr WJ, Aggarwal BB, Goeddel DV. 1984. Human tumour necrosis factor: precursor structure, expression and homology to lymphotoxin. Nature 312:724. 
32. Philip R, Epstein LB. 1986. Tumotir necrosis factor as immunomodulator and mediator of monocyte cytotoxicity induced by itself, $y$-interferon and interlenkin-1. Natthre $323,86$.

33. Scuderi $P$, Sterling $K E$, Ratano $A B$, Grogan TM, Rippe RA, 1987. Recombinanit interferon-y stimulates the production of human tmmor necrosis factor in witro. J Interforon Res 7:155.

34. Urban $\mathbb{N L}$, Shepard HM, Rothstein JL, Sugarman BI, Schreber H. 1986. Tumor necrosis factor; a potent effector molecule for tumor cell killing by activated macrophages. Proc Natl Acad Sci USA 83.5233 .

35. Weaver $C T$, Unanue ER. 1986. $T$ cell induction of membrane IL-1 an makrophages. $J$ Immunol $137: 3868$. 


\title{
Fc-RECEPTOR CROSS-LINKING INDUCES SECRETION OF TUMOR NECROSIS FACTOR BY MONOCYTES
}

\author{
Debets, J.M.H., C.J. van der Linden, I.E.M. Dieteren, J.F.M. \\ Leeuwenberg, and W.A. Buurman. J. Immunol. 1988;141:1197.
}

\section{SUMMARY}

In this study it was demonstrated that cross-linking of $F c R$ on human monocytes induces the secretion of the cytotoxic and immunoregulatory cytokine TNF. Both soluble and insoluble immune complexes, solid-phase antibody and antibody-coated phagocytizable particles were used to cross-link FCR on monocytes. It was observed that monocytes secreted large amounts of TNF in each of these instances. Kinetic studies performed with soluble immune complexes showed that TNF was secreted very rapidly, e.g. within $2 \mathrm{~h}$ after addition of immune complexes to monocytes. These findings are relevant for the understanding of FcR-mediated immune responses by monocytes and macrophages, for example antibody-dependent cellular cytotoxicity and phagocytosis, and for disease states associated with circulating or tissue-fixed immune complexes.

\section{INTRODUCTION}

Receptors for the Fc portion of immunoglobulins (F $\mathrm{CR}$ ) are present on the plasma membrane of most cells of hemopoietic lineage and perform many functions in immune processes. On monocytes and macrophages, FcR are involved in phagocytosis of antibody-coated particles or cells $(1,2)$, in the mediation of antibody-dependent cellular cytotoxicity (ADCC) (3-7), and in the release of various inflammatory mediators (8-12). FcR are also important for the clearance of circulating immune complexes by cells of the mononuclear phagocytic system $(13,14)$. Finally, cross-linking of FcR has been shown to trigger the oxidative burst $(15,16)$.

Tumor necrosis factor (TNF), also known as cachectin, is an important inflammatory mediator produced predominantly by activated monocytes and macrophages 
(17, 18). It has cytotoxic properties, both against tumor cells and against normal cells infected with intracellular pathogens and viruses, and performs many immunoregulatory functions, at least in vitro (reviewed in 19).

Because FcR trigger monocyte and macrophage activation and cytotoxicity, we investigated whether the secretion of TNF, which constitutes an important mediator of monocyte/macrophage cytotoxicity, can be induced by FcR cross-linking. The study shows that cross-linking of $\mathrm{FCR}$, both by soluble and insoluble immune complexes, solid-phase antibodies and by antibody-coated phagocytizable particles, induces rapid secretion of TNF by buman monocytes. These findings are relevant for the understanding of FcR-mediated monocyte/macrophage functions in immune processes, like $A D C C$ and phagocytosis. The data also suggest that TNF may contribute to the pathophysiology of immune complex diseases, notably rheumatoid arthritis.

\section{MATERIALS AND METHODS}

Materials. Bowine serum abumin (BSA; No. A-6003, essentially fatty acid free), lipopolysaccharide (LPS; trom E. coli 0111:B4; chromatographically purified), and o-phenylenediamine (OPD) were purchased from Sigma Chemical Co. (St. Louis, MO). Tween 20 was purchased from Serva (Heidelberg, Federal Republic of Germany). Purified tetanus toxin $(150 \mathrm{Lf} / \mathrm{ml})$ was kindly provided by Dr. H. G. Loggen (Rijksinstituut woor Volksgezondheid, Bilthoven, The Netherlands). It contained less than $20 \mathrm{pg}$ LPS/Lf as determined with a chromogenic Limulus assay, which was used for all other eadotoxin measurements as well (Kabivitrum, Stockholm, Sweden). Human recombinant tumor necrosis factor (hiTNF) was kindly provided by Knoll AG/BASF (Ludwigshafen, Federal Republic of Germany). The specific activity was $8 \times 10^{6}$ lytic units/mg protein in the $48-\mathrm{h}$ L929 assay without mitomycin.

Ab. Normal human gammaglobulin (IgG) was obtained from the Central Laboratory of the Blood Transfision Unit of the Dutch Red Cross (Amsterdam, The Netherlands). It contained less than $5 \mathrm{pg}$ LPS/mg. Human antitetanus lgG (250 Lf/rnl) was a gift of Dr. H. G. Loggen. It contained no detectable

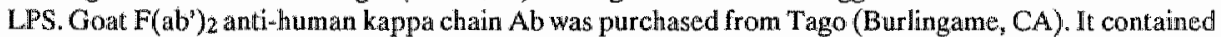
less than $10 \mathrm{pg}$ LPS/mg. Rabbit Ab against sheep erythrocytes (SRBC) was purchased from the Rijksinstitutut voor de Volksgezondheid and contained no detectable LPS. Monoclonal Ab against TNF were derved from anti-TNF secreting hybridomas obtained by a standard cell fusion procedure. Mouse spleen cells from $B A L B / c$ mice immunized with highly purified hrTNF were used for the cell fusions. Rabbit polyclonal Ab against TNF were raised by immunzing rabbits with highly purified hrTNF, and was used at unpurified serum. Peroxidase conjugated goat anti-rabbit IgG was purchased from Jackson Immunoresearch Laboratories (West Grove, PA).

Preparation of $F\left(a b^{y}\right)_{2}$ fragments of human IgG. $F\left(a b^{3}\right)_{2}$ fragments of human $\mathrm{IgC}$ were prepared by pepsin cleavage of the protein $\mathrm{A}$ binding fraction, which was obtained by affinity chromatography on agarose-bound protein A (Pierce, Rockford, IL). Immobilized pepsin (Pierce) was added 1:50 (w/w) to $\lg \mathrm{G}$ in acetate buffer ( $\mathrm{pH} 4.5$ ) and allowed to cleave the $\mathrm{Ab}$ during $24 \mathrm{~h}$ at $37^{\circ} \mathrm{C}$. The extent of cleavage of Ab was judged by SDS-PAGE on PhastGel System (Pharmacia Fine Chemicals, Uppsala, Sweden). Remaining intact $\mathrm{IgG}$ was removed from the $\left.\mathrm{F}(\mathrm{ab})_{2}\right)_{2}$ fraction by protein $\mathrm{A}$ affinity chromatography. Final purity of the F(ab') 2 preparation was affurmed by SDS-PAGE.

Inumune complexes. Insoluble immune complexes containing human $\mathrm{IgG}$ were prepared using teranus toxin and human antitetanus IgG as described elsewhere (16). Immune complexes contained Iess than 125 pg LPS/mg

Solitl-phase Als. Ab were bound to a solid phase by adding human $\operatorname{lgG}$ and $\operatorname{IgG} \mathrm{F}\left(\mathrm{ab}^{3}\right)_{2}$ at a concentration of $100 \mu \mathrm{g} / \mathrm{ml}$ in phosphate buffered saline (PBS) onto 96-well imnunoassay plates (Nunc, Roskilde, Denmark) for $1 \mathrm{~h}$ at roon temperalure. Plates were washed 3 times with PBS before use in the experiments. 
Cells. Peripheral blood mononuclear cells (PBMC) were prepared by buoyant density centrifugation on Lymphoprep (Nycomed, Oslo, Norway) of buffy coats of donor blood kindly prowided by the local Blood Bank. Monocytes were isolated from PBMC by adherence to plastic. For this purpose $5 \times 10^{6}$ PBMC were allowed to adhere to each well of a 24 -well culture plate (Greiner, Nurrtingen, Fedteral Republic of Germany) for $1 \mathrm{~h}$ at $37^{\circ} \mathrm{C}$, followed by 5 washes with Hanks balanced salt solution (HBSS) to remowe nomadherent cells. The adherent cell population, which will be referred to in the text as monocytes for reasons of simplicity, was shown to consist for more than $95 \%$ of alplat-naphtyl esterase positive cells. Monocytes were cultured in humidified $95 \%$ air, $5 \% \mathrm{CO}_{2}$ at $37^{\circ} \mathrm{C}$ in RPMI 1640 (Gibco, Paislcy, Scotland) supplemented with either $10 \%$ heat-inactivated $\left(56^{\circ} \mathrm{C}, 20\right.$ min) fetal calf serum (FCS; Boelhringer, Mamnheim, Federal Republic of Germany), or $2.5 \%$ heat-inactivated normal human serum (NHS; kindly provided by the local Blood Bank) together with $100 \mathrm{lU} / \mathrm{ml}$ penicillin and $100 \mu \mathrm{gg} / \mathrm{ml}$ streptonycin (Flow, Trvine, United Kingdom). In experiments with solict-phase Ab, monocytes, obtained after adherence of $150 \times 10^{6}$ PBMC to $150 \mathrm{~cm}^{2}$ culture flasks (Costar, Cambridge, MA) for 1 h at $37^{\circ} \mathrm{C}$ and removal of non-adherent cells by extensive washing with HBSS, were recovered by gentle scraping with a rubber policeman and subsequently added to 96 -well plates coated with $\mathrm{Ab}$ as described before.

Phagocytosis. In phagocytosis experiments Ab-coated sheep erythrocytes (EA) were used. EA were prepared by incubating a 5\% suspension of sheep erythrocytes (SRBC) in RPMI + 10\% FCS with an equal volume of a sub-hemagglutinating dilution of rabbit anti-SRBCAb in veronal buffer (pH 7.2) for 30 min at $37^{\circ} \mathrm{C}$ with gentle mixing. After centrifugation $\left(3000 \mathrm{rpm}_{3}, 6 \min _{3} 4^{\circ} \mathrm{C}\right) \mathrm{SRBC}$ were resuspended in RPMI $+10 \%$ FCS and dilluted to a final concentration of $0.1 \%(\mathrm{v} / \mathrm{v})$ before addition to monocyle cultures. Unopsonized SRBC (E) at a final concentration of $0.1 \%(\mathrm{v} / \mathrm{v})$ were added to monocytes as at control.

TNF-ELISA. TNF concentrations of cell-free supernatants of the cell cultures were determined with a TNF-specific enzyme-linked inmunosorbent assay (ELISA). In short, imununoassay plates (96-well plates; Nunc) were coated owernight with a monoclonall anti-TNF Ab. Plates were blocked with $1 \%$ (w/v) BSA and test samples were added to the plate for $2 \mathrm{~h}$ at room temperature. A standiard titration curve wats obtained by making serial dilutions of a known sample of hrTNF. Next, the plates were washed and sequentially incubated with rabbit anti-TNF immune serum and peroxidase-conjugated goat anti-rabbit IgG, which does not cross-react with human serum proteins. After adding substrate light absorption wats measured with a microelisa autoreader (Flow) using a $493 \mathrm{~nm}$ filter. The ELISA has a lower detection limit of $5-10 \mathrm{pg} / \mathrm{ml}$.

\section{RESULTS}

\section{Cross-linking of FCR on monocytes with anti-human kappa.}

To examine whether cross-linking of FcR constitutes a signal for monocytes to secrete TNF, monocytes were incubated with various concentrations of goat $\mathrm{F}\left(\mathrm{ab} \mathrm{b}^{\prime}\right) 2$ anti-human kappa light chain and after an 8-h culture period samples of supernatant were harvested for measurement of the amount of TNF secreted. This experiment was performed both in culture medium containing $10 \%$ FCS and in culture medium containing $2.5 \%$ NHS as a source of soluble Ig. In the former circumstances the anti-human kappa associates with FcR-bound human IgG, still present on the cells as evidenced by indirect immunofluorescence using a FITC-labeled anti-human kappa Ab (data not shown), thus cross-linking monocyte FcR. In the presence of NHS the anti-human kappa will form soluble immune complexes with IgG present in the culture medium, which thereupon become cell-associated. In both culture conditions antihuman kappa induces in a dose-dependent manner TNF secretion by monocytes (Fig. 1). The TNF secretory response is shown to be about fivefold stronger when monocytes are incubated with anti-human kappa in the presence of soluble Ig in the culture 


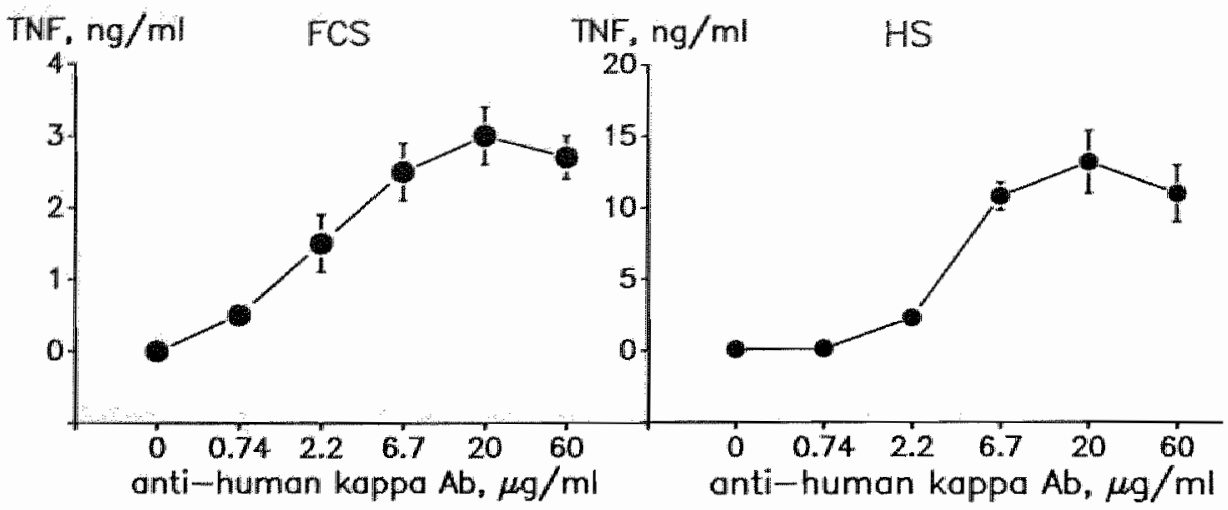

Figure 1. TNF secretion by monocytes following FoR crosslinking with an anti-human IgG Ab. Monocytes isolated as described in Methods were incubated with warious concentrations of goat $F\left(a b^{\prime}\right)_{2}$ anti-human kappa $A b$ and after an 8 -h culture period $T N F$ concentration in the supernatant was determined. The left panel shows TNF concentration in the supernatant of monocytes cultured in RPMI + 10\% FCS, while corresponding values obtained when monocytes were cultured in the presence of $2.5 \%$ NHS as a source of soluble Ig are shown in the right panel. Data are from one representative experiment and are expressed as mean \pm s.d. of triplicate wells. Only error bars larger than symbol circumference are shown.

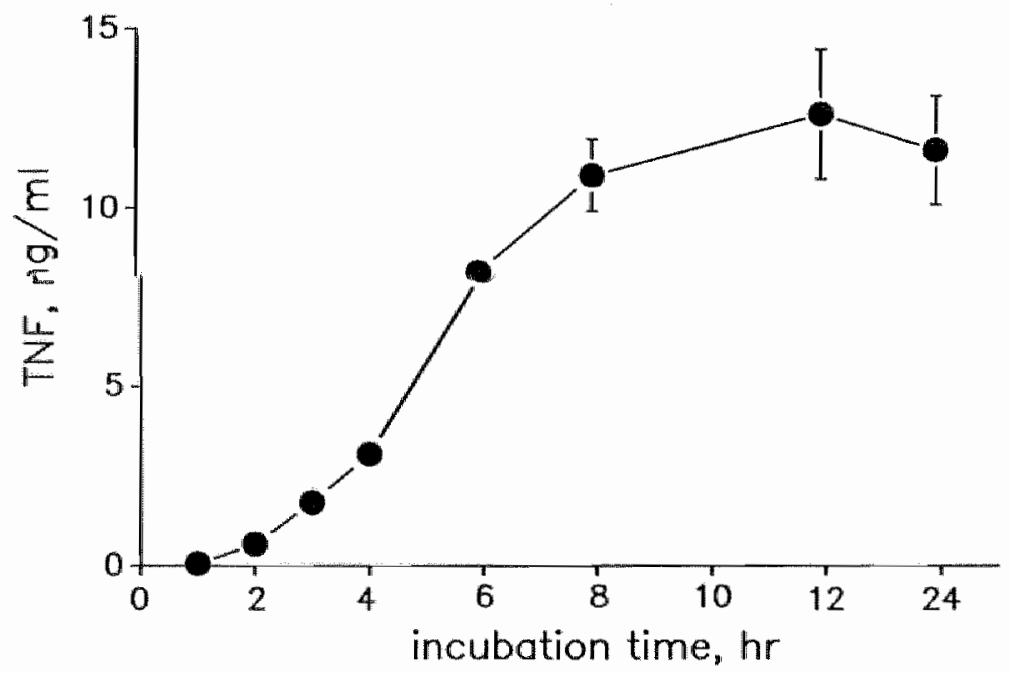

Figure 2. Kinetics of TNF secretion by monocytes induced by goat anti-human kappa Ab. Monocytes isolated as described in Methods were incubated with $20 \mu \mathrm{g} / \mathrm{ml}$ goat $\mathrm{F}(\mathrm{ab}) 2$ anti-human kappa $\mathrm{Ab}$ and after various time periods samples of supernatant were harvested for measurement of TNF concentration. Data are from one representative experiment and are expressed as mean \pm s.d. of triplicate wells. Only error bars larger than symbol circumference are shown. 
medium (Fig. 1). Next, the kinetics of the TNF secretion induced by anti-human kappa were studied. Incubating monocytes with anti-human kappa induces rapid secretion of TNF. TNF concentration in the supernatant is shown to be increased after a $2 \mathrm{~h}$ culture period and reaches plateau level after $12 \mathrm{~h}$ (Fig. 2 ).

\section{Insoluble immune complexes induce TNF secretion by monocytes.}

To examine whether cross-linking of FcR occurring in the course of binding and ingestion of insoluble immune complexes by monocytes is also accompanied by TNF secretion, monocytes were incubated with various amounts of immune complex, consisting of tetanus toxin and human anti-tetanus IgG. TNF concentration of the supernatant was determined after an $8 \mathrm{~h}$ culture period. Insoluble immune complexes induced in a dose-dependent manner TNF secretion by monocytes. The amount of immune complex optimally inducing TNF secretion was about $30 \mu \mathrm{g} / \mathrm{ml}$. At higher concentrations of immune complex TNF secretion decreased (Fig. 3).

\section{Cross-linking FeR by solid-phase Ab induces secretion of TNF by monocytes.}

To exclude the possibility that TNF secretion by monocytes in the former experiments is not caused by FcR cross-linking but instead constitutes a process accompanying endocytosis of immune complexes, experiments were performed to examine

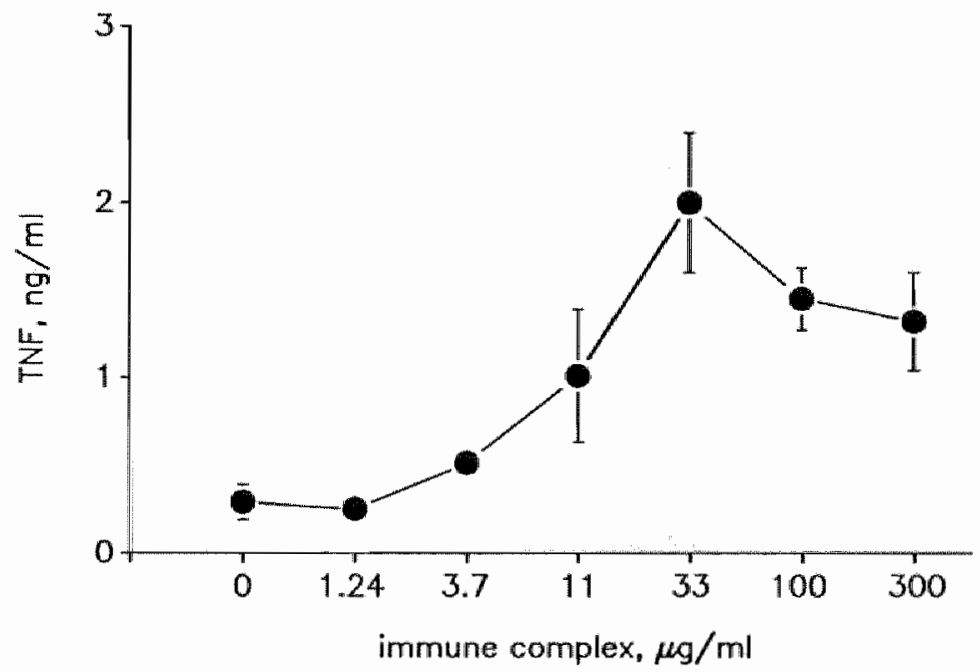

Figure 3. TNF secretion by monocytes induced by insoluble immune complexes. Monocytes isolated as described in Methods were incubated with various concentrations of insoluble immune complexes consisting of tetanus toxin and human antitetanus IgG and after an 8-h culture period TNF concentration in the supernatant was determined. Immune complexes were removed from the supermatant samples before measurement of TNF concentration in the TNF ELISA by centrifugation for 1 min at $12000 \mathrm{~g}$. TWF secretion by monocytes incubated with $10 \mathrm{~L} / \mathrm{ml}$ tetanus toxin or with $10 \mathrm{~L} / \mathrm{ml}$ anti-tetanus. IgC was equal to. TNF secretion by monocytes incubated with medium alone and never exceded $50 \mathrm{pg} / \mathrm{ml}$. Datat are from one representative experiment and are expressed as mean \pm s.d. of triplicate wells. Only error bars larger than symbol circumference are shown. 


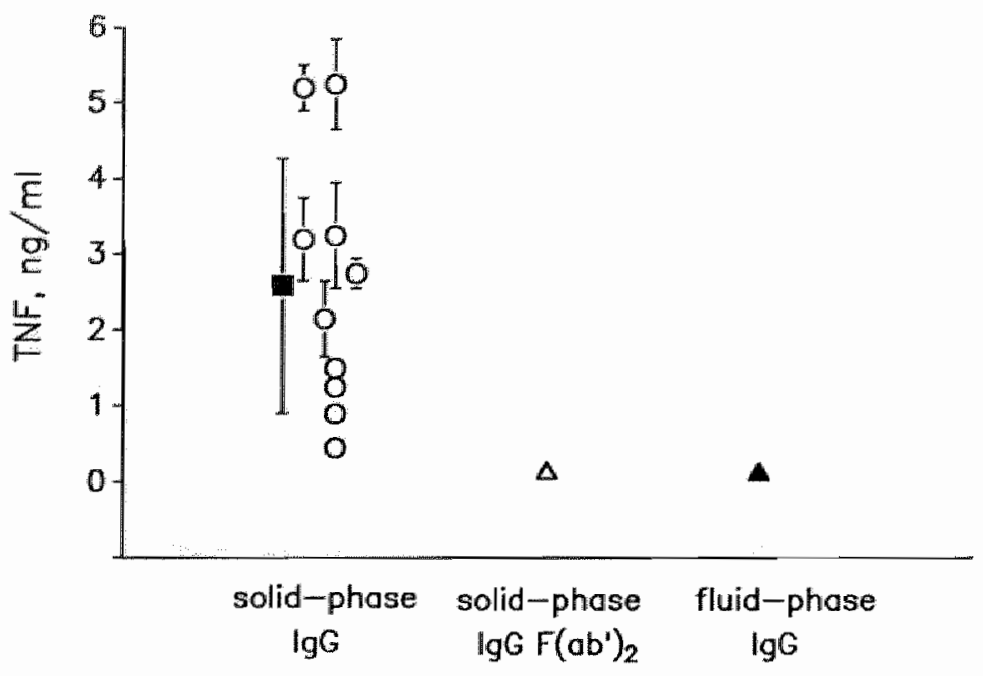

Figure 4. TNF secretion by monocytes induced by solid-phase human IgG. Monocytes, isolated by plastic adherence and recovered by gentle scraping with a policeman, were added to microtiter plates coated with human $\operatorname{IgC}$ or $\operatorname{IgCF} \mathrm{F}\left(\mathrm{ab}^{2}\right)_{2}$ as described in Methods. $1 \times 10^{5}$ monocytes were added to each well and TNF concentration of supernatant harvested after an 8 -h culture period was determined. In control wells $1 \times 10^{5}$ monocytes were incubated with $100 \mathrm{\mu g} / \mathrm{mil}$ soluble IgG. Data from ten different donors are shown. Each open circle represents mean $\pm \mathrm{s}$.d. of triplicate wells of one donor. The closed square, open triangle, and closed triangle represent the mean \pm s.e.m. of the ten donors combined. Only error bars larger than symbol circumference are shown.

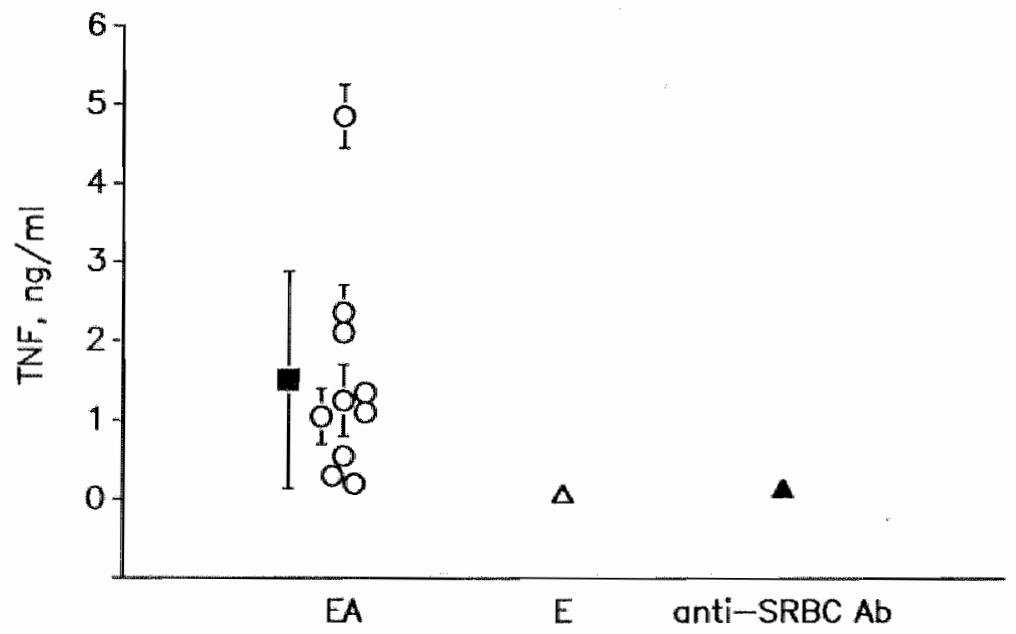

Figure 5. TNF secretion by monocytes accompanying phagocytosis of EA. Monocytes isolated as described in Methods were incubated with $0.1 \%$ (v/v) EA. In control wells monocytes were incubated with $0.1 \% \mathrm{E}$ or with at $1: 3000$ dillution of rabbit anti-SRBC Ab. TNF concentration of supernatant harvested after an 8 h culture period was determined. Data from ten different donors are shown. Each circle represents mean I s.d. of triplicate wells of one donor. The closed square, open triangle, and closed triangle represent the mean \pm s.e.m. of the ten donors combined. Only error bars larger than symbol circumference are shown. 
whether FcR cross-linking by solid-phase Ab induced TNF secretion by monocytes. For this purpose monocytes, which were isolated by plastic adherence and recovered by gentle scraping with a policeman as described in Methods, were added to microtiter plates coated with normal human IgG or with $\operatorname{IgG} \mathrm{F}\left(\mathrm{ab}^{\prime}\right) 2$. After an $8 \mathrm{~h}$ culture period samples of supernatant were harvested for determination of TNF concentration. TNF secretion by monocytes was shown to be induced by solid-phase $\operatorname{IgG}$, but not by solid-phase IgG $F\left(a b^{\prime \prime}\right) 2$ nor by soluble IgG (Fig. 4). TNF secretion was found with all donors tested, although the amount of TNF secreted varied considerably among different individuals. This further strenghtens the evidence provided by the former experiments that $\mathrm{FcR}$ cross-linking is the process responsible for the induction of TNF secretion by monocytes.

\section{Phagocytosis of EA induces secretion of "TNF by monocytes.}

To examine whether FcR cross-linking occurring during binding and ingestion of $\mathrm{Ab}$-coated particles is also accompanied by TNF secretion, monocytes were incubated with EA and after $8 \mathrm{~h}$ samples of supernatant were harvested for measurement of TNF concentration. EA were rapidly phagocytized by monocytes, in contrast with unopsonized SRBC. Phagocytosis of EA was accompanied by secretion of TNF, whereas incubation of monocytes with $E$ or with rabbit anti-SRBC Ab did not lead to significant TNF secretion (Fig. 5). As for solid-phase IgG-induced TNF secretion, there also existed considerable interindividual variability in the amount of TNF secreted during phagocytosis of EA.

\section{DISCUSSION}

Several important functions of mononuclear phagocytes in immune processes are regulated through cell membrane receptors for the Fc domain of $\operatorname{IgG}(\mathrm{FCR})$. Biochemically, two different FcR have been identified on human monocytes: 1) a $72-\mathrm{kDa}$ high affinity FcR (FcRI) and 2) a 40-kDa low-affinity FcR (FcRII). The FcR constitutes an important trigger molecule involved in the activation of cells of the mononuclear phagocytic system. The precise molecular mechanism underlying FcR-mediated cell activation is only partly understood. FcR on murine macrophages form ligand-dependent ion channels $(20,21)$ and an increase in the intracellular second messenger cAMP following FCR cross-linking has been described both in murine (22) and in human systems (23).

This study shows that FcR cross-linking induces rapid secretion of the cytokine TNF by adherent mononuclear cells. This was observed when $F \mathrm{cR}$ were cross-linked with soluble and insoluble immune complexes containing human $\mathrm{IgG}$ as well as with solid-phase human IgG. It was also found that phagocytosis of Ab-coated SRBC induced TNF secretion by monocytes. Although monocytes of all donors tested showed a TNF secretory response after FcR cross-linking, the amount of TNF secreted varied considerably among different individuals, which might be due to differences in $\mathrm{FcR}$ expression at the time of the experiment. In kinetic experiments in which $\mathrm{FcR}$ 
were cross-linked with an anti-human kappa Ab TNF could already be detected in the culture supernatant after $2 \mathrm{~h}$, whereas highest TNF concentration was found at $12 \mathrm{~h}$. It can be excluded that TNF secretion in our experiments was in a significant way influenced by contaminating endotoxin since monocytes were shown not to produce more than $100 \mathrm{pg} / \mathrm{ml}$ TNF when incubated with amounts of endotoxin equal to those present in the experiments (data not shown). Concerning the cellular origin of TNF in our experiments, it seems most probable that it is derived from monocytes, which constituted more than $95 \%$ of the adherent cells, although we can not exclude a minor contribution by other cells like T lymphocytes and natural killer cells, which have been shown to produce TNF after stimulation (24).

TNF is a cytokine which is primarily produced by activated monocytes and macrophages but also, as has recently been shown, by other cells of hemopoietic origin (24-28). TNF was originally described as a factor, present in the serum of BCG-infected mice after injection with endotoxin, which possessed strong antitumor activity (29). Since its original description much attention has focused on the cytotoxic potential of TNF which has led to the concept of TNF as one of the primary mediators of the host antitumor response effected by activated monocytes/macrophages (30-33). The mechanism by which monocytes/macrophages respond to tumor cells with secretion of the cytotoxin TNF has however been elusive. Our finding that FcR cross-linking on monocytes induces secretion of TNF makes it conceivable that TNF is secreted in the course of ADCC against tumor cells. Similarly, TNF may be released in the course of an antibody-mediated immune response against viral and parasitic infections, which would be functional considering the antiviral (34) and antiparasitic (35) properties of TNF. Indeed, raised serum levels of TNF have been found in patients suffering from the parasitic infection kala-azar (36).

TNF, which is identical to the macrophage-derived cytokine cachectin, has been suggested to play a crucial role in the etiology of cachexia accompanying chronic infections and malignancies (37-39). Support for this hypothesis has recently emerged from a study in which cachexia was observed in mice inoculated with a TNF-producing tumor (40). Our findings provide a hypothetical model explaining the mechanism of TNF production in the course of chronic infections or malignancies. In this model chronic infection or malignancy triggers an ongoing immune response, which leads, through binding of opsonized pathogens or tumor cells to monocyte/macrophage $\mathrm{FcR}$, to a continuous release of low amounts of TNF, causing metabolic derangement and cachexia.

The data also show that TNF secretion by monocytes is strongly induced by both soluble and insoluble immune complexes, which is relevant to disease states accompanied or caused by circulating or tissue-fixed immune complexes. These diseases are frequently accompanied by fever, which could be, in view of the pyrogenic properties of TNF (41), explained by immune complex-induced TNF production. Immune complex-induced TNF production could also contribute to the articular damage observed in rheumatoid arthritis. In this disease immune complexes can be detected in articular cartilage of affected joints (42). TNF has been shown to stimulate the resorption of bone and cartilage in vitro, partly in synergism with other cytokines, most importantly interleukin-1 $(43,44)$. 
In summary, this study shows that the secretion of the cytotoxic and immunoregulatory cytokine TNF by monocytes can be induced through FeR cross-linking, which is relevant for imnune processes in which FCR are involved, such as ADCC and phagocytosis of opsonized particles, and for disease states associated with circulating or tissue-bound immune complexes. Further study has to clarify which type of FCR is involved in the regulation of this process.

\section{Acknowledgments.}

We thank Mr. J. W. Greve for assaying the endotoxin content of our preparations and Mrs. C. M. P. Spronck for secretarial assistance.

\section{REFERENCES}

1. Shaw DR, Grifin FM. 1981. Phagocytosis requires repeated triggering of macrophage phagocytic receptors during particle ingestion. Nature 289:409.

2. Mellman IS, Plutner H, Steinman RM, Unkeless JC, Cohn ZA. 1983. Internalization and degradation of macrophage Fc receptors during receptor-mediated phagocytosis. J Cell Biol 96:887.

3. Nathan C, Brukner L, Kaplan G, Unkeless J, Cohn Z. 1980. Role of activated macrophages in antibody-dependent lysis of tumor cells. J Exp Med 152:183.

4. Nathan C, Cohn Z. 1980. Rolle of oxygem-dependent mechanisms in antibody-induced lysis of tumor cells by activated macrophages. J Exp Med 152:198.

5. Karpowsky B, Titus JA, Stephany DA, Segal DM. 1984. Production of target-specific effector cellls using heterocross-linked aggregates containing anti-target cell and anti-F 6 receptor antibodies. J Exp. Med 160:1686.

6. Shen L, Guyre PM, Anderson CL, Fanger MW. 1986. Heteroantibody-mediated cytotoxicily? antibody to the high affinity $\mathrm{Fc}$ receptor for IgG mediates cytotoxicity by human monocytes that is enhamced by interferon $\gamma$ and is not blocked by human $\mathrm{IgG}$. J Immunol 137:3378.

7. Graziano RF, Fanger MW. 1987. Human monocyte-mediated cytotoxicity: the use of Ig-bearing hybridomas as target cells to detect trigger molecules on the monocyte cell surface. I Immunol: 138:945.

8. Ragsdale CG, Arend WP, 1979. Neutral protease secretion by human monocytes. J Exp Med 149:954.

9. Passwell JH, Dayer J-M, Merler E. 1979. Increased prostaglandin production by human monocytes after membrane receptor activation. J Immunol 123:115.

10. Passwell JH ${ }_{n}$ Dayer J-M, Gass K, Edelson PJ. 1980. Regulation by Fc fragments of the secretion of collagenase, $\mathrm{PgE} 2$, and lysozyme by mouse peritoneal macroplages. J Iinmunol 125910 .

11. Rouzer CA, Scott WA, Kempe J, Cohn ZA. 1980. Prostaglandin synthesis by macrophages requires a specilic receptor-ligand interaction. Proc Natl Acad Sci USA 77:4279.

12. Ronzer CA, Scott WA, Hamill AL, Cohn ZA. 1980. Dynamics of leukotriene C production by macrophages. I Exp Med 152:1236.

13. Finbloom DS, Plotz. PH. 1979. Studies of reticuloendothelial function in the mouse with model immune complexes. I. Serum cle arance and tissue uptake in normal C3H mice. J Immunol 123:1594.

14. Finbloom DS. 1985. Binding, endocytosis, and degradation of model immune complexes by murine macrophages at various levels of activation. Clin Immunol Immunopathol 36:275.

15. Yamamoto $\mathbb{K}$, Johnston, $\mathrm{Jr}, \mathrm{RB}$. 1984. Dissociation of phagocytosis from stimulation of the oxidative metabolic burst in macrophages. J Exp Med 159:405.

16. Anderson CL, Guyre PM, Whitin JC, Ryan DH, Looney RJ, Fanger MW. 1986. Monoclonal antibodies to Fe receptors for IgG on human mononuclear phagocytes. J Biol Chem $261: 12856$.

17. Beutler B, Krochin N, Milsark IW, Luedke C, Cerami A. 1986. Control of cachectin (tumor necrosits factor) synthesis: mechanisms of endotoxin resistance. Science $232: 977$. 
18. Konbluth RS, Edgington TS. 1986. Tumor necrosis factor production by haman monocytes is a regulated event: induction of TNP-awediated cellalar cytotoxicity by endotoxin. J Immunol 137.2585 .

19. Beutler B, Cerami A. 1987. Cachectin: more than a tumor necrosis factor. N Engl J Med 316379.

20. Young JD, Unkeless JC, Kaback HR, Cohn ZA. 1983. Macrophage membrane potential changes associated witl $/ 2 \mathrm{~b} / \mathrm{1} 1 \mathrm{Fe}$ receptor-ligand binding. Proc Natl Acad Sci USA 80:1357.

21. Young $J \mathrm{D}$, Unkeless $J C_{\text {, }}$ Young TM, Mauro $\mathrm{A}_{*}$ Cohn $\mathrm{ZA}$. 1983. Role for mouse macrophage IgG Fc receptor as ligand-dependent ion channel. Nature 306:186.

22. Nitta $T$, Suzuki T, 1982. Biochemical signals transmitted by Foy receptors: triggering mechanisms of the increased synthesis of adenosine-3, $5^{5}-\mathrm{Cyclic}$ monophosphate mediated by Fo/2a- and Foy $2 \mathrm{~b}$ receptors of a macrophage like cell line (P388D1). J Immunol 129:2708.

23. Una $\mathrm{Y}$, Koide $Y$, Nezu N, Yoshida TO. 1987. Regulation of HLA class II antigen expression: intracellular signaling molecules responsible for the regulation by IFN- $\gamma$ and cross-linking of Fc receptors in HL 60 cells. I Immunol 139:1711.

24. Cuturi MC, Murphy M, Costa-Giomi MP, Weinmann R, Perussia B, Trinchieri G. 1987. Independent regulation of twmor necrosis factor and lymphotoxin production by human peripheral blood lymploocytes. J Exp Med 165:1581.

25. Jadus MR, Schimunk G, Djeu JY, Parkman R. 1986. Morphology and lytic mechanisms of interleukin 3-dependent natural cytotoxic cells: tumor necrosis factor as a possible mediator. $J$ Inmunol $137: 2774$.

26. Christmas SE, Meager A, Moore M. 1987. Production of interferon and tumour necrosis factor by cloned human natural cytotoxic lymphocytes and T cells. Clin Exp Immunol 69:441.

27. Patek PQ, Lin Y, Collins JL. 1987. Natural cytotoxic cells and tumor necrosis factor activate similar lytic mechanisms. J Immunol 138:1641.

28. Wright SC, Bonavida B. 1987. Studies on the mechanism of natural killer cell-mediated cytotoxicity. VI. Functional comparison of human natural killer cytotoxic factors with recombinant lymphotoxin and tumor necrosis factor. J Immunol 1.38:1791.

29. Carswell EA, Old JL, Kassel RL, Green S, Fiori N, Williamson B. 1975. An endotoxin-induced serum factor that causes necrosis of tumors. Proc Natl Acad Sci USA 72:3666.

30. Urban JL, Shepard HM, Rothstein JL, Sugarman BJ, Schreiber H. 1986. Tumor mecrosis factor: a potent effector molecule for tumor cell killing by activated macrophages. Proc Natl Acad Sci USA. 83:5233.

31. Decker T, Lohmann-Matthes M-L, Gifford GE. 1987. Cell-associated tumor necrosis factor (TNF) as a killing mechanism of aciwated cytotoxic macrophages.J Immunol 138:957.

32. Feimman R, Henriksen-Destefano D, Tsujimoto M, Villcek. J. 1987. Tumor necrosis factor is an important mediator of tumor cell killing by human monocytes. J Immunol 138:635.

33. Palladino $J r$, MA, Shalaby MR, Kramer SM, Ferraiolo BL, Baughman RA, Deleo AB, Crase D, Maralino B, Aggarwal BB, Figari IS, Liggitt D, Patton JS. 1987. Characterization of the antitumor activities of human tumor necrosis factor- $C$ and the comparison with other cytokines: induction of tumor-specific immunity. II Immunol 138:4023.

34. Mestan J, Digel W, Mittnach S, Hillen H, Blolm D, Möller A, Jacobsen H, Kirchner H. 1986. Antiviral effects of recombinant tumour necrosis factor in vitro. Nature 323:816.

35. Esparza I, Mannel D, Ruppel A, Falk W, Krammer PH. 1987. Interferon $\gamma$ and lymphotoxin or tumor necrosis factor act synergistically to induce macrophage killing of tumor cells and schistosomula of Schistosoma Mansoni. J Exp Med 166:589.

36. Scuderi P, Lam KS, Ryan KJ, Petersen E, Sterling KE, Finley PR, Ray CG, Slymen DJ, Salmon SE. 1986. Raised serum levels of tumour necrosis factor in parasitic infections. Lancet ii:1364.

37. Beutler B, Mahoney J, Le Trang N, Pekala P, Cerami A. 1985. Purilication of cachectin, a lipoprotein lipase-suppressing hormone secreted by endotoxin-induced RAW 264.7 cells. J Exp Med 161:984.

38. Rouzer CA, Cerami A. 1980. Hypertriglycerictemia associated with Trypanosoma Brucei Brucei infection in rabbits: role of defective triglyceride removal. Mol Biochem Parasitol 2:31.

39. Vlassara H, Spiegel RJ, San Doval D, Cerami A. 1985. Reduced plasma lipoprotein lipase activity in patients with malignancy-associated weight loss. Horm Metabol Res 18:698. 
40. Oliff A, Defeo-Jones D, Boyer M, Martinez D, Kiefer D, Vuocolo G, Wolfe, Socher SH. 198\%. Tumors secreting human TNF/cachectin induce cachexia in mice. Cell 50.555.

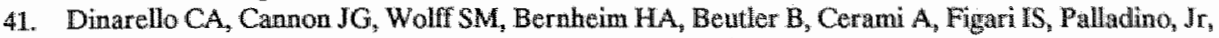
MA, O'Connor JV. 1986. Tumor necrosis factor (cachectin) is an endogenous pyrogen and induces production of interleukin 1. J Exp Med 163:1433.

42. Jasin HE. 1985. Autoantibody specificities of immune complexes sequestered in articular cartilage of patients with rhemmatoid arthritis and osteoarthritis. Arthritis Rhewm $28 \cdot 241$.

43. Bertolini DR, Nedwin GE, Bringman TS, Smith DD, Mundy GR. 1986. Stimulation of bone tesorption and inhibition of bone formation in vitro by humatn numour necrosis factors. Nature $319: 516$

44. Stashenko P, Dewhirst FE, Peros WJ, Kent RL, Ago JM. 1987. Synergistic interactions betwecn interleukin 1, tumor necrosis factor, and lymphotoxin in bone resorption. I Immunol $138: 1464$. 


\title{
CROSS-LINKING OF BOTH Fc $\gamma$ RI AND Fc $\gamma$ RII INDUCES \\ SECRETION OF TUMOR NECROSIS FACTOR BY MONOCYTES, \\ REQUIRING HIGH-AFFINITY Fc-Fc $\gamma$ R INTERACTIONS. \\ FUNCTIONAL ACTIVATION OF Fc $\gamma$ RII BY TREATMENT WITH \\ PROTEASES OR NEURAMINIDASE
}

\author{
Debets, J.M.H., J.G.J. van de Winkel, J.L. Ceuppens, I.E.M. \\ Dieteren, and W.A. Buurman. Submitted for publication.
}

\section{SUMMARY}

Cross-linking of $\mathrm{Fc} / \mathrm{R}$ on human monocytes with human IgG has been shown to induce secretion of the inflammatory and immunoregulatory cytokine TNF. In the present study we examined the role of both constitutively expressed monocyte FcyR, the $72 \mathrm{kDa}$ high-affinity $\mathrm{F} c \gamma \mathrm{R}(\mathrm{Fc} \gamma \mathrm{RI})$ and the $40 \mathrm{kDa}$ low-affinity receptor ( $\mathrm{F} \gamma \mathrm{RII}$ ), in the induction of TNF secretion. On the basis of preferential binding of murine $\mathrm{mAb}$ of different isotype, F $c \gamma R$ I and $F c y$ RII were selectively cross-linked using either solidphase mIgG2a or solid-phase $\mathrm{mIgG1}$ respectively. On freshly isolated, untreated monocytes only solid-phase mIgG2a, cross-linking FcrRI, induced TNF secretion. To resolve the question whether F $F$ RII was functionally incapable of inducing TNF secretion, or whether absence of induction of TNF secretion by solid-pluase mIgG1 was merely due to inefficient cross-linking of FcyRII, the interaction between FoyRII and mIgG1 was enhanced by treatment of monocytes with proteases or with the desialylating enzyme neuraminidase. After treatment of monocytes with these enzymes, TNF secretion was effectively induced by solid-phase $\mathrm{mIgG1}$, apparently through cross-linking of FcyRII. However, mIgG1-induced TNF secretion differed between proteasetreated monocytes from high-responder individuals and monocytes from low-responder individuals, TNF secretion being considerably less in the latter population. To definitively prove the capacity of F $c_{\gamma}$ RII to induce TNF secretion, experiments were performed with monocytes and mononuclear cells from individuals lacking cell mem. brane expression of FcyRI. Protease-treated monocytes and mononuclear cells from these individuals were induced to secrete TNF by solid-phase hIgG, confirming the 
capacity of FcyRII to induce TNF secretion. It was not possible to induce TNF secretion by cross-linking $\mathrm{Fc}_{\gamma} \mathrm{RI}$ or $\mathrm{Fc \gamma R} \mathrm{R}$ with anti-Fcy $\mathrm{RAb}$ and soluble or solidphase anti-murine $\mathrm{IgG}_{\text {, }}$ indicating that high-affinity $\mathrm{Fc}-\mathrm{Fcy}$ interactions are necessary to induce cytokine release. This study demonstrates that cross-linking of both FcyRI and $F_{c \gamma}$ RII induces TNF secretion by monocytes. However, FcyRII requires pretreatment with proteolytic enzymes or neuraminidase to become functionally active, suggesting that induction of cytokine secretion through $\mathrm{F} c \gamma \mathrm{RII}$ will be limited to areas of inflammation.

\section{INTRODUCTION}

Receptors for the Fc domain of immunoglobulins ( $\mathrm{FcR}$ ) play an important role in the regulation of immune processes such as phagocytosis $(1,2)$, ADCC (3-7), clearance of immune complexes (8,9), and secretion of inflammatory mediators (10-14), and of reactive oxygen intermediates $(15,16)$ by immune cells. On monocytes, two different $\mathrm{FcR}$ for $\mathrm{IgG}\left(\mathrm{F}_{\mathrm{c} \gamma \mathrm{R}}\right)$ are constitutively expressed: a $72 \mathrm{kDa}$ receptor ( $\mathrm{F} c \mathrm{RI} ; \mathrm{CD} 64$ ), binding human $\mathrm{IgG}$ (hIgG) and murine $\operatorname{lgG} 2 \mathrm{a}(\mathrm{mlgG} 2 \mathrm{a}$ ) with high affinity (Ka = $10^{8}-10^{9} \mathrm{M}^{-1}$ ), and a $40 \mathrm{kDa}$ receptor (FcrRII; CD32), binding murine IgG1 (mIgG1) with low affinity $\left(\mathrm{Ka}=10^{6} \mathrm{M}^{-1}\right)(17-20)$. For $\mathrm{F}_{\gamma} \mathrm{RII}$ a structural polymorphism has been demonstrated. Monocytes of approximetaly $30 \%$ of Caucasian individuals (lowresponders, LR) fail to bind (complexed) mIgG1 to FcyRII, although the receptor is expressed in equal density on the cell surface compared with monocytes of the rest of the population, which bind (complexed) mIgG1 to Fcy RII (high-responders, HR). In contrast to HR monocytes, LR monocytes therefore do not support $T$ cell mitogenesis mediated by mIgG1 anti-CD3 mAb (21,22). Isoelectric focussing studies of Fcr RII suggest the existence of two allelic forms of this receptor (23).

In recent years knowledge of the structure of $\mathrm{F}_{\mathrm{c}}$, both on the protein and on the gene level, has increased considerably (reviewed in 24,25 ). However, much remains to be learned about the function of these receptors in immune processes. On monocytes, both $\mathrm{For}$ RI and $\mathrm{F} c \gamma \mathrm{RII}$ have been shown to be capable of inducing monocyte cytotoxicity $(6,7,26,27)$, and to mediate phagocytosis of IgG-coated particles (28). Also, F $\gamma R I$ and ForRII cross-linking has been shown to induce superoxide production by a monocyte-like cell line (16). Recently, we have shown that cross-linking of monocyte Frof $R$ induces secretion of the cytotoxic and immunoregulatory cytokine tumor necrosis factor (TNF) (29). In the present study we investigated the capacity of both constitutively expressed monocyte For R to induce secretion of TNF. It is shown that cross-linking of monocyte $\mathrm{F} \gamma \mathrm{RI}$ as well as of $\mathrm{F} \gamma \gamma \mathrm{RI}$ induces TNF secretion, requiring high-affinity $\mathrm{Fc}-\mathrm{Fc} / \mathrm{R}$ interactions, which is, in the case of $\mathrm{F} c \mathrm{RII}$, achieved by pretreatment of monocytes with proteolytic enzymes or with neuraminidase. 


\section{MATERIALS AND METHODS}

Materials. BSA (No. A-6003, essentially fatty acid free), neuraminidase (type V), pronase, phemylmethylsulfonylfuoride (PMSF), and polymyxin B sulphate were purchased from Sigma Chemical $\mathrm{Co}$. (St. Louls, MO). Trypsin was purchased from Flow (Irwine, United Kingdom). Pronase and trypsin used in the binding experiments were purchased from Boehringer (Mamnhein, Federal Republic of Germany). Human reconbinant TNF (hTNF), used as a standard for the TNF ELISA, was kindly provided by Knoll AG/BASF (Ludwigshafen, Federal Republic of Germany).

Antibodies. The mAb R4D10 (anti-human myosin mAb; mIgG2a), and Fab fragnents of R4D10 were kindly provided by Centocor (Leiden, The Netherlands). The mAb Mac32 (anti-BSA; migG1) and CB1 (MOPC21; mIgG1) were kindly prowided by Cellech (Slough, United Kingdom). Normal human IgG (hilgG), purified from human serum by (NH4)2SO4 precipitation and DEAE-Sephadex chromatography, and consisting for more than $99.9 \%$ of $\mathrm{IgG}$, was kindly provided by Dr. A. Vhug (Central Laboratory of the Netherlands Red Cross Blood Transfusion Services, CLB, Amsterdam, The Netherlands). These antibodies do not bind monocyte surface antigens with their antigen-binding site and were therefore used to cross-link monocyte FcyR by Fc-FcyR interactions. The mlgG1 anti-CD3 mAb WT31 (30) was kindly provided as unpurified ascites by Dr. W. J. M. Tax.

The following anti-Fcy RAb were used: 32.2 (16), 22 and 197 (26) (anti-FcyRI, kindly provided by Dr. M.W. Fanger, Hanower, NH); 10.1 (31) (anti-F $\mathrm{c}$ RI, kindly provided by Dr. N. Hogg. London, UK); IV.3 (17) (anti-FçRII, kindly provided by Dr. C. Anderson, Columbus, OH); CIKMS (32,33) (antiFcy RII, kindly provided by Dr. G. Pillkingron, Melbourne, Australia).

The mAb TB-3 (IgG2a), reactive with an unknown monocyte surface antigen, was a kind gift of $\mathrm{Dr}$, R.A.W. van Lier (CLB, Ansterdam, The Netherlands) (34). Goat F(ab")2-anti-mIgG Ab (GAM) and fluorescein-conjugated goat $F(a b$ ') 2 -anti-mlgG Ab were purchased from Jackson Immunoresearch Laboratories (West Grove, PA).

Solid-phase Ab. Solid-phase Ab were prepared by incubating Ab $(500 \mu \mathrm{g} / \mathrm{mil})$ in phosphate buffered saline (PBS, pH 7.5) overnight at $4{ }^{\circ} \mathrm{C}$ in 96-well immunoassay plates (Nunc, Roskillde, Denmark). $\mathrm{Ab}$ were incubated in the presence of $25 \mu \mathrm{g} / \mathrm{ml}$ polymyxin $\mathrm{B}$ sulphate, in order to eliminate any remaining endotoxin. Solid-phase mIgG1 anti-BSA were prepared by adding anti-BSA ( $1 \mathrm{mg} / \mathrm{ml}, 1 \mathrm{~h}$ at room temperature) to microtiter plates precoated for $1 \mathrm{~h}$ at room temperature with BSA (1 $\mathrm{mg} / \mathrm{ml} \mathrm{in} \mathrm{PBS}$ ). Unbound mAb were removed by three washes with PBS.

Cells. Buffy coats obtained after cytaphoresis of healthy donors were kindly provided by the local Blood Bank and used to prepare monocyte cultures. In experiments with monocytes lacking cell membrane expression of Fc $\gamma \mathrm{RI}, 50 \mathrm{ml}$ heparinuzed blood samples, obtained from three ForRI-deficient individuals $(28,35)$, were used to prepare cultures of peripheral blood mononuclear cells (PBMC) and monocytes. Monocytes were isolated as described elsewhere (26). In short, mononuclear cell suspensions, obtained after buoyant density centrifugation of buffy coats or heparinized blood on Lymphoprep (Nycomed, Oslo, Norway), were allowed to clump by low-speed centrifugation at $4^{\circ} \mathrm{C}$. Cell clumps, consisting for more than $90-95 \%$ of monocytes, as evidenced by esterase staining, were separated from

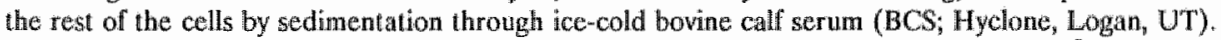
Monocytes were cultured in microtiter plates (Nunc) in humidified $95 \%$ air, $5 \% \mathrm{CO}_{2}$ at $37^{\circ} \mathrm{C}$ in RPMI 1640 (Gibco, Paisley, United Kingdom) supplemented with $10 \%$ heat-inactivated BCS, $100 \mathrm{IU} / \mathrm{mI}$ penicillin, and $100 \mu \mathrm{g} / \mathrm{ml}$ streptomycin (Flow, Irvine, United Kingdom). In each well, $5 \times 10^{4}$ monocytes were cultured in $300 \mu$ culture medium. After indicated time periods $125 \mu \mathrm{l}$ samples of supernatant, from which cells were remowed by centrifugation of the plates for 5 min at $1200 \mathrm{rpm}$, were harvested and kept frozen at $-20^{\circ} \mathrm{C}$ for measurement of TNF concentration at a later date. In the EA-rosette assays, monocyte monolayers were prepared by adding monocytes $\left(4 \times 10^{5} /\right.$ well) to microtiter plates (Costar, Cambridlge, MA) and allowing them to adhere for 45 min at $37^{\circ} \mathrm{C}$, after which non-adherent cells were removed by no washes with PBS. Viability of cells, which was tested by trypan blue exclusion, exceeded 95\% in all experiments.

Enzyme treatment of monocytes. Enzyme-treated monocytes were prepared by incubating monocyles at a cell density of $10 \times 10^{6} / \mathrm{ml}$ in RPMI 1640 containing pronase $(0.1 \mathrm{mg} / \mathrm{ml})$, trypsin $(0.5 \mathrm{mg} / \mathrm{ml})$, or neuraminidase $(1 \mathrm{U} / \mathrm{ml})$ for 30 min at $37^{\circ} \mathrm{C}$. After three washes with RPMI $1640_{*}$ monocyles were 
resiuspended in culture medium for tse in the experiments. In EA-rosette assays, monocyte monolayers were treated with enzymes at the same conditions as abowe. After enzyme treatment, monolayers were washed twice with PBS before use in the EA-rosette assay.

EA-rosette assay. Quantitation of binding of (rhesus D-positive) human erythrocytes (HRBC), sensitized with either hIgG (alloserum against rhesus D), or migGil (anti-glycophorin A), was performed photometrically at $450 \mathrm{~nm}$ as deseribed elsewhere (36). Binding indices were calculated, in order to correct for variations in background absorbance values between different experiments, as follows:

$\left[1-\left(\mathbb{E}_{450} / \mathbb{E}_{4} 450\right)\right] \times 100=$ binding index, where $\mathbb{E}_{450}$ is extinction at $450 \mathrm{~nm}$ in wells to which $H R B C$ withoul sensitizing antibody were added, and EA450 is extinction al $450 \mathrm{~nm}$ in wells to which sensitized HRBC were added. All determinations were performed in duplicate. In inhibition experiments monocyte monolayers were preincubated with the following inhibitors: $\mathrm{mAb} 10.1$, which has been shown to inhibit binding of EA-hIgG to FcyRI (31); TB-3, which blocks monocyte FoyRI by a phenomenon described by Kurlarider (34); IV.3 and CIKMS, which block F c $\gamma$ RII $(17,32)$. Blocking mAb were added to monocytes in RPMI 1640 for 15 min at $4 \%$, after which binding of sensitized HRBC was determined. Percentage inhibition was calculated by comparing absorbances in the presence or absence of inhibitor, as described before (30).

Ant1-CD3 T cell mitogenesis. To distinguish between HR and LR individuals, the capacity of the mlgG1 anti-CD3 mAb WT31 to induce Tt cell mitogenesis was determined. For this purpose, PBMC were cultured at a concentration of $5 \times 10^{5} / \mathrm{mn}$ in round-bottomed microtiter plates (Costar), together with a $1: 10^{5}$ dilution of WT 31 ascites. After 3 days of culture, cells were pulsed for $4 \mathrm{~h}$ with $0.5 \mu \mathrm{Ci}\left[^{3} \mathrm{H}\right.$ ] thymidine $\left(l^{3} \mathrm{H}\right] \mathrm{T} \mathrm{TR}$; specific activity $5 \mathrm{Ci} / \mathrm{mmol}$; Amersham, United Kingdom), after which the cells were harvested with a cell harvester, and the radioactivity of the filters counted with a liquid scintillation counter. Proliferation was assessed in triplicate. Stimulation indexes (SI) were calculated as follows: SI = $\left.\|^{3} \mathrm{H} \rrbracket \mathrm{TdR}(\mathrm{WT} 31) /{ }^{3} \mathrm{H}\right] \mathrm{TdR}$, where $\left[{ }^{3} \mathrm{H}\left[\mathrm{TdR}(\mathrm{WT} 31)\right.\right.$ and $\left[{ }^{3} \mathrm{H}\right] \mathrm{TdR}$ represents $\left[{ }^{3} \mathrm{H}\right] \mathrm{TdR}$-incorporation by PBMC incubated with or without WT3L respectively. HR were defined as having SI $>3$.

Endotoxin measurement. Endotoxin contamination of the following antibodies was measured with a chromogenic Limulus assay (Kabivitrum, Stockholm, Sweden): R4D10: 104 pg/mg; R4D10 Fab: < 100 $\mathrm{pg} / \mathrm{mg} ;$ Mac32: $<100 \mathrm{pg} / \mathrm{mg} ; \mathrm{hlgG}:<10 \mathrm{pg} / \mathrm{mg} ;$ CB1: $<10 \mathrm{pg} / \mathrm{mg} ;$ goat-anti-mIgG (Jackson): < 10 $\mathrm{pg} / \mathrm{mg} ; 32.2$ (1:100 ascites): $<10 \mathrm{pg} / \mathrm{ml} ; 22(1: 100$ ascites): $<10 \mathrm{pg} / \mathrm{ml} ; 197$ (1:10 hybridoma supernatant): $73 \mathrm{pg} / \mathrm{mll}$; IV 3 ( $1: 10$ hybridoma supernatant): $45 \mathrm{pg} / \mathrm{mll}$. Since the enzymes ncuraminidase, pronase, and trypsine interfered with the Limulus assay, endotoxin contamination of these enzyme preparations could not be determined. Endotoxin contamination of RPMI 1640, BCS, and Lymphoprep were controled regularly by Limulus assay, and never exceeded $50 \mathrm{pg} / \mathrm{ml}$.

TNE ELISA. TNF concentration of the supernatants was determined with a TNF-specific ELISA (37), with slight modifications as described before (29).

Statistics. Student's t-test for paired and unparred data was used for statistical analysis of the data. Differences were considered significant at the $p<.05$ level.

\section{RESULTS}

\section{Solid-phase mIgG2a, but not solid-phase mIgG1 induces TNF secretion by monocytes.}

We used solid-phase mIgG2a or mIgG1 to selectively cross-link either Fcy RI or Fcy RII on monocytes. Solid-phase mIgG2a, but not mIgG1, induced secretion of TNF by freshly isolated monocytes (Fig. 1), suggesting that cross-linking of ForRI, but not of FcyRII, triggers secretion of TNF by monocytes. Fc-dependency of mIgG2a-induced TNF secretion was demonstrated by the absence of TNF secretion by monocytes incubated with solid-phase mIgG2a Fab (Fig. 1). 


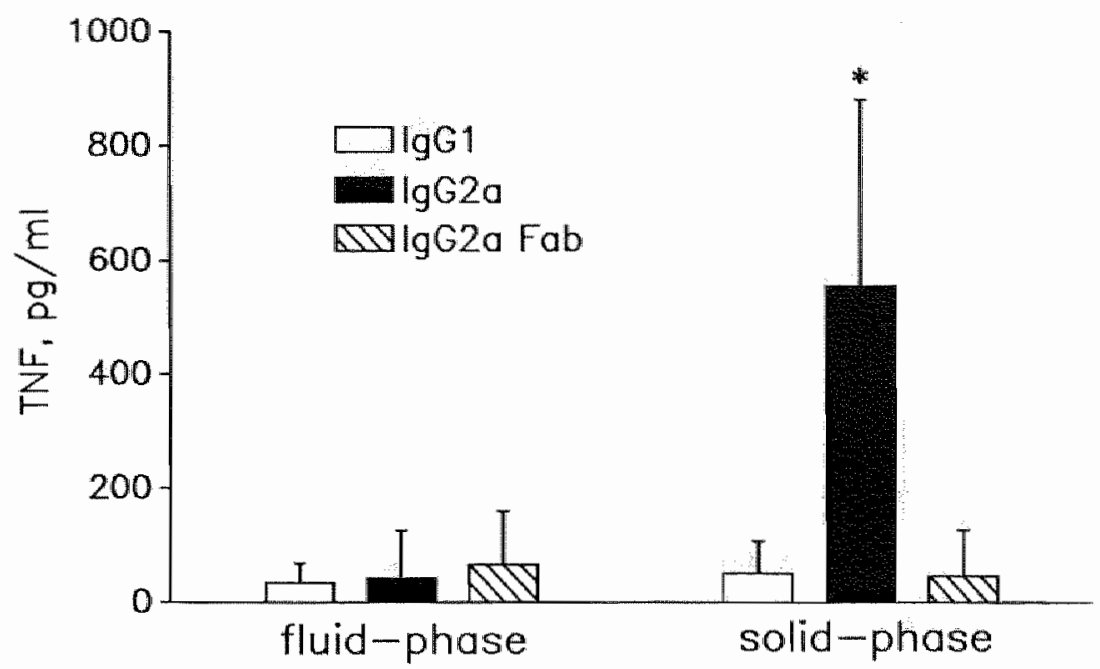

Figure 1. Solid-phase mIgG2a, but mot mIgG1, induces secretion of TNF by monocytes. Monocytes were incubated for $18 \mathrm{~h}$ with either flutd-phase or solid-phase mIgG1 (Mac32), mlgG2a (R4D10), or mIgG2all Fab (R4D10 Fab), after which samples of supernatant were harvested for measurement of TNF concentration. Solid-phase mAb were prepared as described in Methods. Fluid-phase mab wore added to monocytes at concentrations equal to those used to prepare solid phase mAb, e.g. $1 \mathrm{mg} / \mathrm{ml}$ (Mac32 and R4D10) or $500 \mu \mathrm{g} / \mathrm{mll}$ (R4D10 Fab). Data represent mean \pm s.e.m. of triplicate determinations of 10 (mIgGI), 14 (mIgC2a), or 8 (mIgG2a Fab) individuals. ${ }^{* 2} \mathrm{p}<0.001$.

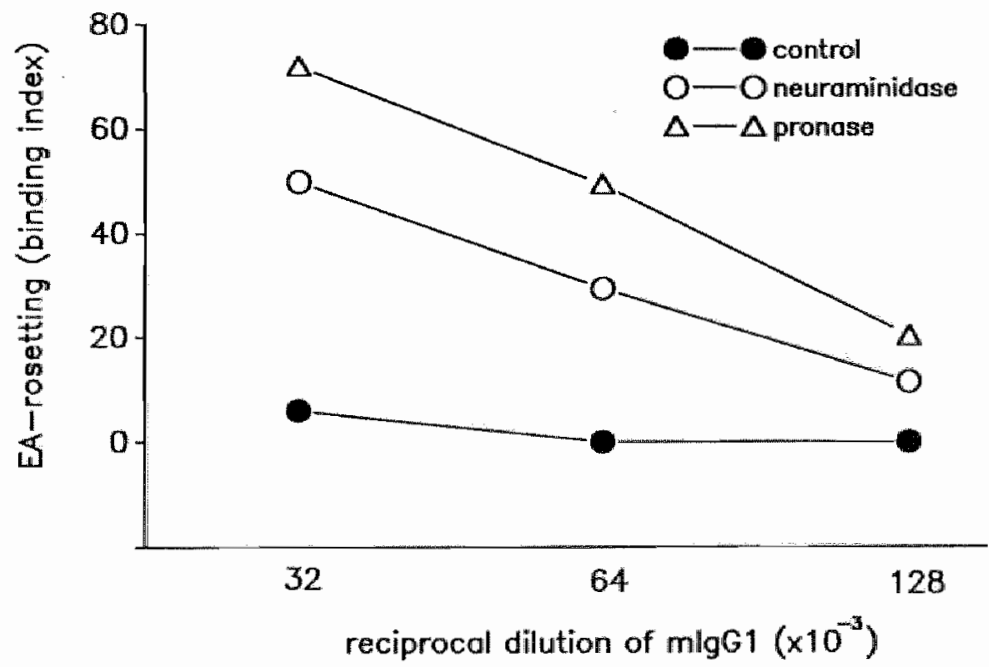

Figure 2. Treatment of monocytes with pronase or neuraminidase enhances binding of EAmigCI. Manocyte monolayers were treated with pronase or neuraminidase as deseribed in Methods. Next, binding of HRBC, sensitized with $\mathrm{mIgCl}$ anti-glycophorin A ascites at three different dilutions, was determined as described in Methods. Data represent the mean of duplicate determinations of one of four different experiments with similar results. 


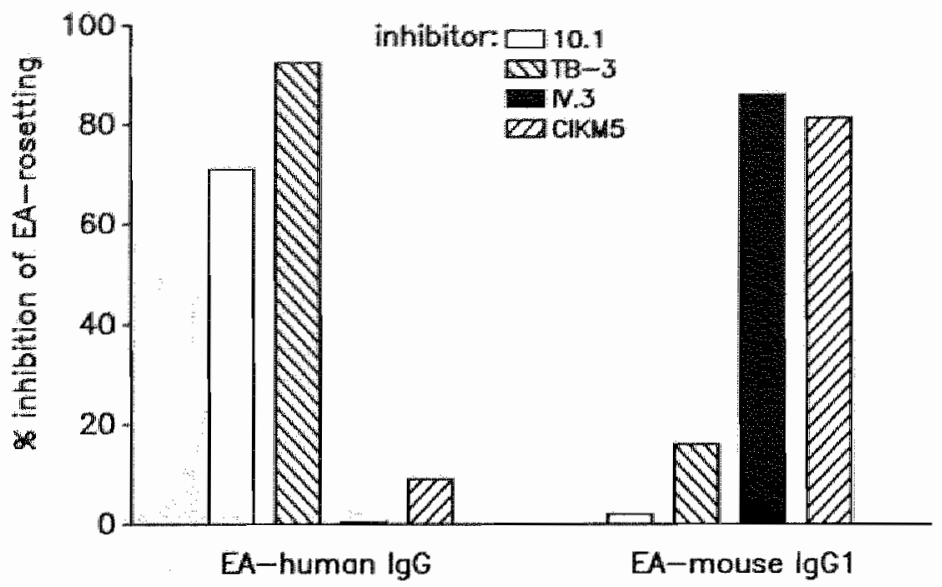

Figure 3. Inhibition of binding of EA-mIgGi or EA-HigG to neuraminidase-treated monocytes by mAb blocking either Fey RI or Fir. Ronocyte monolayers were treated with neuraminidase as described in Methods. After neuraminidase treatment monollayers were washed once with PBS, incubated with culture

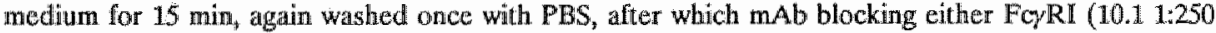
ascites, TB-31:100,000 ascites) or ForRII (IV-31:20 hybridoma culture supernatant, CIKM5 1:50 purified IgG) were added to the monocyles for 15 min. Next, binding, of EA-mlgG1 or EA-hIgG was determined as described in Methods. Data are expressed as percentage inhibition of EA-rosetting as defined in Methods, and represent the mean of duplicate determinations of one of three different experiments with similar results.

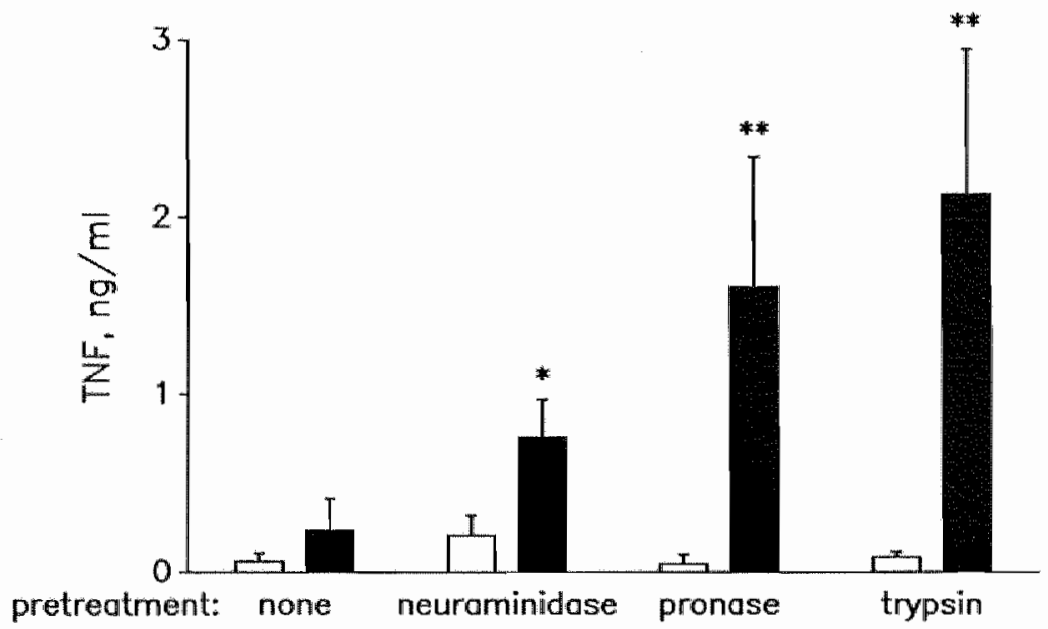

Figure 4. Solid-phase nIgGil induces TNF secretion by monocytes after enzyme treatment. Monocytes were treated with neuraminidase $(1 \mathrm{U})$, pronase $(0.1 \mathrm{mg} / \mathrm{ml})$ or trypsin $(0.5 \mathrm{mg} / \mathrm{ml})$ as described in Methods. After three washes with culture medium monocytes were added to microtiter plates coated with migGll (CB1, $1 \mathrm{mg} / \mathrm{ml}$; solid bars). Enyyme-treated monocytes added to uncoated wells served as controls (open bars). After $18 \mathrm{~h}$ samples of supernatant were harvested to determine TNF concentration. Data represent mean \pm s.e.m. of triplicate determinations of 6 different individuals.

*pe .001 vs, control.

* $\mathrm{p}<.01 \mathrm{vs}$. control. 
Treatment of monocytes with neuraminidase or pronase increases the interaction between mIgG1 and ForRI.

In a recent study by one of us it was shown that the interaction between ForRII and mIgGl increases after treatment of monocytes with proteolytic enzymes (38). In this study it was also demonstrated that treatment of monocytes with proteolytic enzymes increases the affinity of ForRII for hIgG. Since $\mathrm{F} g \mathrm{R}$ are sialoglycoproteins we were interested to know whether treatment of monocytes with the desialylating enzyme neuraminidase also affects the interaction between FcyII and mIgGl. Treatment of monocytes with either the proteolytic enzyme pronase or with neuraminidase strongly enhanced binding of human erythrocytes sensitized with mIgG1 (EA-mIgG1) (Fig. 2). Control experiments were performed to exclude the possibility that the observed increase in binding of EA-mIgG1 after neuraminidase treatment was attributable to proteolytic enzymes contaminating the neuraminidase preparation used. The increase in binding of EA-mIgG1 after neuraminidase treatment was not affected by pretreatment of neuraminidase with the protease-inhibiting compound PMSF $(0.5 \mathrm{mM}, 30 \mathrm{~min}$; $0 \%$ reduction in binding vs. cells treated with neuraminidase in the absence of PMSF; data from 4 different individuals). The increase in binding of EA-mIgG1 after pronase treatment was however largely abolished by pretreatment of pronase with PMSF 90.7 \pm 8.1 reduction in binding vs. cells treated with pronase not pretreated with PMSF; mean \pm s.e.m. of four different individuals). The increase in binding was consistently found to be greater after treatment of monocytes with pronase than after neuraminidase treatment. Increased binding of EA-mIgG1 to neuraminidase-treated monocytes could, as has been shown for proteolytic enzyme-treated monocytes in the above-mentioned study (38), be inhibited almost totally by the FcyRII-blocking mAb IV.3 and CIKMS, but not or only minimally by the ForRI-blocking mAb 10.1 and TB-3. In contrast, rosetting between neuraminidase-treated monocytes and EA-hIgG was strongly inhibited by mAb 10.1 and TB-3, but only minimally by mAb IV.3 and CIKM 5 , indicating that after neuraminidase treatment rosetting between monocytes and EA$\mathrm{hIgG}$ is predominantly mediated by Fc $\gamma \mathrm{RI}$ (Fig. 3). These data indicate that increased binding of mIgG1 to monocytes after treatment with proteolytic enzymes or neuraminidase can be accounted for by an increased interaction between ForRIT and mIgGI.

\section{Solid-phase mIgG1 induces TNF secretion by monocytes treated with proteolytic enzymes or neuraminidase.}

Since the interaction between FoyRII and mIgG1 increases considerably after treatment of monocytes with proteolytic enzymes or neuraminidase, we investigated whether incubation of enzyme-treated monocytes with solid-phase mlgGi leads to TNF secretion. Solid-phase mIgG1 significartly increased TNF secretion above control values after enzyme treatment (Fig. 4). The increase in TNF secretion was greater after treatment of monocytes with proteolytic enzymes than with neuraminidase, paralleling the greater increase in interaction between FcrRII and mIgG1 on pronase-treated monocytes observed in the rosetting experiments. These data indicate that cross-linking 


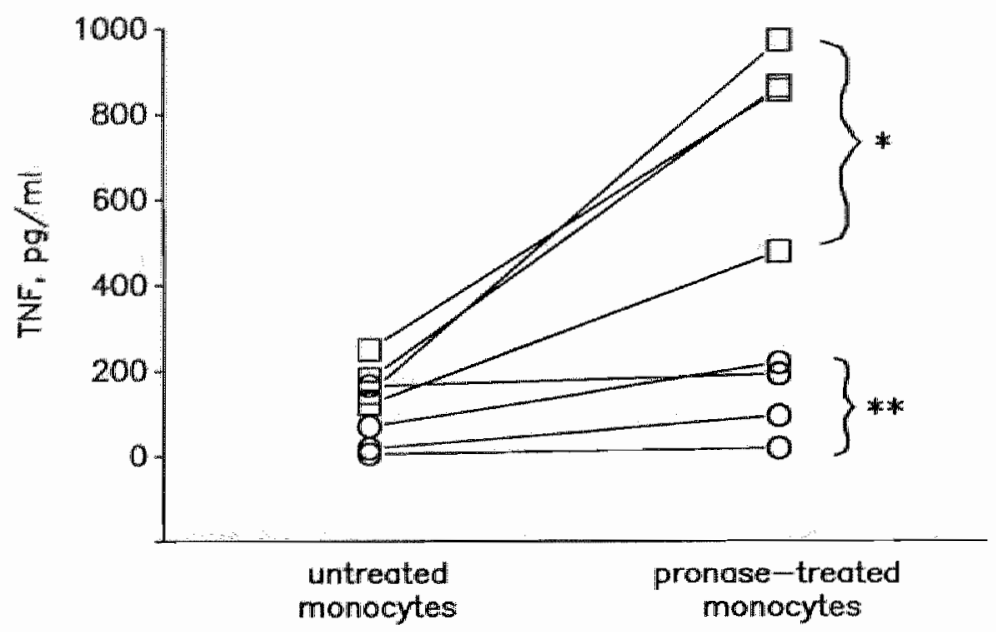

Figure 5. Solid-phase mIgG1-induced TNF secretion by HR or LR monocytes after protease treatment. Monocytes from four HR individuals (squares) or four LR individuals (circles) were treated with pronase $(0.1 \mathrm{mg} / \mathrm{ml})$ as described in Methods: After three washes with culture medium monocytes were added to microtiter plates coated with $\mathrm{mIgG1}(\mathrm{CB1}, 1 \mathrm{mg} / \mathrm{ml})$. Untreated monocytes incubated with solid-phase mIgG1 served as controls. After $18 \mathrm{~h}$ samples of supernatant were harvested to measure TNF concentration. Data represent the means of triplicate determinations. TNF secretion by monocytes incubated in uncoated wells was always less than $200 \mathrm{pg} / \mathrm{ml}$ in these experiments.

$* p<.01$ vs. control.

** * not significant vs. control.

of Fc $\gamma$ RII leads to TNF secretion only after the interaction between this receptor and the cross-linking mIgG1 antibody has been increased above a certain threshold by pretreatment of the monocytes with proteolytic enzymes or neuraminidase.

\section{Difference in solid-phase mIgG1-induced TNF secretory response between protease-treated monocytes from HR or LR individuals.}

Since the affinity of $\mathrm{F}$ or RII for mIgG1 is markedly different between monocytes from HR or LR individuals, we examined the influence of HR or LR phenotype on the solid-phase mIgG1-induced TNF secretion by protease-treated monocytes. Solidphase mlgG1-induced TNF secretion by HR monocytes was significantly increased after protease treatment. No significant increase in TNF secretion was found with monocytes from four LR individuals (Fig. 5). This finding supports the contention that effective induction of TNF secretion is dependent on strong interactions between ForRII and the cross-linking mIgG1 mAb.

\section{Protease-treated monocytes from FcyRI-deficient individuals secrete TNF after incubation with solid-phase hIgG.}

Hypothetically, it remained possible that, through increased interaction between Fc $\gamma$ RI and mIgG1 after enzyme treatment of monocytes, TNF secretion was induced by cross-linking of $\mathrm{Fo}_{\gamma} \mathrm{RI}$ rather than $\mathrm{F}_{\gamma} \mathrm{RII}$. To definitively prove the capacity of $\mathrm{Fc}_{\gamma} \mathrm{RII}$ 


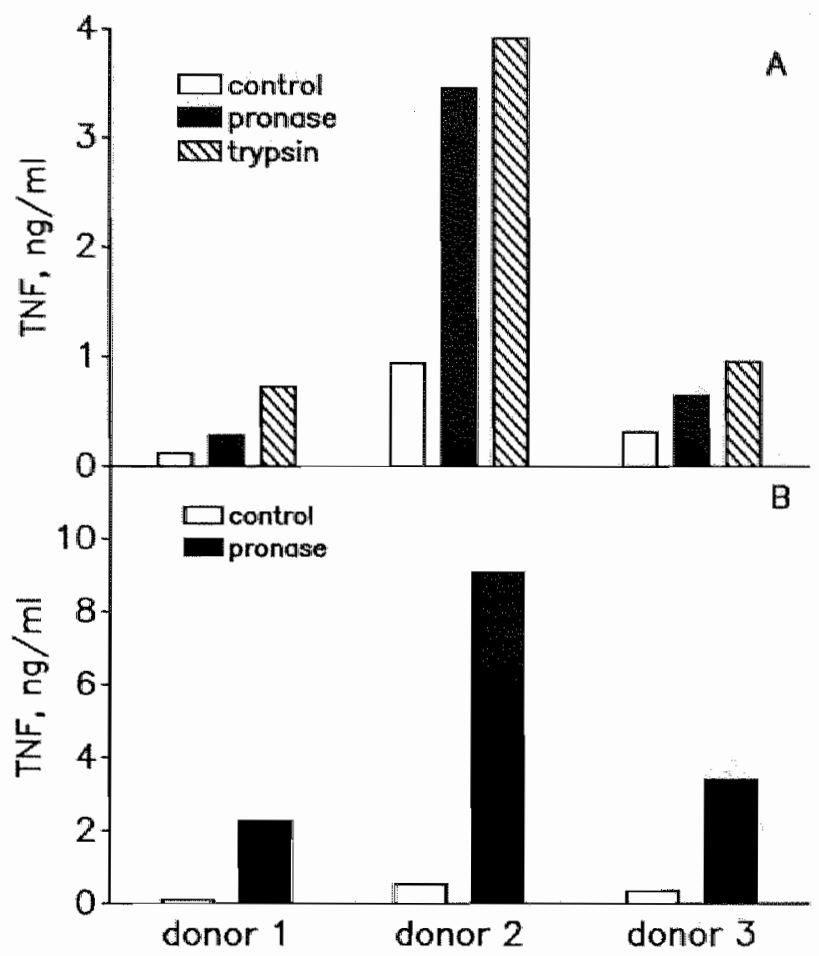

Figure 6. TNF secretion by monocytes or PBMC from Foy RI-deficient individuals after treatment with proteolytic enaymes. Monocytes from three FoyRI-deficient individuals were treated with proteolytic enzymes as described in Methods. Enzyme-treated or control monocytes ( $5 \times 10^{4}$ cells/well) were incubated with solid-phase hilg for $18 \mathrm{~h}$, after which samples of supernatant were harvested for measurememt of TNF concentration (Fig. 6A). Each bar represents the mean of duplicate determinations of one experiment. TNF secretion by enzyme-treated monocytes from all three individuals in the absence of solid-phase hIgG was below the detection limit $(\mathrm{e} . \mathrm{g} .<10 \mathrm{pg} / \mathrm{ml})$. The same experiment was performed using

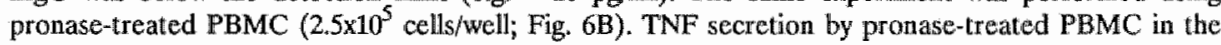
absience of solid-phase hIgG varied between $60-70 \mathrm{pg} / \mathrm{ml}$ for all three individuals.

to induce TNF secretion, we performed experiments with cells from individuals who have an inherited defect in cell membrane expression of Fc $\gamma$ RI $(28,35)$. Since only FyRI is expressed on these cells, solid-phase hIgG could be used instead of solidphase mlgG1 to cross-link this receptor." The affinity of F $c y$ RII for hII G has been shown to increase after proteolysis (38). Protease-treated monocytes from three different FcyRI-deficient individuals were shown to secrete TNF above control levels when incubated with solid-phase hIgG (Fig. 6A). Similar data were obtained when the experiment was performed with unseparated PBMC from these individuals (Fig. 6B). In both experiments the highest increase in TNF secretion was observed with cells from donor 2. This donor was of HR phenotype, whereas donors 1 and 3 were of LR phenotype, which likely explains the difference in TNF secretion between these donors. These data substantiate the capacity of ForRII to induce TNF secretion after its affinity 


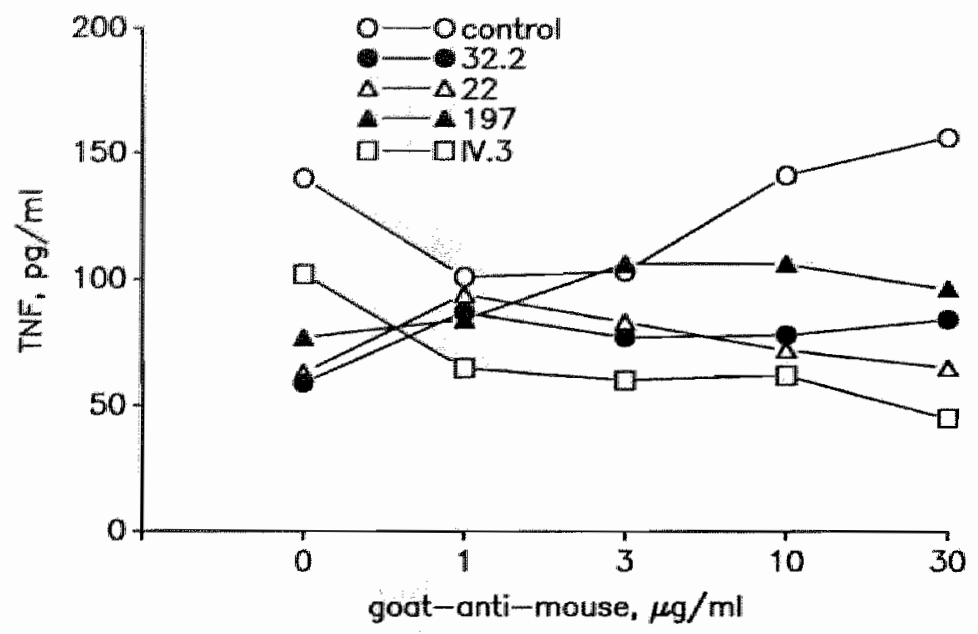

Figure 7. Cross-linking of Fe $\gamma \mathrm{R}$ with different anti-F $\mathrm{f} / \mathrm{R} \mathbf{m A b}$ does not induce TNF secretion by monocytes. Monocytes were incubated with anti-FcyRI mAb 32.2, 22, and 197, or with the anti-FcyRI $\mathrm{mAb}$ IV 3 for $30 \mathrm{~min}$ at $4{ }^{\circ} \mathrm{C}$. Concentrations of anti- $\mathrm{FC} / \mathrm{R}$ mAb giving optimal binding, as determined by indirect immunofluorescence, were used to coat monocytes. After three washes with culture medium monocytes were incubated for $18 \mathrm{~h}$ with different concentrations of GAM to cross-link FcyR, after which samples of supernatant were harvested to determine TNF concentration. Data represent mean of triplicate determinations of four different individuals. Error bars have been omitted for clarity.

for the $\mathrm{Fc}$ domain of the cross-linking $\mathrm{Ab}$ has been increased by enzyme treatment. Moreover, these data also demonstrate that Fcy RII can be effectively cross-linked by $\mathrm{hIgG}$ after protease treatment, suggesting that this process is relevant for in vivo inflammatory processes.

\section{Cross-linking of Fc $\gamma$ RI or F $\gamma$ RII with anti-Fc $\gamma$ R mAb does not lead to TNF secretion.}

The former experiments suggest that effective induction of TNF secretion through cross-linking of either Fcy RI or ForRII depends upon high-affinity interactions of $\mathrm{Ab}$ with $F \subset R$. To examine this hypothesis we used monoclonal anti-For $R$ Ab, which bind with high affinity to $F_{c \gamma} R$, to cross-link both $F_{c y} R I$ and $F_{c \gamma} R I$. These mAb cross-link $F_{c} R$ not by $F c-F c \gamma R$ interactions, but by binding with their antigen-binding site to different epitopes on the $\mathrm{F} \% \mathrm{R}$. Monocytes were incubated with optimal concentrations of one of the following mAb: 32.2, 22, or 197 (anti-FcrRI mAb), and IV.3 (anti-FcyRII $\mathrm{mAb}$ ). Concentrations of anti- $\mathrm{F} \gamma \mathrm{R}$ mAb giving optimal binding were determined by indirect immunofluorescence on monocytes as evaluated by $F A C S$ analysis. $F c \gamma R$ were cross-linked by adding soluble GAM at concentrations ranging between $0.1-100 \mu \mathrm{g} / \mathrm{ml}$ to monocytes coated with the different anti-Fcy $\mathrm{R}$ Ab. Efficacy of cross-linking was judged visually by fluorescence microscopy of monocytes incubated at $37^{\circ} \mathrm{C}$ with anti-For $\mathrm{RAB}$ and fluorescein-conjugated GAM in the absence of sodium azide. Capping of $\mathrm{Ab}$, indicating effective $\mathrm{Fc} \gamma \mathrm{R}$ cross-linking, was observed at concentrations 
of GAM between $10-30 \mu \mathrm{g} / \mathrm{ml}$. Monocytes did not secrete TNF above control values when incubated with any of the anti-F $\mathrm{F}$ mAb and GAM at concentrations between $1-30 \mu \mathrm{g} / \mathrm{ml}$ (Fig. 7). Neuther was TNF secretion observed when the cross-linking GAM was bound to a solid-phase (data not shown). These findings strongly suggest that high-affinity $\mathrm{Fc}-\mathrm{F} \mathrm{c} R$ interactions are necessary to induce TNF secretion by monocytes upon For $\mathrm{R}$ cross-linking.

\section{DISCUSSION}

In this study we investigated the induction of secretion of the immunoregulatory and inflammatory cytokine TNF by cross-linking of both constitutively expressed $F c \gamma R$, FcyRI and FcyRII, on human peripheral blood monocytes. On untreated monocytes, TNF secretion was induced by solid-phase mIgG2a, cross-linking FerRI, but not by solid-phase mIgG1, cross-linking Fc $\gamma$ RII. Since it has been shown that immobilized mIgG1 immune complexes effectively modulate ForRII from the apical surface of adherent monocyte cultures (39), these findings at first sight suggest that TNF secretion can only be induced by cross-linking of ForRI. However, after treatment of monocytes with neuraminidase or proteolytic enzymes, TNF secretion could also be induced by solid-phase mIgG1, cross-linking Fc $\gamma$ RII. This is not a result of enzyme treatment itself, since 'spontaneous' TNF secretion by enzyme-treated monocytes (probably a result of stimulation of monocytes by endotoxin contaminating the enzyme preparations used), cultured in medium alone (Fig. 4), or in the presence of fluidphase mIgG1 (data not shown), was significantly lower than TNF secretion by enzymetreated monocytes incubated with solid-phase mIgG1.

The rosetting experiments show that treatment of monocytes with neuraminidase increases the interaction between Foy RII and mIgG1. The same has recently been demonstrated after treatment of monocytes with proteolytic enzymes (38). Moreover, in the same study an increased binding affinity of $\mathrm{Fc} \gamma \mathrm{RII}$ for hIgG after protease treatment has also been demonstrated. Others have demonstrated increased binding of rabbit IgG immune complexes to monocyte $\mathrm{Fcy} R$ after treatment with proteolytic enzymes $(40,41)$. At the time of these studies, For RII had not yet been discovered. Their findings can however be readily explained by an increased affinity of $F c \gamma R$ II for rabbit IgG. In summary, increased interaction between F $\gamma$ RII and mIgGI is found after treatment with both neuraminidase and proteases, whereas the binding affinity of Fcy RII for hIgG (and possibly also rabbit IgG) is increased after proteolysis.

Increased interaction between $\mathrm{F}_{\mathrm{C}} \mathrm{RII}$ and mlgG1, enhancing the strength of $\mathrm{F}_{\mathrm{c}} \mathrm{RII}$ cross-linking, constitutes a likely explanation for solid-phase mIgG1-induced TNF secretion by monocytes treated with neuraminidase or with proteases. The contention that induction of TNF secretion by FcyRII cross-linking is dependent on strong interactions between $\mathrm{F} c \mathrm{RII}$ and the cross-linking $\mathrm{Ab}$ is supported by the finding that solid-phase mIgG1 enhances TNF secretion by pronase-treated monocytes from HR individuals, but not or only minimally by monocytes from LR individuals. Since the difference in affinity of FCyRII of HR or LR individuals is a relative rather than an absolute one, it remains possible that the inability to induce TNF secretion by LR 
monocytes in these experiments is caused by insufficient cross-linking by the aspecifically coated mIgGI mAb. This conclusion is supported by the finding that, when using solid-phase hlgG instead of solid-phase mIgG1 to cross-link ForII in the experiments with ForRI-deficient cells described in figure 6, LR cells are also induced to secrete TNF, although to a lesser extent than HR cells. Apparently, FcrRI are cross-linked more strongly by solid-phase hIgG than by solid-phase mIgG1. Furthermore, these experiments, performed with cells expressing only FcyRl on their cell surface, convincingly demonstrate the ability of FoRIII to induce TNF secretion.

It was not possible to induce TNF secretion by cross-linking FcrRI or FcyRII with anti-F $c$ R mAb, which bind with their antigen-binding site to various epitopes on $\mathrm{F} c \gamma \mathrm{R}$, together with fluid-phase GAM. Our previous study showed that TNF secretion can be induced effectively by cross-linking cytophilic hIgG with a fluid-phase anti$\mathrm{hIgG} \mathrm{Ab}(29)$. The inability to induce TNF secretion with anti-For $\mathrm{R}$ mAb and fluidphase GAM seems therefore not to be due to $F c \gamma R$ being less effectively cross-linked with fluid-phase Ab as compared to solid-phase Ab. Moreover, TNF secretion was neither induced by anti-F $\mathrm{cr}$ mAb and solid-phase GAM. We therefore conclude that high-affinity $\mathrm{Fc}-\mathrm{F} c \gamma \mathrm{R}$ interactions are required to trigger secretion of the cytokine TNF by monocytes. These findings are in contrast with those of others, who were able to induce superoxide production by a human monocyte-like cell line by cross-linking For RI and $\mathrm{Fcr}$ RII with anti-F $c$ R mAb as well as with hIgG-immune complexes (16). It has also been shown that both For RI and ForRII are cytotoxic trigger molecules on monocytes, when using hybricloma cells expressing mAb 32.2 or IV.3 on their cell surface as target cells $(6,7,26)$. Furthermore, an increase in intracellular $\mathrm{Ca}^{2+}$-levels has recently been observed in the monocyte cell line U937 after cross-linking FcyRI and $F c \gamma R I I$ with anti-Fcy $\mathrm{RAb}$ as well as via $\mathrm{Fc}-\mathrm{Fc} \gamma \mathrm{R}$ interactions (41). Our study strongly suggests that, for as yet unknown reasons, effective induction of TNF secretion requires binding of the $\mathrm{Fc}$ moiety of the cross-linking $\mathrm{Ab}$ to the $\mathrm{F} c \gamma \mathrm{R}$.

TNF is a cytotoxic and immunoregulatory cytokine with a broad range of activities on different cell types (reviewed in 43). Generally speaking, it can be viewed as a cytokine which enhances immune and inflammatory processes. It also has strong pyrogenic activity and induces the production of other pyrogens, like interleukin-1 (44), and interleukin-6 (45). The findings of the present study suggest that circulating monocytes will only be able to secrete TNF via $F_{c} r R I$ cross-linking, occurring for instance by circulating immune complexes or antibody-coated pathogens (29). Since the affinity of $\mathrm{F}_{\mathrm{c}} \mathrm{RI}$ for complexed $\mathrm{IgG}$ or monomeric IgG does not differ much (46), it can be expected that FoyRI cross-linking is strongly inhibited by the excess of monomeric IgG present in the circulation, thereby protecting the organism against massive release of a potentially lethal cytokine. In areas of inflammation, where proteases, released by granulocytes, and neuraminidase, derived for instance from bacteria or viruses, are likely to be present, FcyRII will be 'activated', becoming functional with respect to the induction of TNF secretion. This provides a mechanism limiting cytokine release to areas of inflammation.

It is known from other studies that the expression and function of $F(\gamma R$ can be modulated by treatment with proteolytic enzymes. The high-affinity $\mathrm{F} c y \mathrm{R}$ on mouse macrophages loses its capacity to bind monomeric mIgG2a after treatment with try- 
psin, whereas the low-affinity $\mathrm{Fc} \gamma \mathrm{R}$ present on these cells retains its capacity to bind polymeric $\mathrm{mIgG} 1 / \mathrm{mIgG} 2 \mathrm{~b}$ (47). Recently, the protease elastase was shown to differentially modulate the expression and function of both $\mathrm{For} R$ constitutively present on human neutrophils (48). Our study shows that not only proteolytic enzymes but allso the deglycosylating enzyme neuraminidase is capable of influencing $\mathrm{Fc \gamma} R$ function. Interestingly, neuraminidase has been shown to influence other inmmune responses as well. For example, MHC-restricted alloreactive $T$ cell activation by different cells can be enhanced by pretreatment of these cells with neuraminidase (49-51). Although the significance of these findings remains to be learned, modulation of immune responses or uncovering of latent immune responses by enzymes released in areas of inflammation may constitute an important host mechanism to fine-tune immune processes in areas of active inflammation.

\section{Acknowledgment.}

We thank Margriet Jansze for excellent technical assistance in the rosetting studies.

\section{REFERENCES}

1. Shaw DR, Griffin FM. 1981. Phagocytosis requires repeated triggering of macrophage phagocytic receptors during particle ingestion. Nature 289:409.

2. Mellman IS, Plutner $\mathrm{H}_{x}$ Steinman RM, Unkeless JC, Cohn ZA. 1983. Internalization and degradation of macrophage Fc receptors during receptor-mediated phagocytosis. J Cell Biol 96:887.

3. Nathan C, Brukner L, Kaplan G, Unkeless J, Cohn Z. 1980. Role of activated macrophages in antibody-dependent lysis of tumor cells. J Exp Med 152:183.

4. Nathan C, Cohn Z. 1980. Role of oxygen-dependent mechanisms in antibody-induced lysis of tumor cells by activated macrophages. J Exp Med 152:198.

5. Karpovsky B, Titus JA, Stephany DA, Segal DM. 1984. Production of target specific effector cells using heterocross-linked aggregates containing anti-target cell and anti-Fcy receptor antibodies. J Exp Med 160:1686.

6. Shen L, Guyre PM, Anderson CL, Fanger MW. 1986. Heteroantibody mediated cytotoxicity: antibody to the high affinity Fc receptor for IgG mediates cytotoxicity by human monocytes that is. enhanced by interferon- $\gamma$ and is not blocked by human IgG. J Immunoll 137:3378.

7. Graziano RF, Fanger MW. 1987. Human monocyte-mediated cytotoxicity: the use of Ig-bearing hybridomas as target cells to detect trigger molecules on the monocyte cell surface. I Immunol $138: 945$.

8. Finbloom DS, Plotz PY. 1979. Studies of reticuloendothelial function in the mouse with model. immune complexes. I. Serum clearance and tissue uptake in normal C3H mice. I Innmunol 123:1594.

9. Finbloom DS. 1985. Binding, endocytosis, and degradation of model immune complexes by murine macrophages at various levels of activation. Clin Immunol Immunopathol $36: 275$.

10. Ragsdale CG, Arend WP. 1979. Neutral protease secretion by human monocytes. J Exp Med 149:954,

11. Passwell JH, Dayer J-M, Merler E. 1979. Increased prostaglandin production by thuman monocytes after membrane receptor activation. J Immunol 123:115.

12. Passwell JH, Dayer J-M, Gass K, Edelson PJ. 1980. Regulation by Fc fragments of the secretion of collagenase, PGE2, and lysozyme by mouse peritoneal macrophages. J Immunol 125:910.

13. Rouzer CA, Scott WA, Kempe J, Cohn ZA. 1980. Prostaglandin synthesis by macrophages requires a specific receptor-ligand interaction. Proc Natl Acad Sci USA 77:4279.

14. Rouzer CA, Scott WA, Hamill AL, Cohn ZA. 1980. Dynamics of leukotriene C production by macrophages. J Exp Med 1.52:1236. 
15. Yamamoto $\mathrm{K}$, Mohnston $\mathrm{R} \mathrm{B}, \mathrm{Jr} \cdot 1984$. Dissociation of phagocytosis from stimulation of the oxidatiwe metabolic burst in macrophatges. J Exp Med $159: 405$.

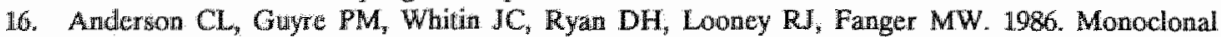
antiboties to Fic receptors for IgG on human mononuclear phagocytes. J Biol Chem 261:12856.

17. Looney RJ, Abraham GN, Anderson CL. 1986. Human monocytes and U937 cells bear two distinct Fe receptors far IgG. I Immunol 136:1641.

18. Anderson CL, Looney RJ. 1986. Human leukocyte IgC Fe receptors Immunol Today 7:264.

19. Stengelin \$, Stamenkovic 1, Seed B. 1988 . Isolation of cDNAs for two distinct human Fe receptors by ligand affinity cloning. EMBO J 7:1053.

20. Allen JM, Seed B. 1989. Isolation and expression of functional high-affinty FC receptor complementary DNAs. Science 243.378

21. Tax WIM, Hermes FFM, Willems RW, Capel PJA, Koene RAP. 1984. Fe receptors for monse IgG1 on human monocytes: polymorphism and role in antibody-induced $\mathrm{T}$ cell proliferation. J Immunol $133 ; 1185$.

22. Ceuppens JL, wan Vaeck F. 1987. Direct demonstration of binding of anti-Leu 4 antibody to the 40 $\mathrm{kDa}$ Fic receptor on monocytes as a prerequisite for anti-Leu 4-induced $T$ cell mitogenesis. I Immunol $139: 4067$.

23. Andersion CL, Ryan DH, Looney RI, Leary PC. 1987. Structural polymorphism of the human monocyte 40 kilodalton Fe receptor for IgG. J Immunol 138:2254.

24. Unkeless JC, Scigliano $\mathrm{E}$, Freedman VH. 1988. Structure and function of human and murine receptors for IgG. Ann Rev Immunol 6:251.

25. Mellman I. 1988. Relationships between structure and function in the FC receptor family. Current Opinion in Immunol 1:16.

26. Graziano RF, Fanger MW. 1987. FcyRI and FcyRIII on monocytes and granulocytes are cytotoxic trigger molecules for tumor cells. J Immunol 139:3536.

27. Van de Winkel JGJ, Boonen GJJC, Janssen PLW, Vug A, Hogg N, Tax WJM. 1989. Activity of two types of Fc receptors, F $\gamma$ RI and F $\gamma / R_{I}$, in human monocyte cytotoxicity to sensitized erythrocytes. Scand J Immunol 29:23.

28. Ceuppens $\sqrt{ }$, Baroja $M L$, van Vaeck $F$, Anderson CL. 1988. Defect in the membrane expression of high affinity $72-\mathrm{kD}$ Fey receptors on phagocytic cells in four healthy subjects. J Clin Invest 82:571.

29. Debets JMH, van der Linden CJ, Dieteren IEM, Leeuwenberg JFM, Buurman WA. 1988. FC-receptor cross-linking induces rapid secretion of tumor necrosis factor (cachectin) by human peripheral blood monocytes. J Immunol 141:1197.

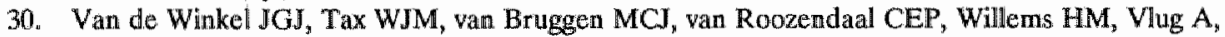
Capel PJA, Koene RAP. 1987. Characterization of two FC receptors for mouse immunoglobulins on human monocytes and cell lines. Scand J Immunol 26:663.

31. Dougherty GJ, Selvendran Y, Murdoch S, Palmer DG, Hogg N. 1987. The hunan mononuclear phagocyte high-affinity Fc receptor, FCRI, defined by a monoclonal antibody, 10.1. Eur J Immunol 17:1453.

32. Tetteroo PAT, wan der Schoot CE, Visser FJ, Bos MJE, von dem Borne AEGKr. 1987. Three difforent types of Foy receptors on human leucocytes defined by workshop antibodies; Fcy/Rlow of neutrophìls, FcyRlow of K/NK lymphocytes, and Fcy RII. In Leukocyte Typing III. AJ MeMichael et al, eds. Oxford Unwersity Press, Oxford, p. 702.

33. Pilkington GR, Lee GTH, Michael PM, Garson OM, Kraft N, Atkins RC, Jose DG. 1986. Subclassification of leukaemia using monoclonal antibodies. In Leukocyte Typing II, Vol. 2 Human B Lymphocytes. Reinherz, EL, BF Haynes, LM Nadler, ID Bernstein, eds. Springer Verlag, New York, p. 353 .

34. Van Lier RAW, Boot JHA, de Groot ER, Aarden LA. 1987. Induction of T cell proliferation with anti-CD3 switch-wariant monoclonal antibodlies: effects of heavy chain isotype in monocyte-dependent systems. Eur J Immunol 17:1599.

35. Ceuppens $\mathrm{JL}_{2}, \mathrm{Bloemmen} F \mathrm{FJ}$, van Wauwe JP. 1985. T cell unresponsiveness to the mitogenic activity of OKT3 antibody results from a deficiency of monocyte $\mathrm{Foy}$ receptors for murine $\mathrm{IgG} 2 \mathrm{a}$ and inability to cross-link the T3-Ti complex. Immunol 135:3882. 
36. Van de Winkel JGJ, Tax WJM, van Brugge MCJ, van Roozendaal CEP, Willents HM, van Duijnhowen JLP, Capel PJA, Koene RAP. 1987. A new photometric meithod for the quantitation of Fe receptors for murine IgG1 on human monocytes and cell lines. J Immunal Methods 101:109.

37. Debets JMH, van der Linden CJ, Spronken IEM, Buurman WA. 1988. T cell-mediated production of tumour necrosis factor- $\alpha$ by monocytes. Scand J Immunol $27: 601$.

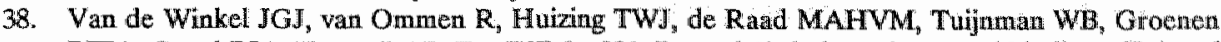
PJTA, Capel PJA, Koene RAP, Tax WJM. 1989. Proteolysis induces increased binding affinity of the monocyte type II FicR for human IgG.J Jmmunol, in press.

39. Van de Winkel JGI, van Duijnhoven HLP, van Ommen R, Capel PIA, Tax WJM. 1988, Selective modulation of two human monocyte Fe receptors for IgG by immobilized immune complexes. I Immunol 140:3515.

40. Cosio FG, Ackerman SK, Douglas SD, Friend PS, Michael AF. 1981. Soluble immune complexes binding to human monocytes and polymorphonuclear leucocytes. Immunology 44:773.

41. Cosio FG, Douglas SD, Michael AF. 1982. The human FCR. MI. Effects of pronase on soluble immune complex binding by polymorphonuclear leucocytes, monocytes and pulmonary macrophages. Immunology 46:395.

42. Van de Winkel JGJ, Tax WJM, Jacobs CWM, Huizinga TWJ, Willems PGHM. 1989. Cross-linking of both types of IgG Fc receptors, Fcy RI and FoyRI, enhances intracellular free $\mathrm{Ca}^{2+}$ in the monocytic cell line U937. Submitted for publication.

43. Beutler B, Cerami A. 1987. Cachectin: more than a tumor necrosis factor. N Engl J Med 316:379.

44. Dinarello CA, Cannon JG, Wolff MH, Bernheim A, Beutler B, Cerami A, Figari IS, Palladino MA, Jr, O'Connor JV. 1986. Tumor necrosis factor (cachectin) is an endogenous pyrogen and induces production of interleukin 1. $\mathrm{J}$ Exp Med 163:1433.

45. Zhang Y, Lin J-X, Yip YK, Vilcek J. 1988. Enhancement of cAMP levels and of protein kinase activity by tumor necrosis factor and interleukin 1 in human fibroblasts: role in the induction of interleukin 6. Proc Natl Acad Sci USA 85:6802.

46. Burton DR. 1985. Immunoglobulin G: functional sites. Mol Immunol 22*161.

47. Unkeless JC. 1977. The presence of two Fc receptors on mouse macrophages: evidence from a variant cell line and differential trypsin sensitivity. J Exp Med 145:931.

48. Tosi MF, Berger M. 1988. Functional differences between the $40 \mathrm{kDa}$ and 50 to $70 \mathrm{kDa}$ IgG Fc receptors on human netrophils revealed by elastase treatnent and antireceptor antibodies. J Immunol 141:2097.

49. Cowing C, Chapdelaine JM. 1983. T cells discriminate between Ia antigens expressed on allogeneic accessory cells and B cells: a potential function for carbohydrate side chains on Ia molecules. Proc Natl Acad Sci USA 80:6000.

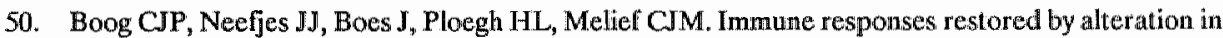
carbohydrate chains of histocompatibility antigens on antigen presenting cells. Eur J Immunol, in press.

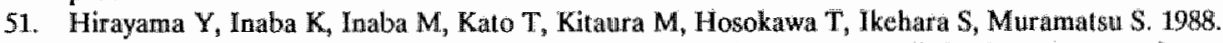
Neuraminidase-treated macrophages stimulate allogeneic CD8 $+\mathrm{T}$ cells in the presence of exogenous interleukin 2.J Exp Med 168:1443. 



\title{
THE INHIBITORY EFFECT OF CORTICOSTEROIDS ON THE
}

\section{SECRETION OF TUMOR NECROSIS FACTOR BY MONOCYTES,}

\author{
INDUCED BY DIFFERENT STIMULATORY AGENTS
}

Debets, J.M.H., T.J.M. Ruers, M.P.M.H. van der Linden, C.J. van der Linden, and W.A. Buurman. Submitted for publication.

\section{SUMMARY}

The cytokine tumor necrosis factor is believed to be involved in the pathophysiology of several human disease states, both septic and non-septic. Difgerent pathways of induction are involved in the generation of TNF in these disease states. We therefore used four different stimulatory agents, i.e. LPS, PMA, silica quartz, and anti-human IgG $\mathrm{Ab}$, to study the influence of the corticosteroids prednisolone and budesonide on the secretion of TNF by human monocytes. Both prednisolone and budesonide inhibited TNF secretion induced by these four stimulating agents in a different degree. Inhibition was strong when TNF secretion was induced by LPS or anti-human $\operatorname{IgG~Ab.~}$ A weaker inhibitory effect was observed when TNF secretion was induced by silica quartz. Only minimal inhibition of PMA-induced TNF secretion was observed. Furthermore, it is shown that inhibition is dependent on the dose of corticosteroid, but not or only minimally on the dose of stimulating agent, indicating that inhibition cannot be overcome by increasing the cell-activating stimulus. Finally, optimal inhibition of TNF secretion by corticosteroids is shown to be dependent on the presence of corticosteroids during the phase of cell stimulation.

\section{INTRODUCTION}

Tumor necrosis factor (TNF) is an inflammatory and immunoregulatory cytokine produced mainly by monocytes and macrophages after stimulation with endotoxin $(1,2)$, but also by other cells of the immune system like T lymphocytes (3) and natural killer cells (4). TNF has numerous regulatory functions in immune processes, thus playing a pivotal role in the enhancement of inflammation and immunity (5). Besides its physiological role TNF is also believed to be involved in the pathophysiology of a 
number of disease processes like sepsis $(6,7)$, cachexia or anorexia accompanying cancer or chronic infection (8-10), parasitic infections (11,12), allograft rejection (13), graft-vs-host disease (14), and autoimmune diseases like rheumatoid arthritis (15-17) and SLE (18).

The corticosteroid drugs prednisolone and budesonide have both been shown to inhibit inflammatory processes and to suppress the immune response in several autoinmune diseases or during allograft rejection $(19,20)$. One of the important mechanisms underlying the antiinflammatory and immunosuppressive effects of corticosteroids is the inhibition of production and secretion of inflammatory mediators by immunocompetent cells $(19,21)$. For example, corticosteroids have been shown to inhibit production of the interleukins IL-1 and $\mathrm{L}-2$, and of interferon- $\gamma(22-24)$.

Corticosteroids have also been shown to imhibit TNF production by murine and rat macrophages $(1,25)$ as well as by human monocytes (26). In these studies endotoxin was used to stimulate TNF production. Besides endotoxin, other compounds have been shown to induce TNF production. The protein kinase C-activating agent PMA is a potent inducer of TNF production by monocytes (27). Recently, we have demonstrated that TNF secretion by monocytes can be induced through cross-linking of monocyte F $\mathrm{C}$ receptors (FoyR), for example with an anti-human IgG Ab or with immune complexes (28). Furthermore, data from our laboratory demonstrate that silica quartz, which is a known inducer of interleukin 1 (IL-1) production in monocytes (29), can also induce TNF production by monocytes (30). We therefore investigated the influence of corticosteroids on the secretion of TNF by monocytes after stimulation with these different compounds.

It is shown that TNF secretion is variably inhibited by corticosteroids, depending on the type of stimulus used. The strongest inhibition was found when TNF secretion was induced by LPS or anti-human IgG Ab, whereas inhibition of PMA-and sillica-induced TNF secretion was considerably weaker.

\section{MATERIALS AND METHODS}

Materials. Prednisolone was purchased from Centrachemie (Etten-Leur, The Netherlands). A stock solution was prepared of $25 \mathrm{mg} / \mathrm{ml}$ prednisolone in water. Budesonide was kindly provided by Dr. R. Brattsind (Drako/Astra, Lund, Sweden). A stock solution of $10^{-2} \mathrm{M}$ budesonide was prepared in $96 \%$ cthanol. Boolh stock solutions were further diluted in culture medium to obtain the final concentrations used in the experiments. Monocytes cultured in medium containing equivalent amounts of ethanol without budesonide were used as controls for budesonide-treated cells. Monocytes cultured in medium without any additions were used as controls for the prednisolone-treated cells. Lipopolysaccharide (LPS; from $\mathrm{E}$. coli 055.B5) was purchased from Difco (Detroit, MI, USA), 4- $\beta$-phorbol-12-myristate-13-acetate (PMA) and silica quartz (particle size $0.007 \mu \mathrm{m}$ ) were purchased from Sigma (St. Louis, MO, USA). Goat $\mathrm{F}\left(\mathrm{ab}^{2}\right)_{2}$ anti-human kappa chain $\mathrm{Ab}$ was purchased from Tago (Burlingame, CA, USA).

Cells. Buffy coats obtained after cytophoresis of healthy donors were kindly provided by the local Blood Bank. Monocytes were isolated as described elsewhere (31). In short, mononuclear cell suspensions obtained after Ficoll-Isopaque centrifugation were allowed to clump by low speed centrifugation at $4 \%$ C. Cell clumps, consisting for more than $90-95 \%$ of monocytes as evidenced by esterase staining, were separated from the rest of the cells by sedimentation through ice-cold bovine calf serum (BCS; Hyclone, Logan, $_{n}$ UT, USA). Monocytes were cultured in 96-well flat-bottom culture plates (Costar, Cambridge, MA, USA) in humidified $95 \%$ air, $5 \% \mathrm{CO}_{2}$ at $37^{\circ} \mathrm{C}$ in RPMI 1640 (Gibco, Paisley, UK) supplemented 
with $10 \%$ heat-inactivated $\mathrm{BCS}, 100 \mathrm{IU} / \mathrm{ml}$ penicillin and $100 \mathrm{\mu g} / \mathrm{ml}$ streptomycin (Flow, Irvine, UK). In each well $2.5 \times 10^{4}$ monocytes were cultured in $300 \mu \mathrm{l}$ culture medium. After indicated time periods $125 \mathrm{ml}$ samples of supernatant, from which cells were removed by centrifugation of the plates for 5 min at 1200 $\mathrm{rpm}$, were harvested and kept frozen at $-20^{\circ} \mathrm{C}$ for measurement of TNF concentration at a later date. Viability of cells, which was determined by trypan blue exclusion, exceeded $95 \%$ in all experiments. All experiments were performed in duplicate or triplicate.

TNF ELISA. TNF concentration of the supernatants was determined with a TNF-speciffic ELISA (32), with slight modifications as described before (28).

Statistics. Student's t-test for paired and unpaired data was used for statistical analysis of the data. Differences were considered significant at the $\mathrm{p}<.05$ level.

\section{RESULTS}

LPS, PMA, silica, and anti-human kappa chain Ab were used as stimulating agents to study the influence of corticosteroids on TNF secretion by monocytes. Concentrations of each of the stimulating agents giving optimal stimulation of TNF secretion were determined in separate experiments (data not shown). These concentrations were used in the first set of experiments, in which the effect of a four hour preincubation period with various concentrations of the corticosteroids prednisolone and budesonide on TNF secretion by monocytes was studied (Fig. 1). TNF secretion was determined by measuring TNF concentration of the cell-free supernatant of monocyte cultures incubated for $17 \mathrm{~h}$ with the stimulating agents in the presence or absence of corticosteroids. It is shown that both prednisolone and budesonide inhibit TNF secretion in a dose-dependent manner. The strongest inhibition was found when TNF secretion was induced by LPS or anti-hIgG Ab. PMA-induced TNF secretion was only moderately inhibited, especially with prednisolone, which even enhanced TNF secretion at lower concentrations. Silica-induced TNF secretion was also inhibited by both corticosteroids, the degree of inhibition being less than that observed after stimulation of TNF secretion by LPS or anti-hIgG Ab.

Next, we examined whether the degree of inhibition of TNF secretion by corticosteroids was dependent on the dose of stimulating agent added to the monocytes. As an example of the dose-response relationships of LPS-induced TNF secretion, data from two individuals are given in figure 2, panel A. Two different concentrations of the corticosteroids prednisolone and budesonide were used to inhibit TNF secretion, one giving optimal inhibition of TNF secretion and one giving suboptimal inhibition of TNF secretion, as determined by the experiments shown in fig. 1. At optimal inhibitory concentrations of prednisolone and budesonide inhibition of TNF secretion was not affected by the dose of LPS added to the monocyte cultures. However, at suboptimal inhibitory concentrations of both corticosteroids a distinct reduction in inhibition was observed when the amount of LPS added to the cultures was increased (Fig. 2, panels $B$ and $C$ ). The same was essentially found when TNF secretion was induced through cross-linking of monocyte $\mathrm{F} c y \mathrm{R}$ with anti-hIgG $\mathrm{Ab}$. The influence of the amount of anti-hIgG $\mathrm{Ab}$ on the degree of inhibition by corticosteroids was however less than that observed with LPS (Fig. 3).

Next, we examined whether the inhibition of TNF secretion by corticosteroids requires the presence of corticosteroids at the time of addition of stimulating agents to 

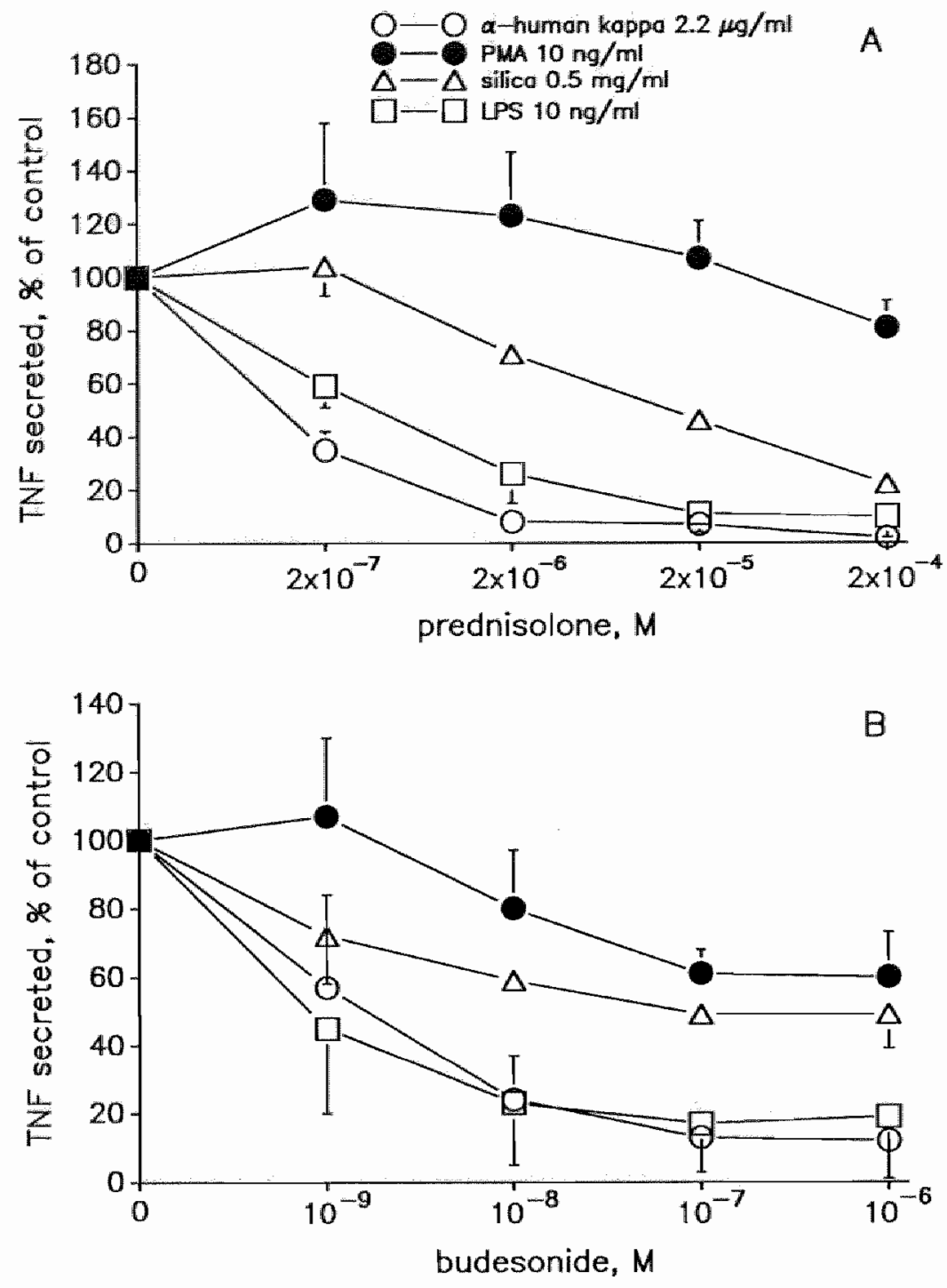

Figure 1. Inhibition by corticosteroids of TNF secretion induced by four different stimulating agents. Monocytes were incubated with various concentrations of either prednisolone (panel A) or budesonide (panel B). After four hr the stimulating agents were added to the cultures. After $17 \mathrm{hr}$, samples of supernatant were barvested to measure TNF concentration. Data represent mean \pm s.e.m. of triplicate determinations of four different individuals. TNF secretion is expressed as percentage of TNF secretion in the absence of corticosteroids. 
the monocytes. Monocytes were preincubated for 4 hours with prednisolone or budesonide at optimal inhibitory concentrations, after which the corticosteroids were washed away. Four hours later monocytes were stimulated with LPS. As shown in table I, monocyte TNF secretion was not inhibited by a four hour preincubation period with prednisolone. TNF secretion was even enhanced by preincubation with prednisolone, although the difference did not reach statistical significance. After a four hour preincubation period with budesonide, TNF secretion was still significantly suppressed (Table I). The degree of inhibition of TNF secretion was however significantly less than that observed in the continual presence of budesonide ( $25 \pm 11 \%$ inhibition vs. 80 $\pm 14 \%$ inhibition, $m \pm$ s.e.m. of four experiments; $p<.01$ ), indicating that the inhibition of TNF secretion is partially reversed after removal of budesonide from the cultures.

\section{DISCUSSION}

In this study it is shown that corticosteroids inhibit the secretion of TNF by human monocytes in a dose-dependent manner. Both prednisolone, which is used as a systemic immunosuppressive drug in clinical medicine, and budesonide, which is used mainly as a topical antiinflammatory drug in respiratory diseases, were shown to inhibit TNF secretion. Budesonide proved to be a more potent inhibitor of TNF secretion than prednisolone (approximately 100 times more potent on a molar basis). Corticosteroids variably inhibited TNF secretion, depending on the type of stimulus used to induce TNF secretion. The strongest inhibition was observed when TNF secretion was induced by a 'receptor-mediated' mechanism, i.e. by LPS or through cross-linking of monocyte Fcy receptors with an anti-hIgG Ab. The inhibition was much less or, at lower concentrations of corticosteroids, even totally absent, when TNF secretion was induced by the protein kinase C-activating agent PMA. The inhibition observed when TNF secretion was induced by silica, which non-specifically activates monocytes, was intermediate in comparison with PMA-induced and LPS/anti-hIgG-induced TNF secretion. These data suggest that, as far as cytokine secretion is concerned, corticosteroids interfere more potently with receptor-transmitted cellular activating pathways than with protein kinase C-mediated cellular activation.

The results shown in figures 2 and 3 indicate that the inhibition by corticosteroids of TNF secretion induced by LPS or anti-hIgG Ab is not of a competitive nature. The inhibition by optimal inhibitory concentrations of corticosteroids cannot be eliminated by increasing the dose of stimulatory agents. Only at suboptimal inhibitory concentrations of corticosteroids a slight reduction of inhibition was observed when the concentration of LPS or anti-hIgG Ab was increased.

Prednisolone-induced inhibition was shown to be rapidly reversible. Four hours after removal of prednisolone from the culture medium inhibition of TNF secretion was no longer observed. Budesonide-induced inhibition was less rapidly reversed, significant inhibition still being present four hours after removal of budesonide from the cultures. Since the washing procedure was identical for both corticosteroids, it seems unlikely that the inhibition observed after preincubation with budesonide is due 

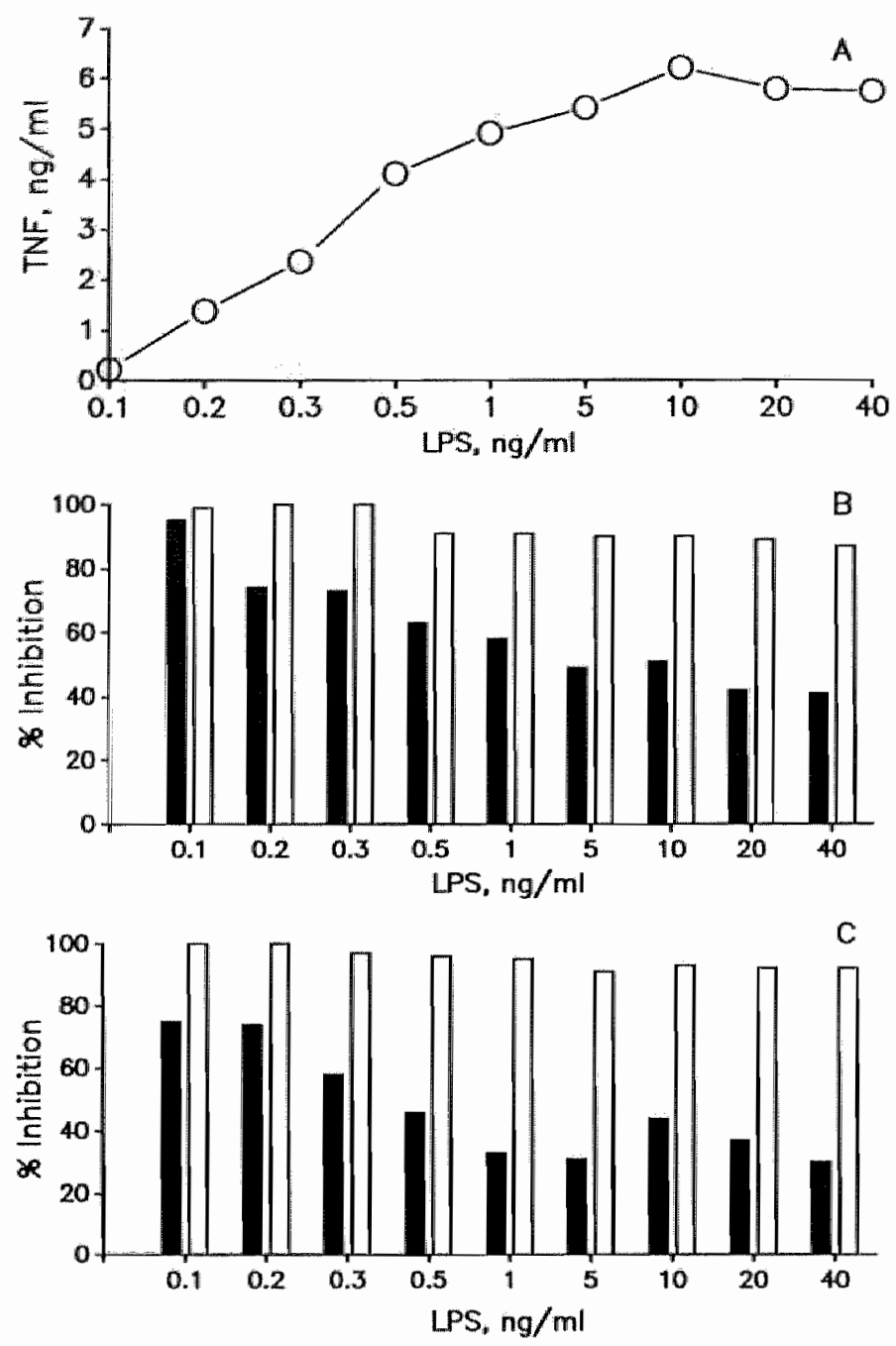

Figure 2. Influence of the concentration of LPS on inhibition of TNF secretion by corticasteroids. Monocytes were preincubated with budesonide (panel B) or prednisolone (panel C) at concentrations giving optintal (open bars) or suboptimal (solid bars) inhibition of LPS-induced TNF secretion, as determined by the former experiments. Optimal inhibitory concentrations chosen were $10^{-7} \mathrm{M}$ and $2 \times 10^{-5}$ $M$ for budesonide and prednisolone respectively. Suboptimal inhibitory concentrations chosen were $10^{-9}$ $\mathrm{M}$ and $2 \times 10^{-7} \mathrm{M}$ for budesonide and prednisolone respectively, Four hr later LPS at different concentrations was added to the cultures. After $17 \mathrm{hr}$ samples of supernatant were harvested to measure TNF concentration. Values in panel $B$ and $C$ are meams of triplicate determinations of two different individuals. Data are expressed as percentage inhibition of TNF secretion, which is defined as [1-(TNF with corticosteroids)/(TNF without corticosteroids)] $\times 100$. Panel A shows the actual dose-response curves of LPS-induced TNF secretion in these two individuals (expressed as mean of triplicate determinations of both individuals). 
to incomplete removal of the drug from the culture medium, since this would have resulted in persistent inhibition in the prednisolone-pretreated cultures as well. The observed difference in duration of inhibition suggests that budesonide is less rapidly cleared from the intracellular compartment, possibly because of greater affinity for intracellular steroid-binding receptor molecules. This is also in accordance with the finding that budesonide is, on a molar basis, a far more potent inhibitor of TNF secretion than prednisolone.

Endotoxin-induced TNF production has been shown to be inhibited by corticosteroids in previous studies, both in murine and in human systems $(1,25,26)$. Dexamethasone was shown to inhibit endotoxin-induced mouse macrophage TNF production at transcriptional as well as posttranscriptional level (1). Only short periods of exposure to dexamethasone were necessary to fully block TNF production, inhibition even being present when dexamethasone was administered to the cells at the same time as endotoxin. Human monocyte TNF production induced by endotoxin was also shown to be inhibited by dexamethasone, requiring however a much longer period ( 48 h) of preincubation of cells with dexamethasone for inhibition to become optimal (26). Our study shows that corticosteroids also inhibit monocyte TNF secretion induced by stimuli other than endotoxin. We also found that only short periods of exposure $(4 \mathrm{~h})$ to prednisolone or budesonide were needed to optimally inhibit TNF secretion.

TNF is believed to be one of the prime mediators of sepsis, on the basis of both experimental animal studies $(6,33)$ and clinical studies in man $(7,34,35)$. Numerous animal studies have demonstrated a protective effect of corticosteroids against mortality in experimental sepsis (reviewed in 36). However, a beneficial effect of corticosteroids in human sepsis has not yet been convincinly demonstrated (36-38). The strong inhibitory effect of corticosteroids on endotoxin-induced TNF production may be one of the mechanisms underlying the protective effect of corticosteroids in experimental animal sepsis.

We have recently demonstrated that TNF secretion by monocytes can be induced through cross-linking of the $\mathrm{Fc} \gamma$-receptor, for example with immune complexes or with an anti-hIgG $\mathrm{Ab}(28)$. This finding suggested to us that TNF may play a role in the pathophysiology of immune complex diseases, for example rheumatoid arthritis. Several investigations support such a hypothesis. TNF has been shown to induce bone and cartilage resorption in vitro, partly in synergism with interleukin 1 (IL-1) (15, 16,39). Furthermore, TNF has recently been detected in synovial fluid of patients with rheumatoid arthritis (40). These disease states can be potently suppressed by corticosteroids. Our finding that corticosteroids inhibit TNF secretion induced through $F_{c} y R$ cross-linking contributes to the understanding of the mechanisms underlying the beneficial effect of corticosteroids in these disease states.

TNF shares many of its biological activities with another important immunoregulatory cytokine, IL-1. Corticosteroids have also been shown to inhibit IL-1 synthesis by human monocytes (22) and by a human monocyte-like cell line (23). IL-1 synthesis by monocytes is mainly inhibited at post-transcriptional level (22). The exact cellular level at which corticosteroids interfere with human monocyte TNF production remains subject of further study. 

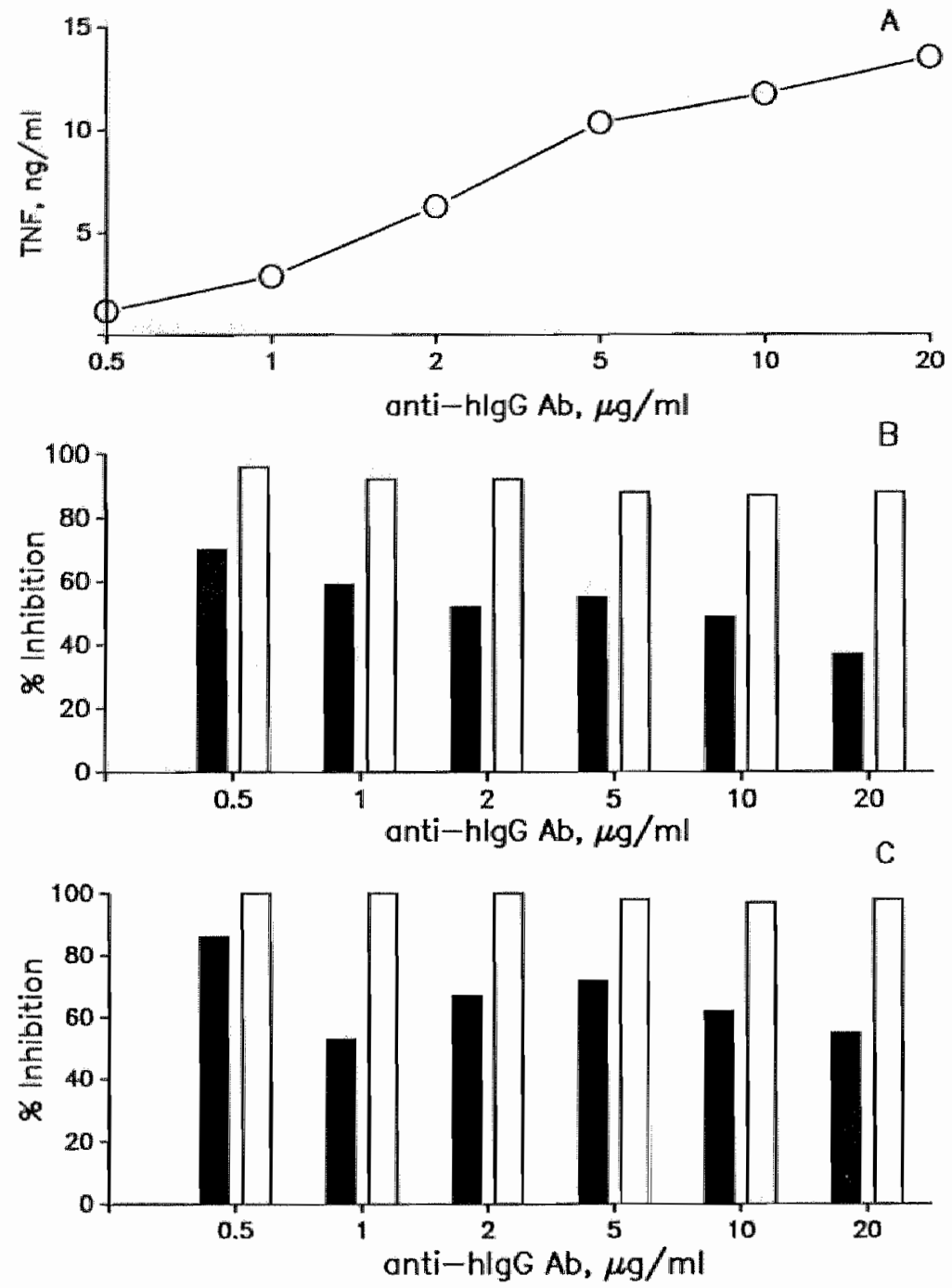

Figure 3. Influence of the concentration of anti-hlgG $\mathrm{Ab}$ on inhibition of TNF secretion by corticosteroids. Legend is the same as for Fig. 2, with anti-human IgG Ab being the stimulating agent instead of LPS. 
TABLE I. Effect of preincubation of monocytes with corticosteroids on LPS-induced TNF secretion. $^{a}$

\begin{tabular}{lcl}
\hline preincubation with: & LPS added $(\mathrm{ng} / \mathrm{mnl})$ & TNF $(\mathrm{pg} / \mathrm{ml})$ \\
\hline- & 100 & $4458 \pm 2422$ \\
prednisolone & 100 & $5564 \pm 3162^{*}$ \\
- & 100 & $4085 \pm 1700$ \\
budesonide & 100 & $2673 \pm 1491^{*}$ \\
\hline
\end{tabular}

a $1.25 \times 10^{6}$ monocytes in 1 ml callure medium were preincubated for 4 lir with either prednisolone $\left(2 \times 10^{4}\right.$ M) or budesonide $\left(10^{-6} \mathrm{M}\right)$, after which corticosteroids were washed away by three washes with culture medium. Four hr later LPS was added to the monocytes preincubated with corticosteroids or their respective controls (see Materials and Methods). After 13 hr supernatant was harvested for measurement of TNF concentration. Data represent the mean \pm s.e.m. of 9 different individuals, each determined in triplicate.

* NS ws. control.

\# $\mathrm{p}<.05$ vs. control.

In conclusion, this study shows that the corticosteroids prednisolone and budesonide variably inhibit TNF secretion by monocytes, depending on the kind of stimulus used to induce TNF secretion. Strong inhibition was found when TNF secretion was induced by LPS or through For R cross-linking, weak inhibition was found with PMA-induced TNF secretion, and inhibition was intermediate with silica-induced TNF secretion. These differences may be of importance in explaining the variable effects of corticosteroids in several human disease states.

\section{REFERENCES}

1. Beuter B, Krochin N, Milsark IW, Luedke C, Cerami A. 1986. Control of cachectin (numor necrosis factor) synthesis" mechanisms of endotoxin resisfance. Science $232: 977$.

2. Kornbluth RS, Edgington TS. 1986. Tumor necrosis factor production by human monocytes is a regulated event: induction of TNF- $\alpha$-mediated cellular cytotoxicity by endotoxin. I Immunol $137: 2585$.

3. Cuturi MC, Murphy M, Costa-Giomi MP, Weinman R, Perussia B, Trinchieri G. 1987. Independent regulation of tumor necrosis factor and lymphotoxin production by human periphtacral blood lymphocytes. J Exp Med 165:1581.

4. Christmas SE, Meager A, Moore M. 1987. Production of interferon and tumour necrosis factor by cloned human natural cytotoxic lymphocytes and T cells. Clim exp Immunol 69:441.

5. Beutler B, Cerani A. 1987. Cachectin: more than a tumor mecrosis factor. N Engl I Med 316:379.

6. Tracey KJ, Fong Y, Hesse DG, Manogue KR, Lee AT, Kuo GC, Lowry SF, Cerami A. 1988 , Anti-cachectin/TNF monoclonal antibodies prevent septic shock during lethal bacteraemia. Nature 330:662.

7. Waage A, Halstensen A, Espevik T. 1987. Association between tumour necrosis. factor in serum and fatal outcome in patients with meningococcall disease. Lancet i.355. 
8. Cerami $A$, Neda $Y_{\text {, Le Trang }} \mathbb{V}_{\mathrm{V}}$ Hotez PJ, Beutler B. 1985. Weight loss associated with an endotoxin-induced mediator from peritomeal macrophages: the role of cachectin (tumor necrosis factor). Innmunol Lett 11:173.

9. Oliff A, Defeo-Jones D, Bryer M, Martinez D, Kiefer D, Vuocolo $G$, Wolfe A, Socher SH. 1987. Tumors secreting buman TNF/cachectin induce cachexia in mice. Cell $50: 555$.

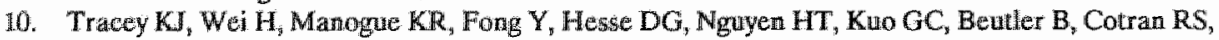
Cerami A, Lowry SE. 1988. Cachectin/tumor necrosis factor induces cachexia, anemila, and inflimmation. Exp Med 167:1211.

11. Scuderi P, Lam KS, Ryan KJ, Petersen E, Sterling KE, Finley PR, Ray CG, Slymen DJ, Salmon SE. 1986. Raised serum levels of tumour necrosis factor in parasitic infections. Lancet i:1364.

12. Clark IA, Cowden WP, Butcher GA, Hunt NH. 1987. Possible roles of tumor necrosis factor in the pathology of mallaria. Am J Pathol 129:192.

13. Malry CPI, Teppo A-M. 1987. Raised serum levels of cachectin/tumor necrosis factor $\alpha$ in renal allograft rejection. J Exp Med 166:1132.

14. Puguet P-F, Grau GE, Allet B, Vassalli P. 1987. Tumor necrosils factor/cachectin is an effector of skin and gut lesions of the acute phase of graft-vs.-host disease. J Exp Med 166:1280.

15. Saklatvala J. 1986. Tumour necrosis factor $\alpha$ stimulates resorption and inhibits synthesis of proleoglycan in cartilage. Nature 322:547.

16. Thomson BM, Mundy GR, Chambers TJ. 1987. Tumor necrosis factors $\alpha$ and $\beta$ induce osteoblastic cells to stimulate osteoclastic bone resorption. J Immunol 138:775.

17. Bertolini DR, Nedwin GE, Bringman TS, Smith DD, Mundy GR, 1986. Stimulation of bone resorption and inhibition of bone formation in witro by human tumour necrosis factors. Nature 319:516.

18. Jacob CO, McDevitt HO. 1988. Tumour necrosis factor- $\alpha$ in murine autoimmune "lupus nepluitis. Nature 331:356.

19. Ruers TJM, Buurman WA, van Boxtel CJ, van der Linden CJ, Kootstra G. 1987. Immunohistological observations in rat kidney allografts after local steroid administration.J Exp Med 166:1205.

20. Ruers TJM, Daemen MJAP, Thijssen HHW, van der Linden CJ, Buurman WA. 1988. Graft rejection in rats proves sensitive to local immunosuppressive therapy. Transplantation $46: 820$.

21. Cupps TR, Fauci AS. 1982. Glncocorticoid-mediated immunoregulation in man. Immunol Rev 65:133.

22. Kern JA, Lamb RJ, Reed JC, Daniele RP, Nowell PC. 1988. Dexamethasone inhibition of interleukin 1 beta production by human monocytes. J Clin Invest 81:237.

23. Knudsen PJ, Dinarello CA, Strom TB. 1987. Glucocorticoids inhibit transcriptional and posttranscriptional expression of interleukin 1 in U937 cells. J Immunod 139:4129.

24. Arya SK, Wong-Staal F, Gallo RC. 1984. Dexamethasone-mediated inhibition of human $T$ cell growth factor and gamma-interferon messenger RNA. J Immunol 133:273.

25. Walage A. 1987. Production and clearance of tumor necrosis factor in rats exposed to endotoxin and dexamethasone. Clin Immunol Immunopathol 45:348.

26. Waage A, Bakke 0 . 1988. Glucocorticoids suppress the production of tumour necrosis factor by lipopolysaccharide-stimulated human monocytes. Immunology $63: 299$.

27. Nedwin GE, Svedersky LP, Bringman TS, Palladino MA, Jr, Goeddel DV. 1985. Effect of interleukin 2 , interferon $\gamma$, and mitogens on the production of tunor necrosis factors $\alpha$ and $\beta$. J Immunol $135: 2492$.

28. Debets JMH, wan der Linden CJ, Dieteren IEM, Leeuwenberg JFM, Buurman WA. 1988. Fc-receptor cross-linking induces rapid secretion of tumor necrosis factor (cachectin) by human peripheral blood monocytes. I Immunol 141:1197.

29.epe-Zuniga JL, Gery I. 1984. Production of intra and extracellular interleukin-1 (IL-1) by human monocytes. Clin Immunol Immunopathol 31:222.

30. Borm P. J, Palmen N, Engelen JJ, Bunrman WA. 1988. Spontaneous and stimulated release of tumor necrosis factor (TNF)-alpha from blood monocytes of miners with coal workers" pneumoconiosis. Amer Rev Resp Dis 138:1589.

31. Graziano RF, Fanger MW. 1987. FcyRI and FcyRII on monocytes and granulocytes are cytotoxic trigger molecules for tumor cells. I Immunol 139:3536. 
32. Debets $\mathrm{JMH}$, van der Linden $\mathrm{CJ}_{3}$ Spronken IEM, Buurman WA. 1988. T cell-mediated production of tumour necrosis factor- $\alpha$ by monocytes. Scand J Immunol $27: 601$.

33. Tracey KJ, Beutler B, Lowry SF, Merryweather J, Wolpe S, Milsark IW, Hariri RJ, Fahey III, TJ, Zentella A, Albert JD, Shires GT, Cerami A. 1986. Shock and tissue injury induced by recombinant human cachectin. Science 234:470 .

34. Girardin E, Grau GE, Dayer J-M, Rowx-Lombard P, Lambert P-H. 1988. Tumor necrosis factor and interleukin- 1 in the serum of children with sewere infectious purpura. N Engl J Med 319:397.

35. Debets JMH, Kampmeijer $R$, van der Linden MPMH, Buurman WA, van der Linden CJ. 1989. Plasma tumor necrosis factor and mortality in critically ill septic patients. Crit Care Med, in press.

36. The veterans administration systemic sepsis cooperative study group. 1987. Effect of high-dose glucocorticoid therapy on mortality in patients with clinical signs of systemic sepsis. N Engl J Med 317:659.

37. Sprung CL, Caralis PV, Marcial EH, Pierce M, Gelbard MA, Long WM, Duncan RC, Tendler MD, Karpf M. 1984. The effects of high-dose corticosteroids in patients with septic shock. N Engl J Med 311:1137.

38. Bone $\mathrm{RC}_{n}$ Fisher CJ, Clemmer TP, Slotman GJ, Metz CA, and Balk RA. 1987. Controlled clinical trial of high-dose methylprednisolone in the treatment of severe sepsis and septic shock. $\mathrm{N}$ Engl J Med 317:653.

39. Stashenko P, DeWhirst FE, Peros WJ, Kent RL, Ago JM. 1987. Synergistic interactions between interleukin $\mathbb{1}$, tumor necrosis factor, and lymphotoxin in bone resorption. Jl Immunol 138:1464.

40. Saxne T, Palladino MA, Jr, Heinegard D, Talal N, Wollheim FA. 1988. Detection of tumor necrosis factor $\alpha$ but not tumor necrosis factor $\beta$ in rheumatoid arthritis synovial fluid and serum. Arthr Rheum 31:1041. 


\title{
EVIDENCE OF INVOLVEMENT OF TUMOR NECROSIS FACTOR
}

\author{
IN ADVERSE REACTIONS DURING TREATMENT OF KIDNEY
}

ALLOGRAFT REJECTION WITH ANTITHYMOCYTE GLOBULIN

\author{
Debets, J.M.H., K.M.L. Leunissen, H.J. van Hooff, C.J. van der \\ Linden, and W.A. Buurman. Transplantation, 1989;47:487.
}

\section{SUMMARY}

Serial plasma concentrations of the pyrogenic cytokines tumor necrosis factor (TNF) and interleukin- $1 \beta(\mathbb{L L}-1 \beta)$ were measured during treatment of acute renal allograft rejection with antithymocyte globulin (ATG) in 7 consecutive kidney transplant recipients. TNF and IL- $1 \beta$ were measured with specific enzyme-linked immunosorbent assays. In 6 of 7 patients TNF could not be detected in the plasma before the start of the ATG infusion. During the first ATG infusion, which was accompanied by fever and other side effects in all patients, plasma TNF levels were shown to be elevated, ranging between 100 and $700 \mathrm{pg} / \mathrm{ml}$. During the second ATG infusion, when side effects were minimal or absent, plasma TNF levels were only slightly raised. Circulating IL- $1 \beta$ could not be detected in any of the patients before or during ATG infusion. Additional experiments showed that TNF is rapidly secreted in cultures of peripheral blood mononuclear cells incubated with both ATG and the monoclonal antibody OKT3. These findings suggest that side effects, including fever and chills, during antilymphocyte antibody infusion are related to increased plasma levels of the pyrogenic cytokine TNF.

\section{INTRODUCTION}

A very effective treatment of acute kidney allograft rejection consists of intravenous administration of polyclonal rabbit or horse antilymphocyte antibodies (ALG) $(1,2)$. More recently monoclonal anti-T cell antibodies like OKT3 are also used for this purpose $(3,4)$. The application of both polyclonal and monoclonal antilymphocyte antibody therapy is in many cases severely hindered by the occurrence of serious side effects rendering it necessary to temporarily discontinue the antibody infusion. Side 
effects include fever and chills, arthralgias, lumbar pain, nausea and vomiting, bypertension, tachycardia angina pectoris, dyspnea caused by bronchospasm, and pulmonary edema (4-8). The application of ALG therapy can therefore be problematic in patients with concomitant pulmonary or cardiac disease.

The release of cytokines originating from lymphocytes lysed as a result of antibody infusion has been suggested to cause these side effects (3). Since fever and chills are such prominent symptoms seen in patients treated with antilymphocyte antibodies, we investigated whether plasma concentrations of the cytokines tumor necrosis factor/cachectin and interleukin-1 1 (IL $-1 \beta$ ), which are known from animal experiments to possess strong pyrogenic activity (9), are elevated during treatment of kidney allograft rejection with antithymocyte globulin (ATG). Also, results of in vitro experiments elucidating the mechanism and cell source of ATG-induced TNF release are shown.

\section{MATERIALS AND METHODS}

Informed consent was obtained from sewen consecutive kidney transplant recipients, treated for acute allograft rejection with antithymocyte globu in (ATG, Rijksinstituut voor de Volksgezondheid, Bilthoven, The Netherlands) to take serial blood samples for measurement of plasma cytokine concentration during ATG treatment.

ATG treatment consisted of intrawenous administration of 100-300 mg ATG together with $50 \mathrm{mg}$ prednisolone in $500 \mathrm{ml}$ saline, infused ower a $6 \mathrm{hr}$ period. All patients received $4 \mathrm{mg}$ of the antihistaminicum chlorepheniraninemaleate orally $1 / 2 \mathrm{hr}$ before start of the infusion. EDTA-anticoagulated $5 \mathrm{ml}$ blood samples were drawn from an intravenous line inserted in the arm opposite the one in which ATG was infused. Samples were obtained at hourly intervals during the period of ATG infusion and once at a point after the end of ATG infusion when side effects, including fever, had completely disappeared. Blood samples were immediately centrifuged and aliquots of plasma were stored at $-70^{\circ} \mathrm{C}$ for measurement of cytokine concentration. During treatment the patient's temperature and blood pressure were monitored and the occurrence of side effects was registrated. Basic immunosuppression, which consisted of cyclosporine and low-dose prednisolone, was maintained during the study.

Enzyme-linked immunosorbent assay for TNF. Plasma TNF concentrations were determined with a TNF-specific ELISA, as described elsewhere (10). Flat-bottomed microtiter plates (Nunc, Roskilde, Denmark) were coated overnight at $4^{\circ} \mathrm{C}$ with the monoclonal anti-TNF antibody $61 \mathrm{E} 71$ at a concentration of $5 \mu \mathrm{g} \mathrm{lg} / \mathrm{mll}$. Plates were blocked with 1\% BSA in PBS for $1 \mathrm{hr}$ at room temperature. Plasma samples were added to the plates in duplicate and incubated for $1 \mathrm{hr}$ at room temperature. A standard titration curve was obtained by making serial dilutions of a known sample of recombinant TNF (rTNF; Celltech, Slough, UK) in EDTA-anticoagulated normal human plasna. After washing the plates four times, the amown of TNF bound to the wells was quantiated by sequential incubation with rabbit anti-human TNF immune serum and a peroxidase-conjugated goat anti-rabbil antibody (Jackson, West Grove, PA, USA; antibody not crossreactive with human serum proteins), followed by adding substrate to the wells and measurement of extinction at $495 \mathrm{~nm}$ with a microELISA autoreader. TNF-specific walnes were obtained by subtracting background extinctions due to nom-TNF plasmat proteins crossreacting in the ELISA, measured in the absence of either the monoclonal anti-TNF antibody coated on the bottom of the microtiter plate or the second, rabbit anti-TNF antibody. The lower detection limit of the ELISA was 5-10 $\mathrm{pg} / \mathrm{ml}$ in plasina. Plasma samples of a large group $(\mathrm{n}=60)$ of healthy volunteers were shown to be negative for "TNF (i.e. less than $5 \mathrm{pg} / \mathrm{ml}$ ) as determined with our assay. Plasma samples of patients were measured in duplicate and duplicate values always differed less than $10 \%$.

Interleukin-1 $\beta$ ELISA. Plasma levels of the endogenous pyrogen interleukin-1 $\beta$ (IL-1 $\beta$ ) were measured in duplicate with a commercially available IL- $1 \beta$ ELISA (kindly provided by Cistron, Pine Brook, NJ, USA). The ELISA proved to thave a lower detection limit of $200 \mathrm{pg} / \mathrm{ml}$ IL- $1 \beta$ in plasma. 
In vitro experiments. Peripheral blood mononuclear cells (PBMC) were prepared by buoyant density centrifugation on Lymphoprep (Nycomed, Oslo, Norway) of buffy coats of donor blood kindly provided by the local Blood Bank. PBMC were cultured in RPMI 1640 (Gibco, Paisley, UK) supplemented with $10 \%$ heat-inactivated $\left(56^{\circ} \mathrm{C}, 20\right.$ min) fetal calf serum (Boehringer, Mannheim, FRG) and $100 \mathrm{rU} / \mathrm{mll}$ penicillin and $100 \mu \mathrm{g} / \mathrm{ml}$ streptomycin (Flow, Irvine, UK). In each well of a 24 well plate (Greiner, Nürtingen, FRG) $2.5 \times 10^{6} \mathrm{PBMC}$ were cultured in $600 \mu 1$ culture medium. To these cultures various concentrations of ATG (for this study kindly provided by Dr. H. Kreeftenberg, Rijksinstituut voor de Volksgezondheid, Bilthoven, The Netherlands) and of the anti-CD3 monoclonal antibody OKT3 (ascites derived from an OKT3-secreting hybridoma, obtained from the ATCC, Rockville, MD, USA) were added and at different times samples of cell-free supernatant were harvested for measurement of TNF concentration. Lymphocyte proliferation was determined by measuring the incorporation of $\left[{ }^{3} \mathrm{H}\right]-$-thymidine. For this purpose $\left.0.5 \mu \mathrm{Ci}]^{3} \mathrm{H}\right]$-thymidine (Amersham, $\mathrm{UK}_{;}$specific activity $5.0 \mathrm{Ci} / \mathrm{mmol}$ ) was added to a sample of $100 \mu$ of the cell cultures transferred into round-bottomed microtiter plates (Greiner) and after a 4-hr culture period the radioactivity incorporated in the cells was measured with a liquid scintillation counter.

\section{RESULTS}

\section{Case reports}

Case 1. A 43-year-old man had had insulin-dependent diabetes mellitus for 27 years, which had led to renal insufficiency. Other long-term effects of diabetes in this patient were blindness due to diabetic retinopathy, hypertension, and intermittent claudication. On June 23, 1987 , he received a cadaver donor kidney graft. After transplantation diuresis gradually increased and renal function improved. On the 18 th postoperative day acute graft rejection was diagnosed on the basis of decreased urinary output, creatinine clearance, and graft perfusion. ATG treatment was started with the intravenous administration of $200 \mathrm{mg}$ ATG and $50 \mathrm{mg}$ prednisolone. Figure 1 shows the time curve of plasma TNF concentrations and body temperature during the first ATG infusion. Plasma TNF was detectable 1 hr after the start of the infusion. Plasma TNF rose to a peak level of $593 \mathrm{pg} / \mathrm{ml}$ at $3 \mathrm{hr}$ and returned to a nondetectable level at $6 \mathrm{hr}$ after start of the infusion. Body temperature rose to 39.4 oC $3 \mathrm{hr}$ after TNF was detectable in the plasma. There was no significant change in systolic blood pressure, while diastolic blood pressure fell slightly during the period of peak TNF levels. ATG infusion was accompanied by chills, headache, diarrhea, and general malaise, which made it necessary to interrupt the infusion once. The patient received daily infusions of ATG for 16 days. Urinary output gradually increased, accompanied by a decline of serum creatinine from 717 to $323 \mu \mathrm{mol} / \mathrm{L}$. After the ATG treatment immunosuppression was maintained with cyclosporine and low-dose prednisolone, and the patient was discharged from the hospital with a satisfactorily functioning renal allograft.

Case 2. This patient, a 54-year-old woman, had terminal renal insufficiency due to chronic pyelonephritis, that had required hemodialysis since March 1986. She also had hypertension, chronic bronchitis, polyneuropathy, and renal osteodystrophy. She received a cadaver donor kidney graft on June 13, 1987. Initially diuresis slowly increased, accompanied by a decrease in plasma creatinine from 1191 to $388 \mu \mathrm{mol} / \mathrm{L}$, but on July 11 creatinine clearance diminished and histological examination of a renal biopsy showed interstitial rejection. The patient was treated with daily infusions of 


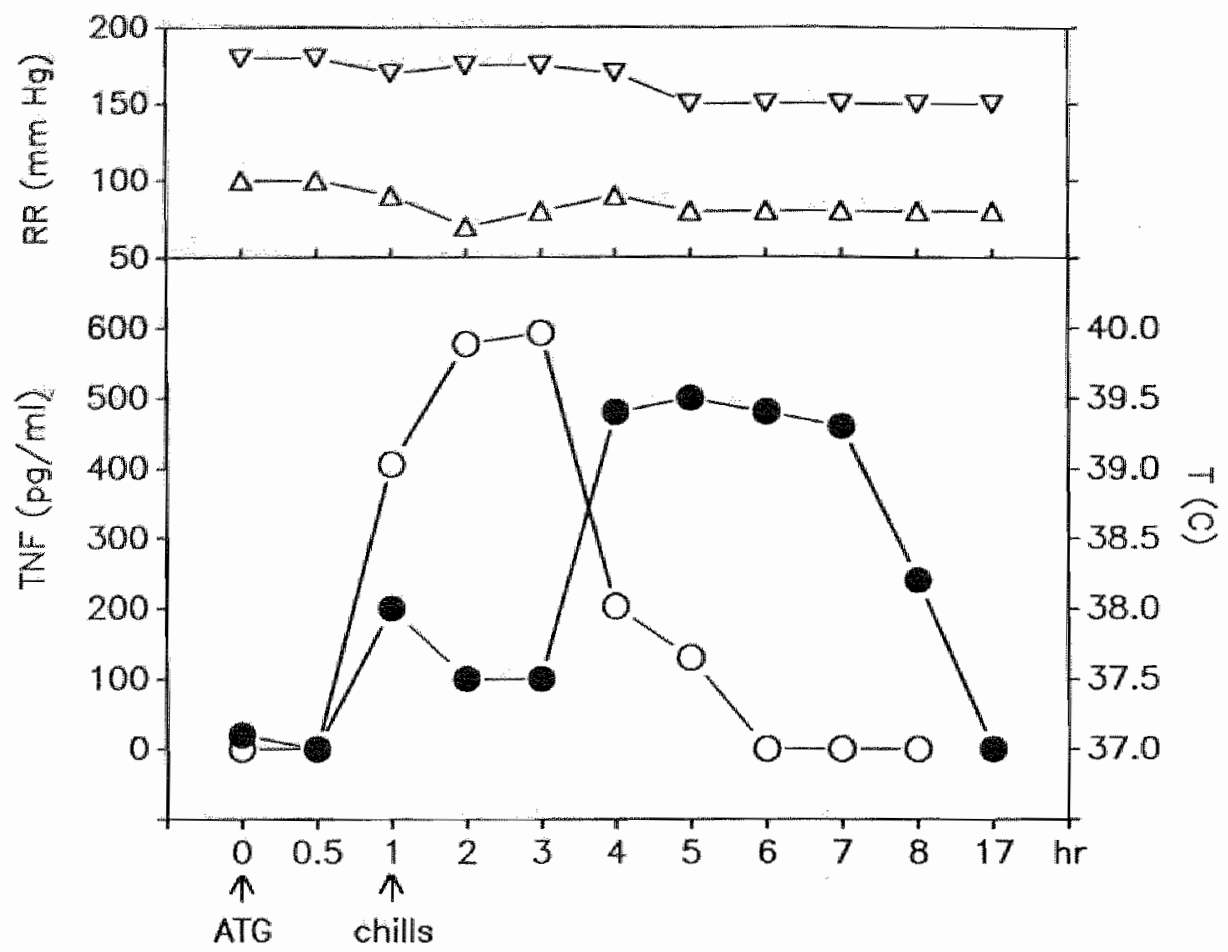

Figure 1. Plasma TNF concentrations, body temperature, and blood pressure in case 1 during the first ATG infusion. Time scale marks hours after start of the ATG infusion. Plasma TNF concentrations are indicated by open circles, body temperature is indicated by closed circles. Systolic and diastolic blood pressures are indicated by downward pointing and upward pointing triangles, respectively.

ATG for 10 days. Figure 2 shows the time curve of plasma TNF levels and body temperature of this patient during the first ATG infusion. In this patient TNF rose to a maximal level of $731 \mathrm{pg} / \mathrm{ml} 3 \mathrm{hr}$ after the start of the infusion, accompanied by a rise in body temperature to $40.4^{\circ} \mathrm{C} 1 \mathrm{hr}$ later. There was a rise in both systolic and diastolic blood pressure during the first few hours of ATG infusion. Side effects observed in this patient were severe dyspnea, which made it necessary to discontinue the ATG infusion twice, chills, headache, and general malaise. The ATG therapy was effective in reversing acute graft rejection. Urinary output increased and serum creatinine fell from 501 to $274 \mu \mathrm{mol} / \mathrm{L}$ in the course of 4 weeks, after which the patient was discharged from the hospital. Immunosuppression was maintained with cyclosporine and low-dose predniisolone.

\section{Plasma levels of TNF and IL- $1 \beta$ in patients treated with ATG.}

Using an assay with a lower detection limit of $200 \mathrm{pg} / \mathrm{ml}$ we could not detect circulating $\mathrm{IL}-1 \beta$ in any of the patients before or during ATG treatment. It remains, however, possible that IL-1 $\beta$ at levels lower than $200 \mathrm{pg} / \mathrm{mll}$ was present in these 


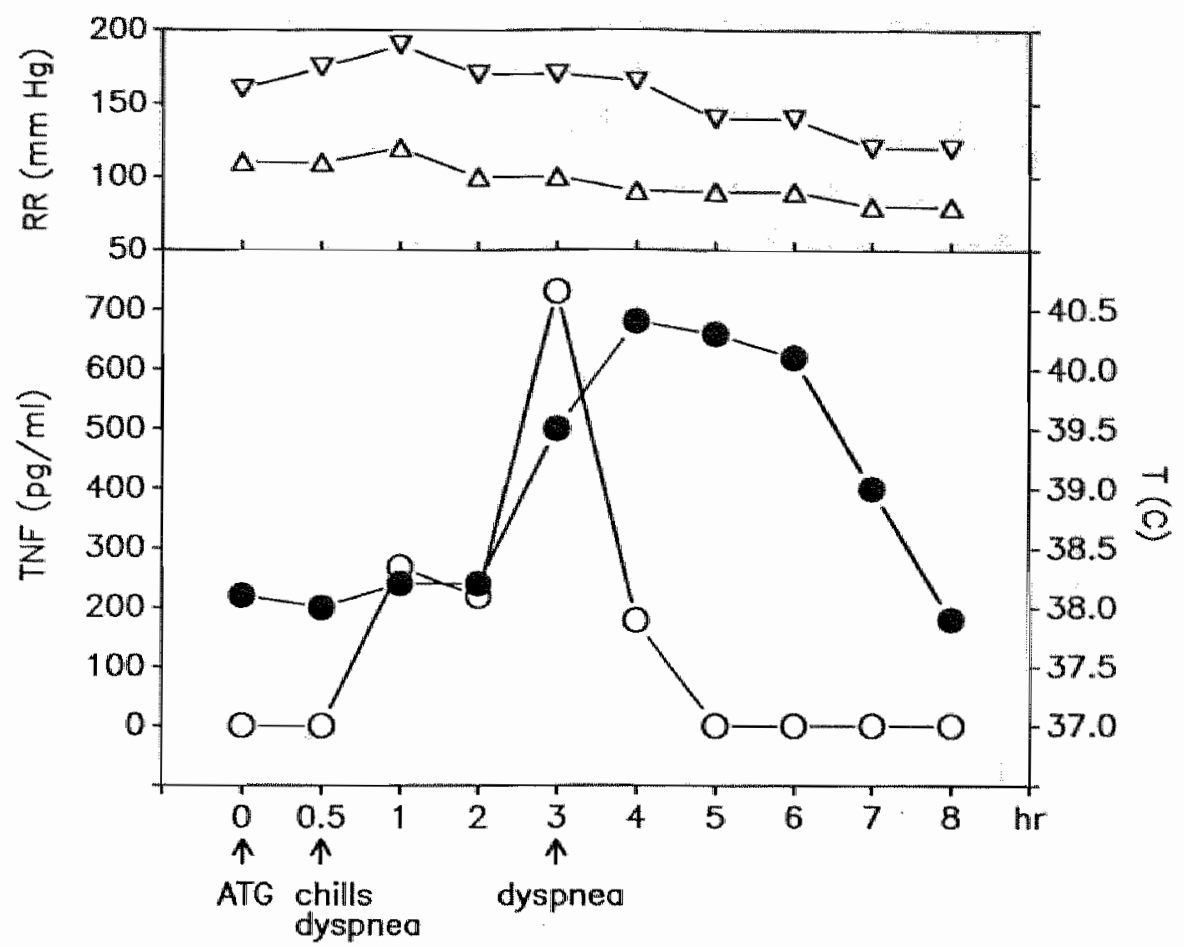

Figure 2. Plasma TNF concentrations, body temperature, and blood pressure in case 2 during the first ATG infusion. Symbols as in Figure 1.

patients, contributing to the fever and other side effects observed. In 6 of 7 patients pretreatment plasma TNF concentrations were below the detection limit of 5-10 $\mathrm{pg} / \mathrm{ml}$. In these patients TNF could be detected in the plasma approximately $1 \mathrm{hr}$ after the start of the ATG infusion. Peak levels of TNF, ranging between 111 and $731 \mathrm{pg} / \mathrm{ml}$, were reached after a $2-3 \mathrm{hr}$ infusion period. Plasma TNF returned to an undetectable level at about $6 \mathrm{hr}$ after the beginning of therapy. In only one patient (patient 2) was the plasma TNF concentration elevated before ATG was given (i.e. $132 \mathrm{pg} / \mathrm{ml}$ ). In this patient plasma TNF rose to $179 \mathrm{pg} / \mathrm{ml}$ during ATG infusion and returned to a value of $112 \mathrm{pg} / \mathrm{ml}$ at the end of the infusion. All patients developed a rise in body temperature shortly after plasma TNF had reached peak values. Body temperature normalized on the average $4 \mathrm{hr}$ after TNF disappeared from the circulation. In most of the patients a slight rise in blood pressure accompanied by an increased heart rate was observed during the ATG infusion. All patients experienced mild-to-severe side effects, which coincided in time with the period of elevated plasma TNF levels, and which made it necessary to temporarily discontinue the ATG infusion in several patients. In all patients symptoms waned shortly after plasma TNF had returned to normal. All 
TABLE I. Plasma TNF concentrations and clinical data of ATG-treated patients

\begin{tabular}{|c|c|c|c|c|c|c|}
\hline $\begin{array}{l}\text { Patient } \\
\text { (sex, age [years] }\end{array}$ & $\begin{array}{l}\text { Treatment } \\
\text { 3) day }\end{array}$ & $\begin{array}{l}\text { ATG } \\
(\mathrm{mg})\end{array}$ & $\begin{array}{c}\text { Highest } \\
\text { TNFconc. } \\
\text { (pg/ml) }\end{array}$ & $\begin{array}{l}\text { Highest } \\
\text { temp }(\mathrm{C})\end{array}$ & $\begin{array}{c}\mathrm{RR}^{*} \\
(\mathrm{~mm} \mathrm{Hg})\end{array}$ & Side effects \\
\hline \multirow[t]{2}{*}{ 1. $(\mathrm{M}, 33)$} & 1 & 300 & 560 & 39.4 & $+50 /+5$ & Chills, vomiting \\
\hline & 2 & 200 & 55 & 37.9 & $0 / 0$ & None \\
\hline $2 .(F, 54)$ & 1 & 100 & 179 & 39.5 & $+10 / 0$ & Chills, dyspnea \\
\hline \multirow[t]{2}{*}{ 3. $(\mathrm{F}, 35)$} & 1 & 200 & 111 & 39.0 & $+5 i+5$ & Chills \\
\hline & 2 & 200 & 24 & 38.0 & $0 / 0$ & None \\
\hline \multirow[t]{2}{*}{ 4. $(M, 49)$} & 1 & 200 & 125 & 38.4 & $-30 /-20$ & Chills, dyspmea, vomiting \\
\hline & 2 & 200 & 11 & 37.2 & $0 / 0$ & None \\
\hline 5. $(\mathbf{F}, 61)$ & 1 & 200 & 138 & 38.2 & $+15 / 0$ & None \\
\hline \multirow[t]{2}{*}{ 6. $(F, 54)$} & 1 & 200 & 731 & 40.4 & $+10 /-10$ & Chills, dyspnea, headache \\
\hline & 2 & 100 & 0 & 37.4 & $0 / 0$ & None \\
\hline 7. $(\mathrm{M}, 43)$ & 1 & 200 & 593 & 39.5 & $+15 t-10$ & Chills, diarrhea, headache \\
\hline
\end{tabular}

*Expressed as difference between systolic and diastolic blood pressure measured before start of the ATG infusion and at the time of the highest plasma TNF concentration.

patients experienced a feeling of great fatigue at the end of the therapy. Table I gives the clinical data of all 7 patients. Only the first ATG infusion was accompanied by a sharp rise in plasma TNF level as well as by significant side effects. During the second ATG infusion, when side effects were considerably less, maximum TNF levels were much lower, i.e. between 0 and $55 \mathrm{pg} / \mathrm{ml}$. Second-day plasma samples were not available from three patients.

\section{Anti-T cell antibodies induce TNF production by peripheral blood mononuelear cells in vitro.}

Both OKT3 and ATG, when added for $6 \mathrm{hr}$ to cultures of PBMC, induced the secretion of TNF in a dose-related manner (Fig. 3). OKT3, which is a T cell mitogen, also induced T lymphocyte proliferation (Fig. 3A). ATG however did not induce T cell proliferation, indicating that proliferation of $T$ lymphocytes is not a necessary prerequisite for TNF production in these cultures (Fig. 3B).

The kinetics of the ATG- and OKT3-induced release of TNF by PBMC was compatible with the rapid release of TNF in the circulation of the ATG-treated patients. Figure 4 shows that TNF concentration in the cell-free supernatant of these cultures rose rapidly after addition of ATG and OKT3 to the cultures, starting after about $2 \mathrm{hr}$. TNF concentration reached a plateau after a 5-6-hr culture period. 

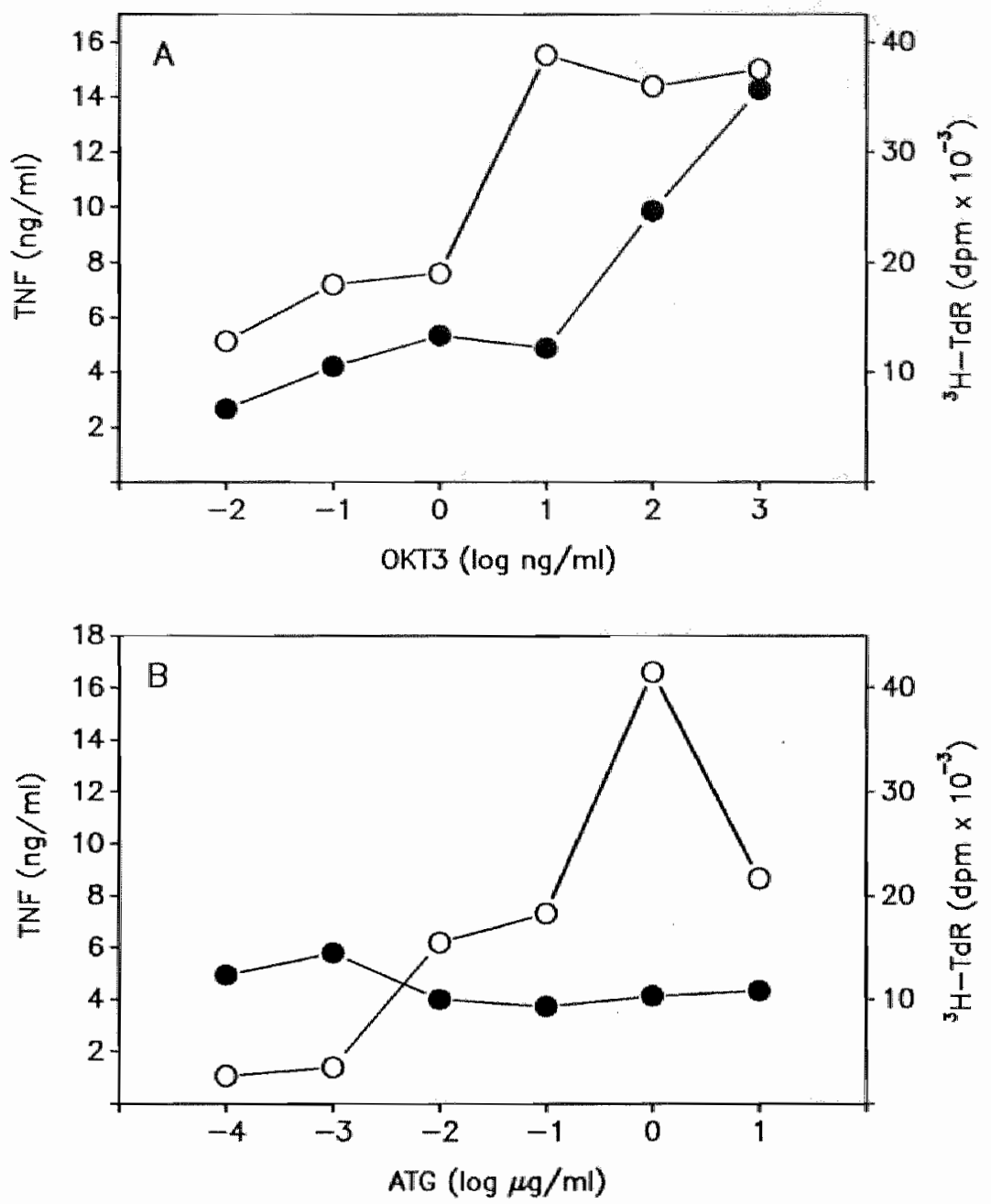

Figure 3. OKT3-induced (A) and ATG-induced (B) "TNF secretion and cell prolliferation in cultures of PBMC. TNF secretion and lymphocyte prolliferation by PBMC after incubation with different concentrations of OKT3 or ATG were determined as described in the Methodis section. Open circles denote TNF concentration in the supernatant after a 6-hr incubation period. Closed circles denote lymphocyte proliferation measured after a 3-day culture period. Data points represent means of triplicate determinations.

\section{DISCUSSION}

The treatment of acute rejection episodes, which occur in $40-60 \%$ of kidney allograft recipients despite immunosuppression with cyclosporine (11), has improved 


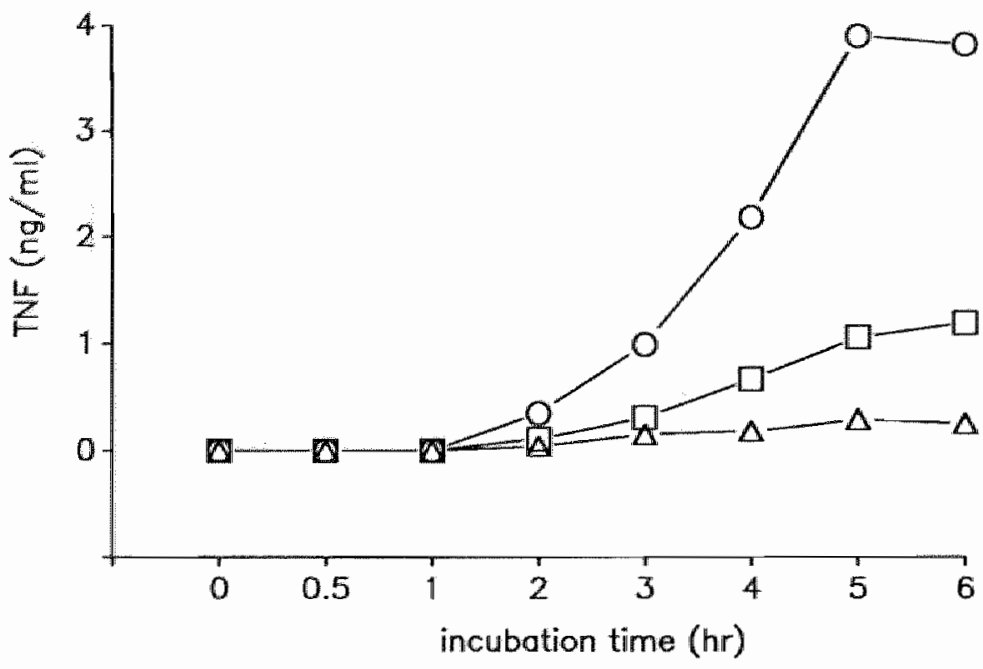

Figure 4. Kinetics of OKT3- and ATG-induced TNF secretion by PBMC. PBMC were incubated with 10 $\mathrm{ng} / \mathrm{ml}$ OKT3 (circles), $1 \mu \mathrm{g} / \mathrm{ml}$ ATG (squares) or culture medium alone (triangles), and after various incubation periods TNF concentration in the supernatant was determined. Data points represent means of triplicate deternanations.

significantly since the advent of antilymphocyte antibody therapy. A one-year graft survival rate of $78 \%$ has been reported for patients treated for acute graft rejection with rabbit antithymocyte globulin (5).

This report shows that treatment of acute graft rejection in kidney transplant recipients with intravenous administration of antilymphocyte antibodies leads to high plasma concentrations of the cytokine TNF, ranging between 100 and $700 \mathrm{pg} / \mathrm{ml}$, during antibody infusion. TNF plasma concentration starts to rise between $30 \mathrm{~min}$ and $1 \mathrm{hr}$ after the start of the ATG infusion, reaches peak levels after $3 \mathrm{hr}$, and declines to nondetectable levels in the course of the following hours, while ATG is still being infused. This indicates that TNF is released as a burst, triggered by the infused ATG. Preliminary data show that infusion of the monoclonal anti-T cell antibody OKT3 into humans also leads to raised plasma TNF levels (data not shown).

Since TNF can induce the production of another group of important endogenous pyrogens, IL-1 (9), we also measured IL-1 levels. On the basis of different isoelectric focusing patterns two forms of IL-1 are distinguished, $\mathrm{IL}-1 \alpha$ and $\mathrm{IL}-1 \beta$, which have very similar biological effects. We measured IL-1 $\beta$ levels in our patients because of the availability of an IL- $1 \beta$ immunoassay. We were not able to detect $I L-1 \beta$ in the plasma of any of the patients before or during ATG treatment. It remains however possible, considering the detection limit of the IL- $1 \beta$ immunoassay, that levels of IL- $1 \beta$ lower than $200 \mathrm{pg} / \mathrm{ml}$ were present in the patients, contributing to the fever and other systemic reactions observed in these patients.

The majority of patients, 6 of 7 , had no detectable TNF plasma levels before start of the ATG treatment. In only one patient (patient 2), who at that time had no fever, was 
the pretreatment plasma TNF level elevated $(132 \mathrm{pg} / \mathrm{ml})$. In this patient there was only a slight rise in plasma TNF level to $179 \mathrm{pg} / \mathrm{ml}$ during the ATG infusion; nevertheless it was accompanied by fever, chills, and dyspnea. Others, however, detected elevated serum TNF levels in the majority of kidney transplant recipients during acute rejection episodes (12). These different findings might be due to differences in the severity of kidney allograft rejection or to differences in the time during allograft rejection when plasma or serum samples for measurement of TNF levels were obtained.

The occurrence of systemic reactions to the ATG infusion correlates with the period of elevated plasma TNF levels, which suggests that side effects are related to or even caused by raised plasma TNF levels. This is further substantiated by data from phase I studies of human recombinant TNF in the treatment of cancer, which show that side effects observed in patients treated with recombinant TNF are remarkably similar to those seen in patients receiving ALG for treatment of graft rejection. Side effects observed in both patient groups include fever, chills, nausea, vomiting, diarrhea, arthralgias, headaches, and fatigue $(13,14)$.

TNF is a cytokine with cytotoxic and immunoregulatory properties (15), that is primarily produced by activated monocytes and macrophages $(16,17)$, but also, as has recently been shown, by activated $T$ lymphocytes (18). The appearance of TNF in the circulation of patients treated with ATG is possibly due to partly complement-mediated intravascular lysis of activated $\mathrm{T}$ lymphocytes. Monocytes and macrophages are known to secrete inflammatory mediators after opsonization of antibody-coated cells (19). We have recently demonstrated that TNF is also secreted by human monocytes after Fc-receptor cross-linking occurring during opsonization and phagocytosis of antibody-coated sheep erythrocytes (20). It is therefore conceivable that in the process of opsonization of ATG-coated lymphocytes TNF is released by circulating monocytes. Our in vitro experiments support the latter hypothesis. In these experiments TNF is rapidly secreted by peripheral blood monomuclear cells after incubation with ATG and OKT3 without complement-mediated lysis of $\mathrm{T}$ lymphocytes, since the experiments were performed in the presence of decomplemented serum. Since activated Tlymphocytes have been shown to produce TNF (18), we cannot rule out that in the case of OKT3 TNF is, at least in part, produced by activated $T$ lymphocytes.

TNF has recently been implicated as a host mediator responsible for shock and tissue damage induced by endotoxin in the course of septic shock. Evidence supporting this hypothesis has primarily come from animal experiments (21). Milce passively immunized against murine TNF were shown to be largely resistant to a lethal dose of endotoxin (22), whereas baboons could be protected from the lethal effects of intravenous injection of live bacteria by prior administration of anti-human TNF antibodies (23). Recently also clinical data have been published that assign an important role to TNF in the pathogenesis of septic shock in man (24). Circulating TNF has been demonstrated in healthy volunteers after injection of endotoxin (25). Our data show that patients can tolerate high levels of endogenously produced TNF without the occurrence of hypotension or shock, indicating that in sepsis other mediators besides TNF probably are involved in the pathogenesis of shock. 
Besides its role in sepsis TNF possibly contributes to the host defence mechanisms against cancer. Its value as an anti-cancer drug is currently being investigated $(13,14)$. Interestingly, TNF-like factors have been discovered in the serum of cancer patients (24).

In conelusion, the data from this study indicate that systemic reactions accompanying treatment of kidney allograft rejection with antilymphocyte antibodies are related to high circulating levels of TNF, although a contribution by other (pyrogenic) endogenous mediators like IL-1, IL-6, lymphotoxin, and IFN- $\alpha$ cannot be excluded.

\section{REFERENCES}

1. Lewey RH, Parkman R. 1977. Whole antilymphocyte serum: a potent safe immunosuppressive agent for intravenous use in man. Transplant Proc 9:1019.

2. Cosimi AB. 1981. The clinical value of antilymphocyte antibodies. Transplant Proc 13:462.

3. Goldstein G, Schindler J, Sheahan M, Barnes L, Tsai H. 1985. Orthoclone OKT3 treatment of acute renal allograft rejection. Transplant Proc 17:129.

4. Goldstein G. 1986. An overview of Orthoclone OKT3. Transplant Proc 18:927.

5. Hoiltma AJ, van Lier HJJ, Reekers. P, Koene RAP. 1985. Improved patient and graft surviwal after treatment of acute rejections of cadaveric renal allografts with rabbit antithymocyte globulin. "Transplantation 39:274.

6. Ortho Multicenter Transplant Study Group. 1985. A randomized clinical trial of OKT3 monoclonal aritibody for acute rejection of cadaveric renal transplants. N Engl J Med 313:337.

7. Ponticelli C, Rivolta E, Tarantino A, et al. 1986. Clinicall experience with Orthoclone OKT3 in renal transplantation. Transplant Proc 18:942.

8. Waymack JP, Penn I, First MR, Alexander JW. 1987. Portal wein gas and sepsis after administration of OKT3. Lancet i:984.

9. Dinarello CA, Cannon JG, Wolff SM, et at. 1986. Tumor necrosis factor (cachectin) is an endogenous pyrogen and induces production of interleukin 1.J Exp Med 163:1433.

10. Debetts IMH, Spronken IEM, van der Linden CJ, Buurman WA. 1988. T cell-mediated production of tumour necrosis factor- $\alpha$ by monocytes. Scand J Immunol 27:601.

11. Klintsualm $G$, Ringden $O$, Growth $C G$. 1984. Clinical and laboratory signs in nephrotoxicity and rejection in cyclosporine-treated renal allograft recipients. In: Kahan BD, ed. Cyclosporine: biological activity and clinical applications. New York: Grune \& Stratton;599.

12. Maury CPJ, Teppo AM, 1987. Raised serum levels of cachectin/tumor necrosis factor in renal allograft rejection. J Exp Med 166:1132.

13. Blick $M_{\text {, Sherwin }}$ SA, Rosenblum M, Gutterman J. 1987. Phase I study of recombimant tumor necrosis factor in cancer patients. Cancer Res 47:2986.

14. Creaven PJ, Plager JE, Dupere $\mathrm{S}$, et al. 1987. Phase I clinical trial of recombinant buman tumor necrosis factor. Cancer Chemother Pharmacol 20:137.

15. Beutler B, Cerami A, 1987. Cachectin: more than a tumor mecrosis factor. N Engl J Med 316:379,

16. Beutler B, Krochin N, Milsark IW, Luedke C, Cerami A. 1986. Control of cachectin (tumor necrosis factor) synithesis: mechanisms of endotoxin resistance. Science 232:977.

17. Kornbluth RS, Edgington TS. 1986. Tumor necrosis factor production by human monocytes is a regulated event: induction of TNF- $\alpha$-mediated cellular cytotoxicity by endotoxin. $J$ lmmunol $137: 2585$.

18. Cuturi MC, Murphy M, Costa-Giomi MP, Weinmann R, Perussia B, Trinchieri G. 1987. Independent regulation of tumor necrosis factor and lymphotoxin production by human peripheral blood lymphocytes. J Exp Med 165:1581.

19. Nathan CF, Murray HW, Cohn ZA. 1980. The macrophage as an effector cell. NEngl I Med 303:622. 
20. Debets JMH, wan der Linden CI, Dieteren IEM, Leeuwenberg JFM, Burrnan WA. 1988. FC-receptor cross-linking induces rapid secretion of tumor necrosis factor (cachectin) by human peripheral blood monocytes. J Immunol 141:1197.

21. Tracey KI, Beutler B, Lowry SF, et al. 1986. Shock and tissue injury induced by recombinant human cachectim. Science $234: 470$.

22. Beutler B, Milsark IW, Cerami AC. 1985. Passiwe immunization against cachectin/tumor necrosis factor protects mice from lethal effect of endotoxin. Science 229:869.

23. Tracey KJ, Fong $Y$, Hesse DG, et al. 1987. Anti-cachectin/TNF monoclonal antibodies prevent septic shock during lethal bacteraemia. Nature 330:662.

24. Waage A, Halstensen A, Espevik T. 1987. Association between tumour necrosis factor in serum and fatal outcome in patients with meningococcal disease. Lancet i:355.

25. Michie HR, Manogue KR, Spriggs. DR, et al. 1988. Detection of circulating tumor necrosis factor after endotoxin administration. N Engl J Med 318:1481.

26. Balkwill F, Burke F, Talbot D, et al. 1987. Evidence for tumour necrosis factor/cachectin production in cancer. Lancet ii: 1229 . 



\title{
PLASMA TUMOR NECROSIS FACTOR AND MORTALITY IN CRITICALLY ILL SEPTIC PATIENTS
}

\author{
Debets, J.M.H., R. Kampmeijer, M.P.M.H. van der Linden, W.A. \\ Buruman, and C.J. van der Linden. Crit. Care Med., in press.
}

\section{SUMMARY}

Tumor necrosis factor/cachectin has been implicated as an important host mediaton responsible for shock and multiple organ failure observed during sepsis. Using a sensitive enzyme-linked immunosorbent assay, we measured plasma TNF levels in 43 septic patients suffering from a broad range of diseases. Measurements were taken on the day that sepsis was diagnosed. Eleven patients had detectable TNF plasma levels ranging from 10 to $100 \mathrm{pg} / \mathrm{ml}$ (TNF-positive group); in 32 patients circulating TNF could not be detected (TNF-negative group). The groups did not differ significantly as to age, underlying disease, percentage positive bacteremia and bacteriologic profile, sepsis score, and extent of MOF. Eight (73\%) of 11 TNF-positive patients died from sepsis during ICU stay, vs. 11 ( $34 \%)$ of $32 \mathrm{TNF}$-negative patients $(\mathrm{p}<.05)$. This study demonstrates that sepsis is accompanied by detectable circulating TNF in $25 \%$ of the cases, and for these patients mortality is twice that for comparable TNF-negative patients.

\section{INTRODUCTION}

In recent years, evidence has accumulated that endogenous mediators play an essential role in the pathogenesis of shock and multiple organ failure (MOF) during sepsis. Circulatory instability during gram-negative bacteremia, originally attributed to circulating endotoxins, is now believed to be caused by cytokines produced by cells of the immune system in response to generalized infection. The cytotoxic and immunoregulatory cytokine tumor necrosis factor (TNF)/cachectin is considered to be one of the prime mediators of the host response to endotoxin involved in the pathophysiology of sepsis (1). Although knowledge on TNF as an inflammatory and immunoregulatory mediator has been gained from experimental studies (2), clinical data on TNF are still scarce. 
We investigated the role of TNF in human sepsis by measuring plasma TNF levels in a series of septic lCU patients using a sensitive enzyme-linked immunosorbent assay (ELISA) developed in our laboratory. Plasma samples were drawn whenewer a severe septic episode occurred. Patients were allocated to TNF-positive or TNF-negative groups depending on whether or not circulating TNF was detectable at the time of sepsis. Both groups were compared as to the underlying disease, presence of bacteremia, severity of sepsis, and severity of MOF. We report a positive correlation between circulating TNF and mortality in septic patients suffering from a diverse range of diseases.

\section{PATIENTS AND METHODS}

Patients. Forty-three patients ( 32 men and 11 women, age 19 to 94 years) admitted to the ICU of Maastricht University Hospital during a 10 -month period were studied. All patients, suffering from a wide range of diseases, underwent a septic episode during their ICU stay. Sepsis was diagnosed when one or more of the following criteria were met: fever $>38^{\circ} \mathrm{C}$ with 1) a drop in systolic BP $>30 \mathrm{~mm} \mathrm{Hg}, 2$ ) urine output $<20 \mathrm{ml} / \mathrm{hr}$ during more than $2 \mathrm{hr}$, 3) platelet count $<100 \times 10^{6} / \mathrm{ml}$, 4) plasma bicarbonate $<15$ mmol/l. On the day that sepsis was diagnosed, one blood sample was collected from each patient for measurement of plasma TNF level. These blood samples were always collected together with the first daily round of routine blood sampling at approximately 8 AM. Five-milliliter EDTA-anticoagulated blood samples were obtained and centrifuged for $5 \mathrm{~min}$ at $3000 \mathrm{rpm}$. Plasma was stored in divided aliquots at $-70^{\circ} \mathrm{C}$ for measurement of TNF concentration at a later date.

Patients were divided into two groups: patients in whom TNF could be detected in the plasma at the time of sepsis (TNF-positive group) and patients in whom circulating TNF could not be detected (TNF-negative group). Both groups were evaluated for age, sex, underlying disease, severity of sepsis, severity of MOF, and presence of bacteremia. All these parameters refer to the patient's condition during the first 24 hr after onset of sepsis.

Severity of sepsis was estimated by the sepsis score developed by Elebute and Stoner (3). This score comprises a simple system for grading the severity of sepsis by scoring the attributes of sepsis under four headings: local effects of infection, which is the major determinant of the score, pyrexia, secondary effects of sepsis, and laboratory data. Each attribute is scored with $0,1,2$, or 3 points (except for the local effects of infection, which are scored double) and the sum of all the scores gives an aggregate criterion representing the total effect of the septic state on the patient.

Extent of MOF was determined by measuring mean blood pressure (BP) and a series of laboratory parameters cstimating basic organ function. Pulmonary function of patients receiving ventilatory support was evaluated by measuring arerial oxygen tension divided by fractional $\mathrm{O}_{2}$ content of the inspired air $\left(\mathrm{PaO}_{2} / \mathrm{FIO}_{2}\right)_{;}$liver function was cstimated by SGPT, SGOT and LDH; renal function was estimated by serum creatinine, and extent of disseminated intravascular coagulation was evaluated by platelet count and presence of fibrinogen degradation products (FDP). All these parameters represent optimal values obtained daring $24 \mathrm{hr}$ of intensive treatment after the onset of sepsis, thereby indicating both severity of disease and the patient's response to therapy.

Enzyme-linked lmmunosorbent Assay (ELISA) for TNF. Plasma TNF concentrations were determined with a modified TNF-specific ELISA, which is described elsewhere (4). In short, patient plasma samples were added onto 96 -well immunoassay plates coated overnight with $0.5 \% \mathrm{~g} /$ well of the monoclonal anti-TNF antibody $61 \mathrm{E} 71$. Before adding test samples, the plates were blocked with $1 \%$ bovine serum albumin (BSA) in phosphate buffered saline (PBS) for $1 \mathrm{hr}$ at room temperature. A standard titration curve was obtained by making serial dilutions of a known sample of human recombinant TNF (kindly provided by Cellted, Slough, UK) in normal human plasma. The amount of TNF bound to the wells was quantified by sequential incubation with a 1:2000 dilution of rabbit anti-TNF immune serum and a 1:1000 dilution of peroxidase-conjugated goat anti-rabbit antibody (Jackson, West Grove, PA; antibody not 
crossreactive with human serum proteins), followed by adding substrate (OPD; Sigma, St. Lauis, MO) to the wells. The color reaction was stopped with $1.0 \mathrm{M}^{\mathrm{H}} \mathrm{H}_{2} \mathrm{SO}_{4}$, after which extinction at $495 \mathrm{~nm}$ wis measured with a microelisa autoreader (Flow, Irvine, UK). TNF-specific values were obtained by subtracting background absorptions due to non-TNF plasma proteins crossreacting in the ELISA, measured in the absence of either the monoclonal anti-TNF antibody coated on the bottom of the ELISA plate or the second, rabbit anti-TNF antibody. The lower detection limit of the ELISA ranged from 5 -10 $\mathrm{pg} / \mathrm{mll}$. Plasma samples of a large group $(\mathrm{n}=60)$ of healthy volunteers were shown to be negative for TNF as determined with our assay.

Statistical analysis. Student's t-test for independent groups and chi-square test without Yates' correction were used lor statistical analysis of the data. Data were considered to be significantly different at the $p<.05$ level.

\section{RESULTS}

Forty-three plasma samples were obtained from the patients on the day sepsis was diagnosed. Eleven patients had detectable plasma TNF levels, ranging from 10 to 100 $\mathrm{pg} / \mathrm{ml}$ (TNF-positive group). In 32 patients, no circulating TNF could be detected (TNF-negative group). Mean ages of TNF-positive and TNF-negative patients (60.7 yr and 61.7 yr respectively) did not differ significantly. Patient characteristics and plasma TNF levels are described for both TNF-positive (Table I) and TNF-negative patients (Table II).

\section{TABLE I. Patient characteristics of TNF-positive patients}

Sex Age Major illness
Culture

bl: H. influenzae

10

sp: Acinetobacter calc.

15

2. $\mathrm{m} 84$ Pneumonia after aortic aneurysm operation

3. $m 67$ Pneumonia and lung carcinoma

4. $\mathrm{m} 79$ Peritonitis after gastric ulcer perforation

5. f 97 Pyelonephritis, pneumonia

6. m 94 Pneumonia

7. f 19 Head injury, pneumonia

8. $\mathrm{f} 48$ SLE, dyspnea, sepsis of unknown origin

9. $\mathrm{m} 68$ Chronic bronchitis, pneumonia

10. $\mathrm{m} 53$ Wound infection and pneumonia after coronary artery surgery

11. m 56 Pelvic abscess after hemicolectomy and aortic aneurysm sp: S. pneumoniae $\quad 9 \quad 45$

bl: S. aureus $\quad 19 \quad 122$

bl: Klebsiella oxytoca $13 \quad 22$

sp: S. aureus $\quad 10 \quad 27$

sp: Acinetobacter calc. $10 \quad 27$

bl: C. albicans, S. aur. $\quad 20 \quad 78$

not available $\quad 11 \quad 30$ sp: C. albicans $\quad 13 \quad 36$

bl: S. aureus $\quad 21 \quad 23$

bl: blood; sp: sputum. 
Sex Age Major illness

1. m 77 Uretercarcinoma, peritonitis after urinary bladder necrosis

2. $f 71$ Femoral fracture, pneumonia

3. m 83 Peripheral vascular occlusion, pneumonia

4. $m 22$ Severe trauma, wound infection

5. f 66 Pelvic abscess, adnexitis, sigmoiditis

6. m 49 Peritonitis, hepatic abscess

7. f 53 Chronic bronchitis, pneumonia

8. in 72 Cholangitis

9. $f \quad 68$ Urinary tract infection

10. m 70 Pneumonia, urinary tract infection

11. m 44 Empyema, pneumonia

12. In 46 Pneumonia after severe trauma

13. f 70 Diabetes mellitus, pneumonia

1.4. $f$ 71 Aspiration pneumonia

15. $m 73$ Pneumonia

16. f 84 Pelvic abscess, coloncarcinoma

17. m 67 Esophageal varices, aspiration pneumonia

18. m 67 Myocardial infarction, fever of unknown origin

19. m 66 Guillain-Barré, pneumonia

20. m 80 Cholecystectomie, pneumonia

21. m 30 Subphrenic abscess after Mason procedure

22. m 22 Autointoxication, pneumonia

23. $\mathrm{m} 72$ Pneumonia

24. im 45 Traumatic splenic rupture

25. m 78 Urinary tract infection

26. m 58 Aspiration pneumonia

27. m 71 Fever after aortic aneurysm

28. m 77 Rectumcarcinoma, peritonitis after low anterior resection

29. m 58 Aortic aneurysm, wound infection, pneumonia

30. m 92 Femoral hernia, pneumonia

31. f 72 Peritonitis after laparotomy

32. m 52 Laryngeal carcinoma, wound infection
Culture

Sepsis score

bl:KJebsiella pneumoniae

15

bl:S.aureus

19

sp:Acinetobacter,E. coli

pus:Acinetobacter,E. coli 16

pus:Morganella morgagnii, $\quad 16$

S. faecalis

b]:gram-negative rods $\quad 10$

bl:S. pneumoniae 11

bl:E. colli $\quad 16$

bl:E. coll 18

sp:H. influenzae 9

ur:E. coli

sp:S. epidermidis $\quad 16$

bl:S. epidermidis, C. alb. $\quad 17$

$\mathrm{sp:S}$. aureus, H. influenzae $\quad 1.8$

sp:E. coli 13

bl:Klebsiella pneum. $\quad 21$

bl:S. epidermidis $\quad 18$

sp:E. coli,Acinetobacter $\quad 17$

$\mathrm{sp}: P$. aeruginosa $\quad 12$

sp:H. inizuenzae $\quad 12$

bl:S. epidermidis $\quad 13$

pus:S. aureus 11

sp:S. pneum.,H. influenz. $\quad 10$

bl:Acinetobacter,S. epiderm. 13

bl:S. epidermidis 23

bl:Klebsiella pneumoniae $\quad 22$

sp:S. hemolyt.,H. influenzae 8

not available 12

bl:S. aureus 23

sp:C. albicans;pus:E. coli $\quad 16$

sp:E. coli 12

bl:S. aureus $\quad 16$

pus:Enterobacter,Bacteroides 11

bl: blood; sp: sputum; ur: urine. 


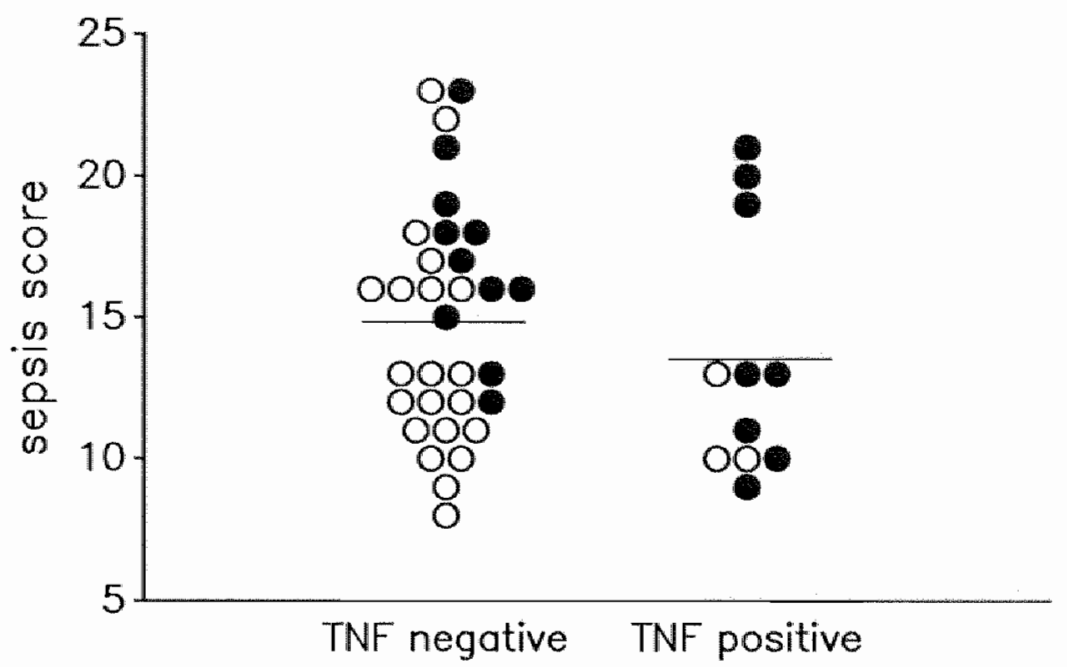

Figure 1. Sepsis score of TNF-negative and TNF-positive patients. Open circles: survivors; closed circles: nonsurwivors.

A significant correlation existed between sepsis score and mortality for the TNF-negative group $(\mathrm{p}<.05)$, as well as for both groups combined $(\mathrm{p}<.05)$ (Fig. 1). The mean. sepsis score was 13.3 for the TNF-positive group and 14.9 for the TNF-negative group $(\mathrm{p}=.18)$.

The severity of organ failure for TNF-positive and TNF-negative patients is outlined in Table III. The parameters given in Table III represent optimal values obtained during a 24-h period after the onset of sepsis, during which each patient was intensively treated. These data, which were always obtained on the same day plasma TNF levels were determined, thereby reflect both severity of disease and the patients' response to therapy. No significant difference was found between both groups for mean BP, pulmonary shunting, liver and kidney function tests, and platelet count. Circulating. FDP were measured in seven TNF-positive and in 21 TNF-negative patients. FDP' were present in six of seven TNF-positive and in 19 of 21 TNF-negative patients.

According to the clinical findings on the day plasma samples were taken, the patients were classified into five disease categories based on the most likely focus of infection causing the sepsis. Twenty-one patients had respiratory tract infection, ten patients peritonitis or pelvic abscess, four urinary tract infection, four wound infection, and of four patients the focus of infection remained unknown. TNF-positive and TNF-negative patients were equally distributed among these categories (Table IV).

Blood cultures obtained on the first day of sepsis from 20 patients were found to be positive: five in the TNF-positive group ( $45 \%$ of TNF-positive patients) and 15 in the TNF-negative group (47\% of TNF-negative patients; $p=.79$ ). The cause of bacteriologically proven sepsis was a Gram-negative microorganism in $44 \%$ of TNF-positive 
TABLE III. Severity of multiple organ failure in TNF-positive and TNF-negative septic patients

\begin{tabular}{lccl}
\hline & $\begin{array}{c}\text { TNF-positive } \\
\text { patients }\end{array}$ & $\begin{array}{c}\text { TNF-negative } \\
\text { patients }\end{array}$ & $\mathrm{p}$ \\
\hline $\mathrm{MBP}(\mathrm{mmHg})$ & 98.3 & 95.9 & 0.31 \\
$\mathrm{PaO} 2 / \mathrm{FIO} 2^{*}(\mathrm{kPa})$ & 34.9 & 27.0 & 0.07 \\
SGPT $(\mathrm{U} / \mathrm{l})$ & 60.6 & 63.7 & 0.46 \\
SGOT $(\mathrm{U} / \mathrm{l})$ & 85.6 & 96.1 & 0.21 \\
LDH $(\mathrm{U} / 1)$ & 768.5 & 896.8 & 0.32 \\
Creatinine $(\mu \mathrm{mol} / \mathrm{l})$ & 134.5 & 177.9 & 0.23 \\
Platelets $\left(10^{6} / \mathrm{ml}\right)$ & 158 & 239 & 0.07 \\
\hline
\end{tabular}

MBP $=$ mean blood pressure

* Seven of 11 TNF-positiwe and 22 of 32 TNF-negative patients received wentilatory support.

TABLEIV. Relation between site of infection, positive blood cultures, and TNF-positive plasma samples in septic patients

\begin{tabular}{|c|c|c|c|c|c|}
\hline Disease category & Total & $\begin{array}{l}\text { Positive } \\
\text { blood culture }\end{array}$ & Survived & Died & $\begin{array}{c}\text { TNF } \\
\text { positive }\end{array}$ \\
\hline Respifatory tract infection & 21 & 8 & 11 & 10 & 6 \\
\hline Peritonitis/pelvic abscess & 10 & 6 & 6 & 4 & 2 \\
\hline Urinary tract infection & 4 & 3 & 3 & 1 & 1 \\
\hline Wound infection & 4 & 1 & 2 & 2 & 1 \\
\hline Unknown focus & 4 & 2 & 2 & 2 & 1 \\
\hline Total & 43 & 20 & 24 & 19 & 11 \\
\hline
\end{tabular}


TABLE V. Relation between plasma TNF and mortality in septic patients

\begin{tabular}{lccc}
\hline & $\begin{array}{c}\text { TNF } \\
\text { positive }\end{array}$ & $\begin{array}{c}\text { TNF } \\
\text { negative }\end{array}$ & Total \\
\hline Patients died & 8 & 11 & 19 \\
Patients survived & 3 & 21 & 24 \\
Total & 11 & 32 & 43 \\
\hline
\end{tabular}

$\mathrm{p}<.05$.

patients and $68 \%$ of TNF-negative patients $(\mathrm{p}=.22)$. Patients received antibiotics at the time plasma samples were taken in $70 \%$ of the cases $(64 \%$ in the TNF-positive group and $72 \%$ in the negative group; $p=.61$ ).

Nineteen patients eventually died from sepsis during ICU stay. Of these, eight patients were in the TNF-positive group and 11 in the TNF-negative group. The mortality rate during the ICU stay was $73 \%$ for the TNF-positive group and $34 \%$ for the TNF-negative group (Table V). This difference was statistically significant $(\mathrm{p}<.05)$

\section{DISCUSSION}

Sepsis is observed frequently in patients admitted to ICU departments, leading to morbidity and mortality. Sepsis can present itself in many different ways, affecting virtually any organ or organ system. Fever, hypotension, cardiorespiratory insufficiency, the adult respiratory distress syndrome, and renal insufficiency are common manifestations of sepsis in man (5).

Sepsis is believed to be caused by several bacterial products, most notably lipopolysaccharides (LPS) derived from the cell wall of Gram-negative microorganisms infecting the host. In recent years, data have accumulated indicating that host derangements observed during sepsis are caused by endogenous mediators produced by cells of the immune system in response to overwhelming infection.

TNF/cachectin is believed to be one of the primary mediators involved in the pathophysiology of sepsis (1). It is produced by monocytes/macrophages in response to LPS, but Gram-positive bacterial products also have been shown to induce TNF production in witro (6). TNF is an endogenous pyrogen, causing fever in experimental animals (7) and in man (8). TNF, when administered at high doses to experimental animals, causes abnormalities indistinguishable from those observed during sepsis (9-11). Moreover, it has been shown that mortality due to experimental sepsis in mice (12) and baboons (13) can be prevented by prior administration of neutralizing antiTNF antibodies, indicating that in these experimental models TNF is a crucial intermediate in the downhill course of sepsis, culminating in shock and death.

In man, raised plasma TNF levels have been found after administration of endotoxin to normal volunteers (14). However, only one study has until now shown that 
raised serum TNF levels negatively affect outcome in septic patients (15). The patients in this study were suffering from meningococcal meningitis complicated with sepsis, a disease entity which is not frequently encountered in general ICU populations.

In the present study, we examined an unselected group of septic patients suffering from a diverse range of diseases underlying the septic state. On the day sepsis was clinically diagnosed, the presence of circulating TNF was determined. On this basis, patients were allocated to TNF-positive or TNF-negative groups. Both groups were comparable with regard to underlying disease, percentage of established bacteremia, bacteriological profile, sepsis score, and extent of MOF. However, the mortality in the TNF-positive group was twice the mortality in the TNF-negative group. Apparently, the presence of TNF at the time of sepsis indicates a decreased chance of survival.

Circulating TNF could be detected in one of four septic patients. This might be due to differences in levels of bacteremia/endotoxemia or, otherwise, to interindividual variation in the biological response to sepsis. Preliminary data from our laboratory indicate that there exists, as previously shown for the cytokine interleukin-1 (16), a great variability in the endotoxin-induced production and secretion of TNF amongst different individuals. Whether this means that TNF-positive patients in our study consist of 'high responders', who therefore are more at risk of developing shock and MOF during sepsis, remains to be clarified. It might also be possible, since a burst-like release of TNF, circulating with a short half-life, has been shown in man after endotoxin administration (14), that the time point at which we obtained blood samples was not always at the peak of TNF release in our patients.

Waage et al. (15), using a TNF bioassay, found in patients suffering from meningococcal meningitis and sepsis TNF plasma values ranging from $3 \mathrm{pg} / \mathrm{ml}$ to $36 \mathrm{ng} / \mathrm{ml}$. TNF levels above $100 \mathrm{pg} / \mathrm{ml}$ were associated with $100 \%$ mortality. TNF levels in our TNF-positive patients were lower, ranging from 10 to $100 \mathrm{pg} / \mathrm{ml}$. This might be due to differences in endotoxin levels, which are known to be very high in meningococcal sepsis. Due to the restricted number of TNF-positive samples, the correlation between plasma TNF concentration and mortality in our patients could not be evaluated.

Data from experimental studies indicate that TNF/cachectin is involved in the etiology of cachexia accompanying infectious and malignant diseases $(17,18)$. Our finding that one of four septic patients had detectable plasma TNF levels suggests that TNF/cachectin may also contribute to the cachexia which is frequently observed in septic ICU patients.

Our data substantiate a correlation between circulating TNF and mortality in septic patients suffering from a broad range of underlying diseases. Further study must establish whether the presence of circulating TNF during sepsis is merely a prognostic sign indicating poor patient survival, or whether TNF plays a pivotal role in the initiation of shock and MOF. In the latter instance, intervention with anti-TNF antibody therapy would offer potential therapeutic opportunities in these patients.

\section{Acknowledgment}

We thank Dr. Hubert Schouten, Department of Medical Statistics, for statistical advice. 


\section{REFERENCES}

1. Beutler B, Cerami A. 1987. The endogenous mediator of endotoxic shock. Clin Res 35:192.

2. Beutler B, Cerami A. 1987. Cachectin: more than a tumor necrosis factor. N Engl I Med 316:379.

3. Elebute EA, Stoner HB. 1983. The grading of sepsis. Br J Surg 70:29.

4. Debets JMH, van der Linden Cl, Spronken IEM, et al. 1988. T cell-mediated production of tumour mecrosis factor $-\alpha$ by monocytes. Scand J Immunol 27:601.

5. Harris RL, Musher DM, Bloom K. 1987. Mamilestations of sepsis. Arch Iat Med 147:1895.

6. Nedwin GE, Svedersky LP, Bringman TS, et al. 1985. Effect of interleukin 2, interferon-y, and mitogens on the production of tumor necrosis factors $\alpha$ and $\beta$.J Immunol 135:2492.

7. Dinarello $C A$, Cannon $\mathrm{JG}_{3}$ Wolff SM, et al. 1986. Tumor necrosis factor (cachectin) is an endogenous pyrogen and induces production of interleukin 1. J Exp Med 163:1433.

8. Chapman PB, Lester TJ, Casper ES, et al. 1987. Clinical pharmacology of recontbinant human tunnor necrosis factor in patients with advanced cancer. J Clin Oncol 5:1942.

9. Tracey KJ, Beutler B, Lowry SF, et al. 1986. Shock and tissue injury induced by recombinant haman cachectin. Science 234:470.

10. Tracey KJ, Lowry SF, Fahey III TJ, et al. 1987. Cachectin/tumor necrosis factor induces lethal shock and stress hormone responses in the dog. Surg Gynecol Obstet 164:415.

11. Kettelhut IC, Fiers W, Goldberg AL. 1987. The toxic effects of turnor necrosis factor in wivo and their prevention by cyclooxygenase inhibitors. Proc Natl Acad Sci USA 84:4273.

12. Beutler B, Milsark IW, Cerami AC. 1985. Passive immunization against cachectin/tumor necrosis factor protects mice from lethal effect of endotoxin. Science 229:869.

13. Tracey $\mathrm{KJ}$, Fong $\mathrm{Y}_{3}$ Hesse DG. 1987. Anti-cachectin/TNF monoclonal antibodies prevent septic shock during lethal bacteraemia. Nature 330:662.

14. Michie HR, Manogue KR, Spriggs DR, et al. 1988. Detection of circulating tumor necrosis factor after endotoxin administration. N Engl I Med 318:1481.

15. Waage A, Espevik T, Halstensen A. 1987. Association between tumour necrosis factor in ser um and fatal outcome in patients with meningococcal disease. Lancet i:355.

16. Lepe-Zuniga JL, Gery I. 1984. Production of intra- and extracellular interleukin-1 (IL-1) by human monocytes. Clin Immunol Immunopathol 31:222.

17. Cerami $A_{n}$ Ikeda $X$, Le Trang $N$, et al. 1985. Weight loss associated with an endotoxin-induced mediator from peritoneal macrophages: the role of cachectin (tumor necrosis factor). Imminnol Lent 11:173.

18. Oliff A, Defeo-Jones D, Boyer $M$, et at. 1987. Tumors secreting human TNF/cachectin induce cachexia in mice. Cell 50:555. 


\section{SUMMARY}

Tumor necrosis factor (TNF)/cachectin is a cytokine released by immunocompetent cells involved in inflammatory processes. Numerous studies indicate that it is a major acute phase reactant involved in the host response to infection and trauma. TNF exerts widespread effects on many different cell types and tissues, influencing inflammatory, hemostatic, hormonal and metabolic processes. TNF also possesses strong cytotoxic and antiviral properties, thus probably constituting an important effector cytokine in the host response against viral and malignant disease. Besides its physiological role TNF is considered to be involved in the pathogenesis of several disease states like sepsis, and cachexia accompanying infectious and malignant diseases.

In this thesis both in vitro and in vivo studies on the cytokine tumor necrosis factor are presented. The results from in vitro experiments, studying various aspects of the regulation of production and secretion of TNF by human monocytes, are presented in chapters 2 to 5 . Chapters 6 and 7 contain results from in vivo studies on the role of circulating TNF in two different patient populations.

In chapter 2 experiments are described which demonstrate that $T$ cell mitogens induce TNF production by peripheral blood mononuclear cells in a $\mathrm{T}$ cell-dependent manner. Although it has been demonstrated by other investigators that activated $T$ lymphocytes are capable of producing TNF, TNF is shown to be produced predominantly by monocytes under the experimental conditions of our study. In this study it is also demonstrated that the T cell lymphokine interferon- $\gamma$ (IFN- $\gamma$ ) is an important humoral mediator of this T cell-dependent pathway of TNF production by monocytes, being capable of inducing TNF secretion by monocytes in endotoxin-free circumstances. This finding confirms data from murine experiments, in which it was demonstrated that IFN-y enhances macrophage TNF synthesis at a transcriptional level. However, in contrast with our findings with human monocytes, secretion of TNF protein by murine macrophages is dependent on the presence of endotoxin. The findings of this study implicate that, in man, TNF production will not only occur during immune responses against infectious diseases, but also during aseptic immune and inflammatory processes accompanied by activation of the T lymphocyte system.

In chapter 3 it is demonstrated that cross-linking of the receptors for the Fc domain of $\operatorname{IgG}\left(\mathrm{F}_{\mathrm{c} \gamma} \mathrm{R}\right)$ strongly stimulates TNF secretion by human monocytes. The $\mathrm{F}_{\mathrm{c} \gamma \mathrm{R}}$ plays an important role in the interaction between the humoral and cellular immune systems, being involved in the mediation of phagocytosis, antibody-dependent cellular cytotoxicity (ADCC), induction of secretion of inflammatory mediators by immune cells, and clearance of potentially harmful immune complexes. Our finding that TNF 
secretion by monocytes is strongly stimulated by FcyR cross-linking has several implications as to the role of TNF in these immune processes. First, TNF is considered to be an important mediator of monocyte/macrophage cytotoxicity. Our finding that monocyte TNF secretion is induced by Fcy R-ligand interactions makes it conceivable that TNF is an important effector molecule of monocyte/macrophage ADCC. Since TNF has been shown to possess antiviral and antiparasitic properties, these findings also suggest its involvement in phagocytic processes during viral and parasitic infections. Finally, TNF has been shown to exert detrimental effects on various normal cells and tissues. It might thus be involved in the pathogenesis of tissue destruction occurring in the course of immune complex diseases like rheurnatoid arthritis and (antibodymediated) autoimmune diseases like type I diabetes mellitus.

The role of the two constitutively expressed monocyte $F \subset R$ in the regulation of TNF secretion has been studied more elaborately in chapter 4 . It is demonstrated that on freshly isolated, untreated monocytes, only cross-linking of the $72 \mathrm{kDa}$, high-affinity $F_{c \gamma} R$, F c rRI, triggers TNF secretion, whereas cross-linking of a second class of $F c \gamma R$, the $40 \mathrm{kDa} F \mathrm{R}$ RII, does not lead to TNF secretion. However, after treatment of monocytes with proteolytic enzymes or with the desialylating enzyme neuraminidase, ForRII gains capacity to induce TNF secretion. It is demonstrated that the capacity of ForRII to induce TNF secretion after enzyme treatment of monocytes is related to an increase in affinity of this receptor for $F_{c}$ ligand. Moreover, $F_{c} \gamma$ R-mediated TNF secretion is shown to be dependent on $\mathrm{Fc}-\mathrm{Fcy} \mathrm{R}$ interactions, TNF secretion being absent when $F_{c \gamma} R$ are cross-linked with anti-FcrR monoclonal antibodies, which interact with $\mathrm{F} c \mathrm{R}$ via their antigen-binding site. This study suggest a differential role of both $\mathrm{Fc}_{\mathrm{c}} \mathrm{R}$ in the regulation of TNF secretion by monocytes. Furthermore, the findings of this study make it conceivable that TNF secretion is limited to areas of active inflammation, thus protecting non-inflamed areas against its potential harmful effects.

In chapter 5 we have studied the effect of corticosteroids, which have strong immunosuppressive and antiinflammatory properties, on monocyte TNF secretion induced by four different stimulating agents. Corticosteroids inhibit, as has also been shown for various other inflammatory mediators, TNF secretion. The degree of inhibition is, however, dependent on the type of stimulus used to induce TNF secretion. TNF secretion induced by endotoxin and through $\mathrm{F} / \mathrm{R}$ cross-linking is shown to be strongly inhibited, whereas TNF secretion following protein kinase $C$ activation is only poorly inhibited. Inhibition of silica-induced TNF secretion is intermediate in comparison with LPS/Fcy R-induced and PMA-induced TNF secretion. Furthermore, sustained inhibition of TNF secretion requires the continual presence of corticosteroids, inhibition being reversible after removal of corticosteroids from the cultures. These findings explain yet another mechanism by which corticosteroids exert their immunosuppressive and antiinflammatory effects. Since TNF is considered to be a key mediator of endotoxic shock and sepsis, this finding offers a possible explanation for the protective effect of corticosteroids observed in experimental sepsis studies in animal models. This study also clarifies one of the mechanisms underlying the therapeutic efficacy of corticosteroids in immune complex diseases like rheumatoid arthritis, in which TNF is believed to be pathogenetically involved. 
In chapter 6 it is demonstrated that treatment of kidney allograft rejection with antithymocyte globulin (ATG) is accompanied by a sudden, short-lived, rise in circulating TNF levels. Moreover, side effects observed during this treatment are shown to occur concurrently with elevated plasma TNF levels, which suggests that TNF is involved in the causation of these symptoms. This conclusion is substantiated by findings of phase I clinical trials with recombinant TNF as an anticancer drug. Side effects observed during administration of rTNF to humans are remarkably similar to those we observed in our patients treated with ATG. It seems clear from this study that under non-septic circumstances raised plasma TNF levels are by themselves not sufficient to cause lethal shock and widespread organ damage, as has been suggested by findings from animal experiments. In vitro studies indicate that TNF release induced by ATG is not due to lysis or activation of T lymphocytes. Possibly, TNF is secreted by monocytes/macrophages upon opsonization of ATG-coated T lymphocytes via a Fc receptor-mediated process, as has been described in chapter 3.

Finally, in chapter 7 it is demonstrated that in septic patients circulating TNF can be detected in one of four patients. It is shown that in septic patients with cirulating TNF at the time of sepsis, mortality is twice the mortality of patients without circulating TNF. The difference in mortality between patients with or without circulating TNF seemed not to be caused by differences in degree of sepsis or extent of multiple organ failure, since parameters used to estimate the severity of sepsis and multiple organ failure did not differ significantly between both patient groups. Numerous experimental animal studies have implicated TNF as a crucial endogenous mediator involved in the pathogenesis of sepsis and septic shock. Two clinical studies have demonstrated a relation between the presence of circulating TNF and mortality during meningococcal sepsis. Our study corroborates these findings and extends them to patients suffering from a broad range of diseases underlying the septic state. 


\section{SAMENVATTING}

Het immunnsysteem van de mens heeft als doel het menselijk organisme te beschermen tegen infecties met pathogene micro-organismen, zoals bacterieën, virussen, parasieten en schimmels. Daarnaast speelt het immuunsysteem een belangrijke rol bij het voorkomen van het onstaan van kwaardaardige gezwellen. Het goed functioneren van het immuunsysteem vereist een complexe samenwerking tussen vele verschillende soorten cellen, zowel van hematopoietische als niet-hematopoietische oorsprong. Voor de onderlinge communicatie maken deze cellen gebruik van cytokines. Dit zijn molecullen, veelal proteinen, die door immunncompetente cellen gesecreteerd worden tijdens immuun- en ontstekingsprocessen. Deze cytokines kunnen een regulerend effect uitoefenen op dezelfde cellen waardoor ze geproduceerd zijn (autocriene beïnvloeding), op andere cellen in de onmiddellijke omgeving (paracriene beïnvloeding), of op cellen elders in het lichaam (endocriene beïnvloeding).

Tumor necrosis factor (TNF), ook wel cachectin genaand, is een van deze cytokines. TNF is een $17 \mathrm{kDa}$ eiwit, dat in de mens voomamelijk wordt geproduceerd door mononucleaire leukocyten, i.e. monocyten, macrofagen, en lymfocyten. TNF productie door monocyten en macrofagen wordt zeer krachtig gestimuleerd door het lipopolysaccharide (LPS) van gram-negatieve bacterieën (endotoxine). TNF heeft een groot aantal immunoregulatoïre en inflammatoire eigenschappen en vormt een belangrijke endogene mediator betrokken bij de acute fase respons tijdens infecties en bij trauma. TNF bezit tevens cytotoxische en antivirale eigenschappen en vormt daardoor een belangrijk effector proteine van de immuunrespons tegen maligniteiten en virale infecties. Naast een fysiologische rol zijn er aanwijzingen dat TNF ook betrokken is bij de pathogenese van verschillende ziekteprocessen, met name bij sepsis en septische shock, en bij cachexie optredend tijdens infecties of maligniteiten.

In dit proefschrift worden in vitro en in vivo studies van het cytokine TNF beschreven. Hoofdstuk 1 geeft een algemene inleiding en een overzicht van de literatur met betrekking tot de fysiologische en pathofysiologische betekenis van TNF. Hoofdstuk 2 geeft een inleiding tot en bespreking van het experimentele werk beschreven in dit proefschrift. In vitro studies, die verschillende aspecten van de regulatie van TNF productie en secretie door humane monocyten als onderwerp hebben, worden beschreven in hoofdstuk 3 tot en met 6 . Hoofdstuk 7 en 8 bevatten studies naar de in vivo rol wan circulerend TNF bij twee verschillende patiëntenpopulaties.

In hoofdstuk 3 worden experimenten beschreven die aantonen dat $T$ cel mitogenen op een T cel-afhankelijke wijze TNF secretie door mononucleaire cellen induceren. Hoewel andere onderzoekers hebben aangetoond dat geactiveerde T lymfocyten TNF 
kunnen produceren, wordt TNF onder de experimentele condities van onze studie voornamelijk geproduceerd door monocyten. In deze studie word took aangetoond dat het door "T' lymfocyten geproduceende cytokine interferon- $\gamma$ (IFN-y) een belangrijke humorale mediator is van deze T cel-afhankelijke TNF productie door monocyten. IFN-y induceert dosis-afhankelijk TNF secretie door monocyten. Deze bevinding bevestigt de resultaten van andere onderzoekers, die in muizestudies aantoonden dat IFN- TNF productie door macrofagen op transcriptieniveau verhoogt. In tegenstelling echter tot deze studies, waarin TNF secretie alleen maar plaatsvindt in de aanwezigheid van endotoxine, wordt in onze studie TNF secretie door monocyten ook geinduceerd door IFN- $\gamma$ in de afwezigheid van endotoxine. De bevindingen van onze studie impliceren dat in de mens TNF productie en secretie niet alleen tijdens infectieuze ziektes zal optre den, maar ook tijdens niet-infectieuze immuun-en onstekingsprocessen waarbij het $\mathrm{T}$ cel systeem wordt geactiveerd (bv. transplantaatrejecties, autoimmunziektes etc.).

In hoofdstuk 4 wordt aangetoond dat cross-linking van de receptor voor de Fe staart van $\operatorname{IgG}$ (Fcy receptor) TNF secretie door monocyten induceert. Foy receptoren spelen een belangrijke rol bij de interactie tussen het humorale en het cellulaire immuunsysteem. $\mathrm{F}_{\mathrm{c} \gamma}$ receptoren zijn van belang voor verschillende immuunprocessen, zoals fagocytose, antilichaam-afhankelijke cellulaire cytotoxiciteit (ADCC), de inductie van secretie van onstekingsmediatoren door immuncompetente cellen, en de klaring van potentieel schadelijke immuncomplexen. Onze bevinding dat TNF secretie door monocyten in sterke mate gestimuleerd wordt door cross-linking van Fc $\gamma$ receptoren, heeft verschillende implicaties met betrekking tot de rol die TNF in deze immuunprocessen speelt. TNF wordt beschouwd als een mediator van de cytotoxische activiteit van monocyten en macrofagen, bijwoorbeeld gericht tegen tumorcellen. TNF vormt waarschijnlijk een belangrijk effector molecuul in de afweer tegen maligne processen. Foy receptor-geinduceerde TNF secretie vormt een mogelijke verklaring van het mechanisme van TNF productie tijdens ADCC gericht tegen maligne cellen. Daarnaast bezit TNF antivirale en antiparasitaire eigenschappen. Tijdens een humorale immuunrespons tegen viraal geinfecteerde cellen of tegen parasieten zal TNF secretie worden geinduceerd via cross-linking van Fcy receptoren op monocyten/macrofagen betrokken bij de immuunrespons. TNF secretie door monocyten blijkt ook zeer krachtig geinduceerd te worden door immuncomplexen. Deze bevinding is relevant voor de pathofysiologische rol van TNF in immunncomplexziektes zoals rheumatoide arthritis. Op monocyten komen twee verschillende $\mathrm{F} c \gamma$ receptoren tot expressie, een $72 \mathrm{kDa}$ receptor met hoge affiniteit voor $\mathrm{Fc}$ ligand ( $\mathrm{Fcy}$ RI), en een $40 \mathrm{kDa}$ receptor met lage affiniteit voor $\mathrm{Fc}$ ligand $(\mathrm{Fc} \gamma \mathrm{RII})$. De rol van beide receptoren bij de regulatie van secretie van TNF door monocyten wordt beschreven in hoofdstuk 5. Op onbehandelde monocyten leidt alleen cross-linking van Fcy RI tot TNF secretie. Echter, na behandeling van de monocyten met proteolytische enzymen of met het deglycosylerende enzym neuraminidase kan TNF secretie ook door cross-linking van FerRII worden geinduceerd. Dit berust op een toename van de binding van $F c$ ligand aan $F c y$ RII na behandeling van de monocyten met deze enzymen, waardoor effectievere cross-linking van FcyRII kan plaatsvinden. Tevens wordt aangetoond dat TNF secretie alleen geinduceerd kan worden middels $\mathrm{Fc}-\mathrm{F} c \gamma$ receptor interacties, maar niet wanneer cross-linking van $\mathrm{Fc} \gamma$ 
receptoren door monoclonale anti-Fy receptor antilichamen plaatswindt. Deze antilichamen binden met het $\mathrm{F}(\mathrm{ab}) 2$ deel aan verschillende epitopen van Fo receptoren; waarbij cross-linking van Fcy receptoren platsvindt zonder dat TNF secretie wordt geinduceerd. Deze bevindingen suggereren dat FcyRI fungeert als een "stand-by" receptor, die onder invloed van proteases en neuraminidase, vrijkomend in ontstekingsgebieden, functioneel wordt ten aanzien van de inductie van TNF secretie.

In hoofdstuk 6 wordt het effect bestudeerd van twee verschillende corticosteroiden, prednisolon en budesonide, op de secretie van TNF door monocyten, geinduceerd door verschillende stimulerende agentia. Beide corticosteroiden remmen dosis-afhankelijk TNF secretie, maar de mate van remming is afhankelijk van het stimulerend agens. Sterke remming treedt op wanneer TNF secretie wordt geinduceerd door LPS of na cross-linking wan Foy receptoren. Slechts geringe remming wordt gezien na inductie van TNF secretie door het proteine kinase $\mathrm{C}$-activerende agens PMA. Intermediaire remming treedt op na inductie van TNF secretie door silica quartz. Tevens wordt aangetoond dat remming van TNF secretie door beide corticosteroiden snel reversibel. is. De aanwezigheid van corticosteroiden tijdens de fase van celactivatie is noodzakelijk voor optimalle remming van TNF secretie. Deze bevindingen verklaren een van de mechanismen van het immunosuppressieve en antiinflammatoire effect van corticosteroiden in vivo. TNF wordt beschouwd als een cruciale endogene mediator betrokken bij de pathogenese van septische shock. Het sterk remmende effect van corticosteroiden op de door endotoxine geinduceerde TNF secretie verklaart mogelijk ten dele de beschermende werking van corticosteroiden in experimentele sepsisstudies in proefdiermodellen. Daarnaast draagt remming van de door Foy receptoren geinduceerde TNF secretie bij tot de therapeutische werkzaamheid van corticosteroiden bij immuuncomplexziektes zoals rheumatoide arthritis, waarin TNF mogelijk een pathofysiologische rol speelt.

In hoofdstuk 7 wordt aangetoond dat behandeling van acute niertransplantaatrejectie met antithymocyten globuline (ATG) gepaard gaat met een verhoging van de plasma TNF spiegel. De bijwerkingen van deze therapie, zoals koorts, koude rillingen, misselijkheid, braken, dyspnoe e.an, treden op in de periode dat de plasma TNF spiegel verhoogd is. Toediening van de tweede dosis ATG aan de niertransplantatiepatiënten van onze studie gaat slechts met geringe bijwerkingen gepaard, en plasma TNF spiegels zijn dienovereenkomstig laag. Dit suggereert dat TNF, althans ten dele, verantwoordelijk is voor het ontstaan van deze bijwerkingen. Deze conclusie wordt gesteund door bevindingen uit fase I studies van recombinant TNF (rTNF) als antitumor middel in de mens. De bijwerkingen van toediening van rTNF aan mensen gelijken sterk op de bijwerkingen van toediening van anti-T cel antilichamen zoals ATG. In vitro experimenten tonen aan dat ATG de secretie van TNF door mononucleaire cellen induceert. Dit wordt niet veroorzaakt door activatie of lysis van $\mathrm{T}$ lymphocyten. Mogelijk wordt TNF in deze experimenten gesecreteerd door monocyten na opsonisatie van, met ATG gecoate, lymfocyten via een door Fc receptoren gemedieerd proces.

In hoofdstuk 8 wordt tenslotte aangetoond dat bij septische patiënten in een van de vier gevallen verhoogde TNF spiegels in het plasma aantoonbaar zijn. De mortaliteit van patiènten met aantoonbare plasma TNF spiegels blijkt significant loger te zijn dan die van septische patiënten zonder aantoonbare TNF spiegels. Het verschil in morta- 
Jiteit lijkt niet verklaard te konnen worden door verschillen in ernst van de sepsis of ernst vari het multi-orgaan falen (MOF), aangezien de parameters gebruikt om de ernst van sepsis of MOF te schatten $n_{;}$niet verschillen tussen beide groepen patiënten. Talrijke dierexperimentele studies bewatten aanwijzingen dat TNF een belangrijke pathogenetische betekenis heeft woor het onstaan van shock en MOF tijdens sepsis. Twee klinische studies hebben een verband aangetoond tussen de aanwezigheid van circulerend TNF en mortaliteit biy patienten met meningococcensepsis. Onze studie bevestigt deze bevindingen voor een populatie septische patiënten met een breed scala aan onderliggende zlektes. 


\section{DANKWOORD}

Het schrijven van een proefschrift is te vergelijken met het lopen van een marathon. Het is een uitputtingsslag, waarbij menige inzinking te boven moet worden gekomen. De promovendus wordt geplaagd door mislukte proeven, manuscripten die eindeloos vaak moeten worden gecorrigeerd, afgewezen artikels, en huiselijke crises als gevolg van de dwangmatige preoccupatie met het promotieonderzoek. Daartegenover staan echter ook hoogtepunten zoals 'la jole de se voir imprimé', congresbezoeken in verre oorden, het plezier van het wetenschappelijk succces en als hoogtepunt het behalen van het doctoraat. Het met succes voltobien van een promotieonderzoek is dan ook een resultante van elkaar opvolgende hoogte- en dieptepunten.

Het lopen van een marathon vereist intensieve voorbereiding en training. Goede begeleiding is hierbij onontbeerlijk. Maar minstens zo belangrijk zijn de aanmoedigingen van hen die onderweg langs de kant van de weg staan. Allen die mij als begeleider of als supporter geholpen hebben het doctoraat te behalen wil ik van harte bedanken.

De vakgroep Algemene Heelkunde van het Academisch Ziekenhuis Maastricht, en met name mijn promoter Prof. dr. G. Kootstra, dank ik voor de gelegenheid die mij geboden is om mijn opleidng gedurende twee jaar te onderbreken om dit proefschrift te bewerken.

Wim Buurman, soms leek je een slavendrijver, maar het oog van de meester heeft niet nagelaten het paard vet te maken.

Cees van der Linden, je stoïcijnse kritiek was noodzakelijk ter ontnuchtering van al te voortvarend enthousiasme. Je begeleiding van het klinische onderzoek was onmisbaar.

Ilse Dieteren, jij hebt met grote ijver en volharding, ondanks rege /matig terugkerende tegenslagen, een groot deel van de experimenten die de basis vormen van dit proefschrift daadwerkelijk uitgevoerd.

Ineke Daemen, jij hielp mij de eerste schreden te zetten in de wereld van pipetten en kweekplaten. Jouw ELISA bleek, overigens niet alleen voor mij, goud waard.

Trudy Jeunhomme, jij gaf antwoord op vele vragen en verleende menigmaal eerste hulp bij de experimenten.

Marielle van der Linden, jij liep alleen al een marathon door het ophalen van bloedmonsters uit de kliniek. Door jouw bijdrage aan de experimenten kwam je alles te weten over corticosteroiden en sigmaplot.

René Kampmeier nam de moeizame taak op zich om in het doolhof van intensive care statussen de gegevens van de sepsisstudie te verzamelen en te bewerken. Naar het schijnt heeft hij hierna de wijk genomen naar Oeganda.

Mijn collegae promovendi en ex-promovendi Jet Leeuwenberg, Jan-Willem Greve en Jos Maessen dank ik voor de waardevolle discussies en suggesties. Jullie hielpen het klimaat te scheppen waarin wetenschappelijk onderzoek goed gedijt.

Jan van de Winkel, aan de samenwerking met jou bewaar ik zeer goede herinneringen. Jouw enthousiasme en collegialiteit hebben grote indruk op mij gemaakt. 
Jan Ceuppens dank ik voor het bereidwillig ter beschikking stellen van unieke bloedmonsters en woor de waardewolle bijdragen aan het onderzoek. Christel, Lut en Marleen dank ik voor hun aderlating.

Hans van Hooff en Karel Leunissen vulden mijn nefrologische lacunes deskundig op.

De verpleegkundigen betrokken bij het verzamelen van de patientenmonsters wil ik danken voor hun onbaatzuchtige medewerking.

Van Karin Spronk ontving ilk de nodige secretariële ondersteuning.

De beoordelingscommissie dank ik voor het nauwgezet lezen van het manuscript, resulterend in waardevolle adviezen ter verbetering van het proefschrift.

Tenslotte Lisette, $42 \mathrm{~km}$ lang liep jij met mij mee. Ook bij een promovendus geldt: 'cherchez la femme'. 
De auteur van dit proefschrift werd geboren op 9 augustus 1958 te Kerkrade. Hij behaalde in 1976 het gymnasium $\beta$ diploma aan het gymnasium Rolduc in zijn geboorteplaats. Van 1976 tot 1982 studeerde hij geneeskunde aan de Rijksuniversiteit Limburg te Maastricht, alwaar hij in 1982 het artsdiploma behaalde. Na werkzaamheden als poortarts in het St. Jans Gasthuis te Weert en als assistent-chirurg in het Havenziekenhuis te Rotterdam, begon hij in 1985 met de opleiding chirurgie in het Academisch Ziekenhuis Maastricht (Prof. Dr. J.M. Greep en Prof. Dr. G. Kootstra). Van juli 1986 tot juli 1988 verrichte hij in het biomedisch laboratorium van de vakgroep Algemene Heelkunde de in dit proefschrift beschreven wetenschappelijke studie. 